\title{
EFEITO DO MANEJO DA PALHA DA CANA-DE-AÇÚCAR NAS PROPRIEDADES FÍSICO-HÍDRICAS DE UM SOLO
}

\author{
LUÍS CARLOS TIMM
}

Tese apresentada à Escola Superior de Agricultura "Luiz de Queiroz", Universidade de São Paulo, para obtenção do título de Doutor em Agronomia, Área de Concentração: Irrigação e Drenagem.

P I R A C I C A B A

Estado de São Paulo - Brasil

Fevereiro - 2002 


\title{
EFEITO DO MANEJO DA PALHA DA CANA-DE-AÇÚCAR NAS PROPRIEDADES FÍSICO-HÍDRICAS DE UM SOLO
}

\section{LUÍS CARLOS TIMM}

Engenheiro Agrícola

\author{
Orientador: Prof. Dr. KLAUS REICHARDT
}

Tese apresentada à Escola Superior de Agricultura "Luiz de Queiroz", Universidade de São Paulo, para obtenção do título de Doutor em Agronomia, Área de Concentração: Irrigação e Drenagem.

P I R A C I C A B A

Estado de São Paulo - Brasil

Fevereiro - 2002 


\title{
Dados Internacionais de Catalogação na Publicação (CIP) DIVISÃO DE BIBLIOTECA E DOCUMENTAÇÃO - ESALQ/USP
}

\author{
Timm, Luís Carlos \\ Efeito do manejo da palha da cana-de-açúcar naspropriedadesfísico- \\ hídricas de um solo / Luís Ca rlos Timm. - - Piracic aba, 2002. \\ $115 \mathrm{p}$. \\ Tese (doutorado) - Escola Superior de Agricultura Luiz de Queiroz, 2002. \\ Bibliografia. \\ 1. Balanço hídrico 2. Cana-de-açúc ar 3. Cobertura do solo 4. \\ Geoestatística 5. Manejo do solo 6. Relação solo-planta 7. Umidade do solo \\ I. Título
}

CDD 633.61 
Dedico este trabalho

a meus pais, Edemar e Elly, pelo seu amor e constante incentivo, fonte de inspiração e força para abraçar os desafios 


\section{AGRADECIMENTOS}

Meus sinceros agradecimentos às pessoas e instituiçõos que tornaram possível a realização deste trabalho:

Ao Prof. Dr Klaus Reichardt pela orientação, confiança e amizade;

Ao Prof. Dr. Osny Bacchi pela amizade e colaboração durante todo o período do projeto.

Aos Profs. Dr. Sérgio Duarte e Dr. Paulo Libardi pelos ensinamentos e pela amizade durante este período;

Ao Prof. Dr. Emanuel Barbosa do Departamento de Estatística da Universidade Estadual de Campinas pela colaboração durante a etapa de análise e aplicação de séries temporais neste trabalho;

Ao Prof. Dr. Ole Wendroth do "Institute for Soil Landscape Research (ZALF)", Müncheberg, Alemanha pela colaboração e auxílio durante a fase final do projeto;

Ao Prof. Dr. Donald Nielsen da Universidade da Califórnia, Davis, USA, pela amizade, colaboração e auxílio durante o projeto;

Ao Prof. Dr. Jan Hopmans pela orientação e amizade durante o período de estágio na Universidade da Califórnia, Davis, Califórnia, USA.

À equipe técnica do laboratório de Física dos Solos do CENA-USP (Dudu e Ademir) pela amizade e companheirismo;

À Escola Superior de Agricultura Luiz de Queiroz, pela oportunidade de realização do curso de doutorado;

À FAPESP, pelo suporte através de concessão de bolsa de estudo de doutorado e concessão de auxílio financeiro à execução do projeto;

Aos colegas e amigos André Lacerda, Cláudia Teixeira, Diniz Fronza, Edemar Corazza, Éder Pozzebon, Eraldo de Carvalho, Fábio Cássaro, Jarbas Honório Miranda, 
José Ronaldo Macedo, Júlio César de Oliveira, Lourival Fante Jr., Luciana de Castro, Luiz Fernando Pires, Márcia Simonetti, Marcos Gama, Reges Heinrichs, Tânia Tominaga e Vladia Correchel.

À Janaynna Barbosa pela amizade, dedicação e carinho durante este período. 


\section{SUMÁRIO}

Página

RESUMO viii

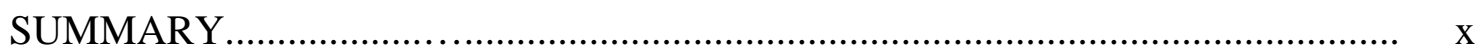

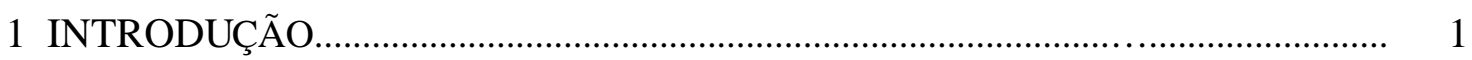

2 REVISÃO DE LITERATURA.................................................................... 3

2.1 Aspectos gerais sobre a prática de colheita da cana crua .......................... 3

2.2 A formulação de espaço de estados ("state-space approach")........................ 6

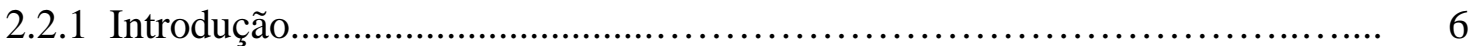

2.2.2 A função de autocorrelação............................................................. 8

2.2.3 A função de crosscorrelação............................................................... 12

2.2.4 A representação em espaço de estados............................................... 13

3 TEMPERATURA DO SOLO NA CULTURA DA CANA-DE-AÇÚCAR COMO UMA FUNÇÃO DO SISTEMA DE MANEJO............................. 17

Resumo................................................................... 17

Summary............................................................... 18

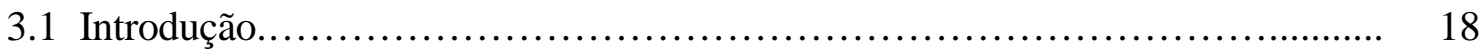

3.2 Material e Métodos........................................................... 20

3.3 Resultados e Discussão................................................... 23

3.4 Conclusões............................................................. 30

4 BALANÇO DE ÁGUA NO SOLO NA CULTURA DE CANA-DE-AÇÚCAR: ASPECTOS QUANTITATIVOS E QUALITATIVOS DE SUA CONTABILIZAÇÃ

Resumo.............................................................. 31

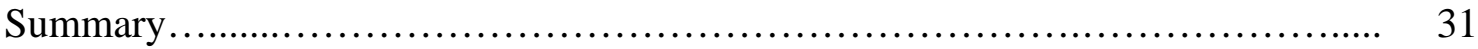


4.1 Introdução.................................................................. 32

4.2 Material e Métodos............................................................. 35

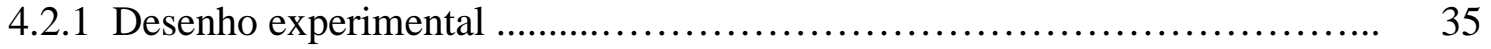

4.2.2 Balanço hídrico............................................................. 37

4.3 Resultados e Discussão.............................................................. 39

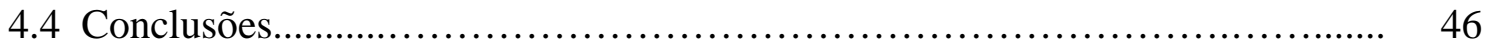

5 ABORDAGEM DE ESPAÇO DE ESTADOS NA ANÁLISE DA UMIDADE E TEMPERATURA DO SOLO NA CULTURA DE CANA-DE-AÇÚCAR............ 48

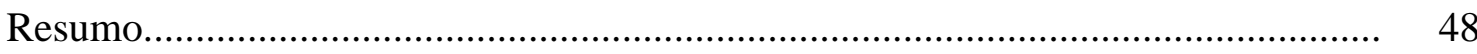

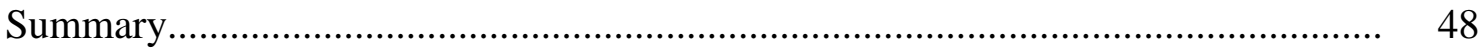

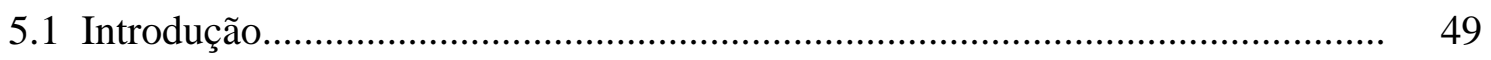

5.1.1 Aspectos teóricos.................................................................................. 51

5.2 Material e Métodos..................................................................................... 53

5.3 Resultados e Discussão.............................................................................. 56

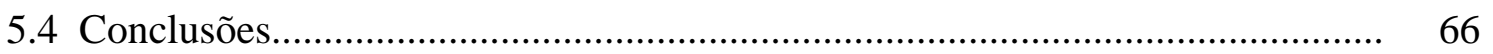

6 ABORDAGEM DE ESPAÇO DE ESTADOS PARA AVALIAR A RELAÇÃO ENTRE AS PROPRIEDADES QUÍMICAS E FÍSICAS DO SOLO........................ 67

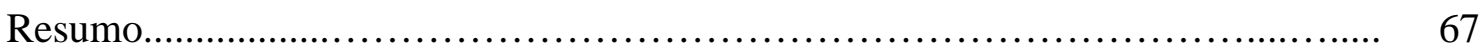

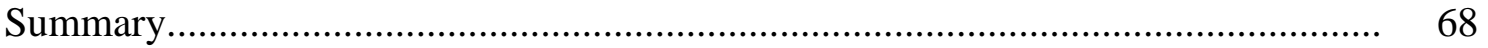

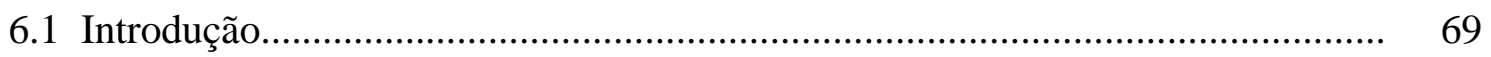

6.1.1 Aspectos teóricos..................................................................................

6.2 Material e Métodos....................................................................................... 71

6.3 Resultados e Discussão................................................................................. 73

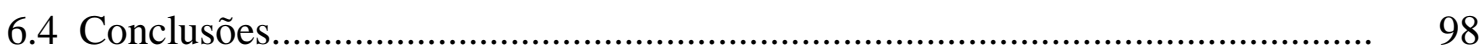

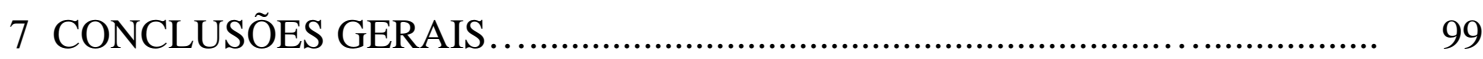

REFERÊNCIAS BIBLIOGRÁFICAS...................................... 101 


\title{
EFEITO DO MANEJO DA PALHA DA CANA-DE-AÇÚCAR NAS PROPRIEDADES FÍSICO-HÍDRICAS DE UM SOLO
}

\author{
Autor: LUÍS CARLOS TIMM \\ Orientador: Prof. KLAUS REICHARDT
}

\section{RESUMO}

Diferentes práticas de manejo da cultura de cana-de-açúcar foram estudadas por meio da avaliação de propriedades físico-hídricas do solo. Os principais aspectos avaliados foram as variações da umidade do solo, temperatura do solo, fluxo de água no solo, armazenamento da água no solo e escoamento de superficial durante um período de dois anos, um de cana-planta e um de soqueira. As diferentes práticas de manejo foram: i. entrelinha com solo nu; ii. presença de cobertura vegetal na superfície do solo (palhas + ponteiros) após a colheita; e iii. presença de resíduos na superfície do solo provenientes da queima da cana antes da colheita. Algumas variáveis foram amostradas ao longo de uma transeção de 84 pontos, com o objetivo de aplicar técnicas geoestatísticas e a abordagem de espaço de estados. O efeito da cobertura vegetal na superfície do solo, como uma consequiência da adoção da nova prática de colheita sem queima prévia da cana, reduziu as temperaturas médias na camada superficial do solo na ordem de $7{ }^{\circ} \mathrm{C}$, evitando picos de temperatura na superfície durante o período inicial de estabelecimento da cana soca. A cobertura vegetal, contudo, afetou negativamente o desenvolvimento da cultura reduzindo o número de colmos e seu peso úmido, no presente estudo em torno de $13 \%$. Por outro lado, a presença da cobertura vegetal não 
afetou nenhum dos seguintes componentes do balanço hídrico: escoamento superficial, fluxo de água no solo no limite inferior do volume de solo em estudo e o armazenamento de água no solo, sendo o estabelecimento do balanço hídrico da cultura de cana-de-açúcar, prevalecendo estas condições, problemático principalmente devido ao fato de que o escoamento superficial e os fluxos de água no limite inferior do volume de solo considerado foram fortemente afetados pela variabilidade espacial do solo. A análise de espaço de estados aplicada à dados de umidade e temperatura do solo coletados ao longo da transeção espacial de 84 pontos, sugeriu que, em muitas situações, devido ao fato de que os dados de temperatura do solo são mais fáceis e mais rápidos de serem obtidos no campo de que os de umidade, uma medida poderia substituir a outra. Quando esta análise foi aplicada à dados de umidade do solo, matéria orgânica do solo, conteúdo de argila e estabilidade de agregados coletados ao longo da mesma transeção, foi possível identificar como uma variável se relaciona ao comportamento local de outras variáveis e estocasticamente quantificar este relacionamento, levando em consideração os erros associados às observações e ao modelo. Devido a isto, a análise de espaço de estados é uma ferramenta analítica aplicável sob condições locais no campo, podendo, potencialmente, ajudar os agricultores no manejo adequado do solo e dos recursos naturais para o aumento da produção e, simultaneamente, a qualidade do meio ambiente. 


\title{
EFFECT OF SUGARCANE TRASH MANAGEMENT ON PHYSICAL AND HYDROLOGICAL SOIL PROPERTIES
}

\author{
Author: LUÍS CARLOS TIMM \\ Adviser: Prof. KLAUS REICHARDT
}

\section{SUMMARY}

Different practices of sugarcane trash management were studied by the evaluation of soil physical and hydrological properties. The main aspects evaluated were changes in soil water content, soil temperature, soil water fluxes, soil water storage and run-off during a period of two years, corresponding to the planted sugarcane crop and the first ratoon crop. The different management practices were: i. interrow with bare soil; ii. trash mulching, maintaining harvest residues (straw + tips) on soil surface; iii. soil with residues of trash burning prior harvest. Some variables were also collected along a 84 point transect aiming to apply geostatistical techniques and statespace approach. The effect of soil surface mulching in sugarcane ratoon crops, as a consequence of the adoption of new harvest practices with no straw burning, can reduce average soil surface layer temperatures by about $7{ }^{\circ} \mathrm{C}$, avoiding peak surface temperatures during the initial period of the ratoon crop establishment. The mulch can, however, affect negatively the crop development reducing the number of stalks and their weight, in the present case by about $13 \%$. On the other hand, mulching did not affect any of the following water balance components: run-off, soil water fluxes at the lower soil volume limit, and soil water storage. The establishment of the water balance 
of the sugarcane crop, under these prevailing conditions, was problematic mainly due to the run-off and soil water flux components which were strongly affected by soil spatial variability. The state-space approach applied to soil water content and soil temperature data along the 84 point transect suggested that, in many situations, since temperature measurements are easier and quicker to be measured than those of soil water content, one measurement could replace the other. On the other hand, when the state-space analysis was applied to soil water content, soil organic matter, clay content and aggregate stability data set along the same transect, it was possible to identify a variable that relates to the local behavior of several variables and stochastically quantify that relationship accounting for both, measurement and model errors. Due to the fact that the state-space approach is an analytical tool applicable to local field conditions, it potentially helps farmers to manage soil and soil resources adequately to maximize crop production and to simultaneously improve the quality of the local environment. 


\section{INTRODUÇÃO}

A crescente preocupação da sociedade com a sobrevivência do homem no planeta tem concretizado conceitos como produção sustentável, na qual procura-se adequar a atividade agrícola a uma ação que seja ambientalmente correta, socialmente justa e economicamente viável (Hansen, 1996).

A cana-de-açúcar tem grande importância econômica e social para o Brasil e em, particular para o Estado de São Paulo. Atualmente, o Brasil é o maior produtor mundial de cana-de-açúcar e cultiva aproximadamente 5 milhões de hectares com uma produção de 337 milhões de toneladas de cana, 14,4 milhões de toneladas de açúcar e 13 bilhões de litros de álcool (FNP - Consultoria \& Comércio, 2001).

A prática de queima dos canaviais é geralmente adotada nas diversas regiões canavieiras do Brasil e do mundo com o objetivo de facilitar as operações de corte e carregamento. Entretanto, tal prática está associada a impactos ambientais, tais como elevadas emissões de gases a atmosfera devido à queima que normalmente antecede a colheita, a degradação dos solos e a poluição de mananciais e centros urbanos (Sparoveck et al., 1997). Devido a isto, a recente tendência de adoção de práticas agrícolas que levem à uma maior sustentabilidade do sistema, pressiona a agroindústria sucroalcooleira a rever seus processos, incluindo a colheita da cana sem queima prévia ou sem despalha a fogo (colheita de cana crua ou cana verde).

Nessa nova prática de colheita de cana crua, o palhiço é deixado à superfície do solo como folhas inteiras, caso a colheita seja realizada manualmente; ou triturado, caso a colheita seja realizada mecanicamente. A manutenção da camada de material vegetal no sistema pode trazer grandes vantagens para o solo, minimizar o problema da poluição atmosférica e, provavelmente reduzir o uso de fertilizantes minerais. 
Nessa última década, a colheita mecanizada de cana verde é prática que vem sendo desenvolvida na região de Ribeirão Preto (SP), por iniciativa de algumas empresas sucroalcooleiras mais tecnificadas, observando os decretos do Governo do Estado de São Paulo n ${ }^{\mathrm{o}} 28848$ (30/08/1988) e n ns 28894 e 28895 (20/09/1988), que proíbem queimadas na faixa de $1 \mathrm{~km}$ do perímetro urbano.

Do cenário acima, verifica-se que é possível viabilizar a colheita da cana crua, buscando produtividade econômica da cultura e o fornecimento à indústria de uma matéria-prima de melhor qualidade, visando a preservação do ambiente no que concerne ao solo, ar e água. O presente trabalho visa contribuir para esta viabilização, uma vez que, nas condições do Estado de São Paulo, em áreas com colheita de cana crua, com deposição do palhiço à superfície do solo, quase tudo está por se conhecer. Entre os diversos aspectos que merecem avaliação, em diferentes condições de solo, clima, variedade de cana e ciclo da cultura, têm-se as transformações das propriedades físicas do solo.

Neste novo século a colheita de cana verde deverá ser adotada como prática principal nas regiões canavieiras do Estado de São Paulo, sendo de fundamental importância conhecer a dinâmica desta nova prática, com o intuito de maximizar seus pontos positivos, tornando-a sustentável ao longo dos anos.

Neste sentido, o trabalho teve como primeiro objetivo acompanhar, comparativamente, as modificações que ocorrem nas propriedades físico-hídricas do solo (umidade do solo, temperatura do solo, fluxo de água no solo, escoamento superficial e variação do armazenamento de água no solo), ao se passar do tradicional manejo da queima da cana, para o novo sistema de colheita de cana verde. O segundo objetivo foi o de utilizar técnicas geoestatísticas e a formulação de espaço de estados (“state-space approach") com intuito de separar as diferentes causas da variabilidade espacial das variáveis relacionadas ao sistema solo-planta. 


\section{REVISÃO DE LITERATURA}

\subsection{Aspectos gerais sobre a prática de colheita da cana crua}

O Brasil é o maior produtor mundial de cana-de-açúcar e cultiva aproximadamente 5 milhões de hectares com uma produção de 337 milhões de toneladas de cana, 14,4 milhões de toneladas de açúcar e 13 bilhões de litros de álcool (FNP - Consultoria \& Comércio, 2001).

A prática de queima dos canaviais é geralmente adotada nas diversas regiões canavieiras do Brasil e do mundo com o objetivo de facilitar as operações de corte e carregamento. Entretanto, tal prática está associada a impactos ambientais, tais como elevadas emissões de gases a atmosfera, a degradação dos solos e a poluição de mananciais e centros urbanos (Sparoveck et al., 1997). Devido a isto, a recente tendência de adoção de práticas agrícolas que levem à uma maior sustentabilidade do sistema, pressiona a agroindústria sucroalcooleira a rever seus processos, incluindo a colheita da cana sem queima prévia ou sem despalha a fogo (colheita de cana crua ou cana verde). Trivelin et al. (1997) salienta que, nos últimos anos, a área total de cana despalhada a fogo, para posterior colheita manual, diminuiu muito no Estado de São Paulo e em outras regiões de países produtores de cana, ocasionando um aumento das áreas colhidas mecanicamente sem prévia despalha a fogo.

Nessa nova prática de colheita de cana crua, o palhiço é deixado à superfície do solo como folhas inteiras, caso a colheita seja realizada manualmente; ou triturado, caso a colheita seja realizada mecanicamente. A manutenção da camada de material vegetal no sistema pode trazer grandes vantagens para o solo, dentre elas podemos destacar o aumento da infiltração de água no solo, redução das perdas de solo por erosão, redução da evaporação da água no solo e me lhoria da estrutura do solo devido a presença de 
matéria orgânica que atua como agente cimentante das partículas constituintes do solo (Kiehl, 1979). Além disso, poderá contribuir para minimizar o problema da poluição atmosférica causada pela queima do canavial, reduzir o uso de fertilizantes minerais atuando como fonte de nutrientes para a macro e microflora do solo e para a própria cultura da cana-de-açúcar (Wood, 1991; Ceddia et al., 1996; Pinheiro et al., 1996).

Nessa última década, a colheita mecanizada de cana verde é prática que vem sendo desenvolvida na região de Ribeirão Preto (SP), por iniciativa de algumas empresas sucroalcooleiras mais tecnificadas, observando os decretos do Governo do Estado de São Paulo n ${ }^{\mathrm{o}} 28848$ (30/08/1988) e n ns 28894 e 28895 (20/09/1988), que proíbem queimadas na faixa de $1 \mathrm{~km}$ do perímetro urbano. Sparoveck et al. (1997) avaliaram a aptidão das terras para o corte mecanizado da cana-de-açúcar sem queima prévia na região de Piracicaba, considerando-se a declividade do terreno e fatores restritivos ligados ao solo. Os autores concluíram que, levando-se em conta as restrições impostas, a introdução deste sistema de colheita em toda a região iria significar uma redução em pelo menos 32.000 ha ou $37 \%$ da produção atual, o que certamente estaria associada a profundas alterações sócio-econômicas da organização rural desta região.

De acordo com Oliveira et al. (1999), na colheita mecanizada da cana-de-açúcar sem o uso do fogo, as folhas secas são trituradas e os ponteiros são cortados e lançados sobre a superfície do solo, formando uma cobertura morta denominada de palhada. Essa palhada vai se decompondo por ação física, química e biológica, constituindo-se primeiramente em fonte de nutrientes para os macro e microorganismos do solo e posteriormente para a própria cultura da cana.

Em relação às propriedades físicas do solo, Igue \& Pavan (1984) salientaram que com a adição de material orgânico promove-se a formação e estabilização dos agregados constituintes do solo melhorando a sua estrutura, ocasionando melhorias nas condições de aeração e aumento da capacidade de infiltração e retenção de água. Orlando Filho et al. (1998) estudaram o efeito do sistema de despalha (cana crua x cana queimada) e do manejo da adubação em algumas propriedades de um Latossolo Vermelho Escuro em Piracicaba, SP. Os autores concluíram que na presença da palhada (cana crua), ocorreram maiores teores de água, matéria orgânica, P, Ca, Mg e S no solo. 
Alguns trabalhos, dentre eles podemos destacar: Ripoli et al. (1991); Ripoli \& Villa Nova (1992); Ripoli et al. (2000), tem indicado a queimada como um desperdício tanto do ponto de vista da identificação dos fatores que compõem a palhada, decorrentes da cana crua após a colheita como do seu potencial energético. Embora, o potencial de utilização da palha na indústria seja considerável, o seu uso como cobertura vegetal é o fator principal na mudança do cultivo tradicional da cana-de-açúcar queimada para a cana crua. Neste sentido, Abramo Filho et al. (1993) indicaram mudanças que ocorrem com a presença da palha no campo, tais como: diminuição da temperatura do solo, maior umidade e retardamento da brotação. Entretanto, os mesmos autores salientam que não há quantificação desses efeitos.

A indústria produtora de máquinas agrícolas vem, nos últimos anos, desenvolvendo colhedoras de cana-picada, visando adaptá-las à áreas de cana verde. Atualmente existem diversos tipos de equipamentos já em operação nas unidades de produção, ocorrendo uma tendência bastante clara de se operar em canaviais sem a despalha a fogo (Orlando Filho et al., 1998).

Segundo Delgado (1985), a queima da cana ocasiona alguns problemas de certa relevância, como: destruição do palhiço da cana que seria deixado no solo; predisposição do solo à ação mais agressiva devido à água da chuva; perda mais rápida da água do solo por evaporação e menor retenção de água; destruição de organismos, principalmente insetos, inimigos naturais das pragas da cana; predisposição do solo ao desenvolvimento de ervas daninhas. Por outro lado, a prática da queima da cana favorece os trabalhos de aração do solo na reforma de canaviais, as práticas de cultivo mecânico de soqueiras, eliminação da broca da cana e de outras pragas e doenças, além de possibilitar maior facilidade para o corte manual.

Na Austrália (Freney et al., 1991) e em Cuba (Ministerio del Azucar, 1992), a colheita mecanizada da cana crua é prática que vem sendo realizada, com benefícios no controle de ervas daninhas, conservação da água do solo, redução das emissões de $\mathrm{CO}_{2}$ e fuligem, durante a queima de canaviais, aumento da matéria orgânica do solo e o controle da erosão. A presença de resíduos da cultura na superfície do solo (palha), após a colheita, resultou, porém, em problemas para operações mecanizadas voltadas à 
melhoria das condições do solo e na adubação de soqueiras, com reflexos, algumas vezes, na produtividade.

A colheita de cana crua contribui significativamente para a melhoria da fertilidade do solo, uma vez que a produção de palha corresponde de 10 a 30 t/ha de material seco, 20 a $80 \mathrm{~kg} / \mathrm{ha}$ de nitrogênio e metade desses valores na forma de enxofre, que seriam lançados à atmosfera, principalmente como óxidos, com a queima do canavial. Esses nutrientes de plantas, além de outros que não estão aqui contabilizados, passam a estar disponíveis à cultura após o ataque pelos organismos do solo (Abramo Filho et al., 1993 e Trivelin et al., 1995, 1996).

Urquiaga et al. (1991), verificaram, após 5 anos, que com a despalha manual, 74 t/ha de matéria seca foram depositadas na superfície do solo, somente 6 t/ha ficaram como resíduo (no sistema com queima encontrou-se apenas $0,4 \mathrm{t} / \mathrm{ha}$ ), indicando que 92\% da palha foi degradada em cada ano, sendo o processo relativamente rápido o que favoreceu a atividade biológica ao solo.

\subsection{A formulação de espaço de estados ("state -space approach")}

\subsubsection{Introdução}

Existe uma grande classe de fenômenos físicos, químicos e biológicos que, quando observados e numericamente quantificados, resultam em uma sequência de dados distribuídos ao longo do tempo e/ou espaço. Alguns exemplos são:

(i) valores médios mensais de temperatura do ar em um dado local;

(ii) valores médios anuais de precipitação em um dado local;

(iii) produção anual de cana-de-açúcar em uma dada área;

(iv) valores de temperatura do solo coletados ao longo de uma dada transeção no mesmo tempo;

(v) produção de cana-de-açúcar medida ao longo de uma dada transeção durante a colheita; 
(vi) valores de $\mathrm{pH}$ do solo coletados ao longo de uma dada transeção em um dado tempo.

Inicialmente, as ferramentas estatísticas foram desenvolvidas para analisar uma sequiência de dados coletados ao longo do tempo (t). Contudo, para uma série de dados coletados ao longo do espaço (x) são também válidas, somente substituindo t por x.

Uma série temporal pode ser discreta ou contínua, sendo constituída de um conjunto de observações discretas (Y), descrita por:

$$
\mathrm{Y}\left(\mathrm{t}_{\mathrm{i}}\right) ; \quad \mathrm{i}=1,2,3, \ldots, \mathrm{n}
$$

avaliada em tempos (t) eqüidistantes:

$$
\mathrm{t}_{\mathrm{i}}-\mathrm{t}_{\mathrm{i}-1}=\alpha
$$

que apresentam uma dependência serial entre si. Séries coletadas continuamente durante um dado intervalo de tempo tem que ser transformadas em séries discretas com intervalos de tempo eqüidistantes. O intervalo $(\alpha)$ entre observações é, geralmente, escolhido pelo cientista, contudo, em diversas situações, é definido pelo conjunto de dados disponí veis.

A definição de séries temporais acima, embora simples, evidencia a "Análise de Séries Temporais" como sendo uma área bem definida dentro da Estatística, visto que estão sendo claramente descartados aqueles dados independentes e identicamente distribuídos, comumente utilizados nos diversos modelos estatísticos clássicos (Souza, 1989). Dentro deste ponto de vista, pode-se verificar que a estatística clássica e a análise estatística de dados que apresentam dependência serial, se complementam, uma não excluindo a outra, e questões respondidas por uma, diversas vezes, podem não ser respondidas pela outra (Reichardt, 1996). 
Até recentemente, as pesquisas na área agronômica concentravam-se no uso da estatística clássica (análise de variância, média, coeficiente de variação, análise de regressão, etc), que pressupõe a independência entre as observações, desconsiderando o local de amostragem no campo. Neste caso, os experimentos são conduzidos tendo em vista a minimização do impacto da variabilidade espacial, is to é, ignorando o fato de que as observações podem ser dependentes espacialmente. Nielsen \& Alemi (1989) comentam que o fato das observações dentro e entre tratamentos não serem independentes entre si, em muitos casos, torna o desenho experimental inadequado.

A variabilidade espacial do solo pode ocorrer em diferentes níveis, relacionados à diferentes fatores, tais como: variação do material de origem, clima, relevo, organismos e tempo, isto é, relacionada com o processo de formação do solo e/ou efeitos das práticas de manejo adotadas no uso agrícola (McGraw, 1994). Ferramentas estatísticas como autocorrelogramos, crosscorrelogramos, semivariogramos, análise espectral, kriging, co-kriging, modelos autoregressivos (AR), modelos autoregressivo integrado média móvel (ARIMA), MODELOS DE ESPAÇO DE ESTADOS, etc., tem sido usados para estudar a variabilidade espacial dos atributos do solo, e podem, potencialmente, conduzir à práticas de manejo que permitam um melhor entendimento do processo de interação entre o sistema solo-planta-atmosfera (Vieira et al., 1981; Vauclin et al., 1982; Nielsen et al., 1983; Morkoc et al., 1985; Shumway, 1988; Nielsen \& Alemi, 1989; Wendroth et al., 1992; Katul et al., 1993; Wendroth et al., 1997; Hui et al., 1998; Nielsen et al., 1998; Dourado-Neto et al., 1999; Timm et al., 2000; Wendroth et al., 2001).

\subsubsection{A função de autocorrelação}

Séries espaciais (ou temporais) podem ser estudadas como sendo uma realização particular de um processo estocástico, baseado em leis probabilísticas (Morettin \& Toloi, 1987). A correlação que existe entre observações adjacentes freqüentemente limitam a aplicação de métodos estatísticos clássicos, os quais são baseados na independência entre observações adjacentes. 
Após amostrar uma variável $\mathrm{Y}$, sua média $\overline{\mathrm{Y}}$ e variância $\mathrm{s}^{2}$ são calculadas para refletir a população amostrada, assumindo que o conjunto de observações $\mathrm{Y}$ é representativo da população e que elas são distribuídas ao acaso. Em muitos casos, as observações não são independentes entre si, sendo possível calcular um coeficiente de autocorrelação, que quando plotado em função da distância entre as observações, indica o nível de auto-dependência. Para processos estacionários (aqueles em que as propriedades estatísticas são independentes do espaço ou tempo, i.e., não variam), a covariância entre observações é uma função do número de lags (h) entre os pontos amostrados. Séries espaciais são coletadas ao longo de uma transeção, espaçadas de um lag $\alpha\left(x_{i}-x_{i-1}=\alpha\right)$, em cm, m, km, etc.

Alguns exe mplos são:

a) Observações de temperatura do solo coletadas em um dado tempo:

$\alpha=2 \mathrm{~m}$, número total de observações, $\mathrm{n}=100$

$$
\begin{aligned}
& \mathrm{W}\left(\mathrm{x}_{15}\right)=35,2{ }^{\circ} \mathrm{C} \\
& \mathrm{W}\left(\mathrm{x}_{16}\right)=33,8{ }^{\circ} \mathrm{C} \\
& \mathrm{W}\left(\mathrm{x}_{17}\right)=34,9{ }^{\circ} \mathrm{C} \\
& \mathrm{W}\left(\mathrm{x}_{18}\right)=32,6{ }^{\circ} \mathrm{C} \\
& \mathrm{W}\left(\mathrm{x}_{19}\right)=34,2{ }^{\circ} \mathrm{C}
\end{aligned}
$$

média $\overline{\mathrm{W}}=34,7^{\circ} \mathrm{C}$ 
$\Delta \mathrm{x}$ para $\mathrm{h}=1\left(1^{\mathrm{o}}\right.$ vizinho $)$ é $2 \mathrm{~m}$, ou um $\alpha$

$\Delta \mathrm{x}$ para $\mathrm{h}=2\left(2^{\mathrm{o}}\right.$ vizinho) é $4 \mathrm{~m}$, ou dois $\alpha$

$\Delta \mathrm{x}$ para $\mathrm{h}=\mathrm{h}$ é $2 \mathrm{~h} \mathrm{~m}$, ou ho

b) Observações de umidade do solo coletadas em um dado tempo:

$\alpha=2 \mathrm{~m}$, número total de observações, $\mathrm{n}=100$

$$
\begin{aligned}
& Y\left(x_{15}\right)=0,348 \mathrm{~cm}^{3} \cdot \mathrm{cm}^{-3} \\
& Y\left(x_{16}\right)=0,411 \mathrm{~cm}^{3} \cdot \mathrm{cm}^{-3} \\
& Y\left(x_{17}\right)=0,387 \mathrm{~cm}^{3} \cdot \mathrm{cm}^{-3} \\
& Y\left(x_{18}\right)=0,428 \mathrm{~cm}^{3} \cdot \mathrm{cm}^{-3} \\
& Y\left(x_{19}\right)=0,399 \mathrm{~cm}^{3} \cdot \mathrm{cm}^{-3}
\end{aligned}
$$

média $\bar{Y}=0,375 \mathrm{~cm}^{3} \cdot \mathrm{cm}^{-3}$

$\Delta \mathrm{x}$ para $\mathrm{h}=1\left(1^{\mathrm{o}}\right.$ vizinho $)$ é $2 \mathrm{~m}$, ou um $\alpha$

$\Delta \mathrm{x}$ para $\mathrm{h}=2\left(2^{\mathrm{o}}\right.$ vizinho $)$ é $4 \mathrm{~m}$, ou dois $\alpha$

$\Delta \mathrm{x}$ para $\mathrm{h}=\mathrm{h}$ é $2 \mathrm{~h} \mathrm{~m}$, ou ho

A covariância da variável Y para um dado h, é obtida por (Salas et al., 1980): 


$$
C(h)=\frac{1}{(n-h)} \sum_{i=1}^{n-h}\left[Y\left(x_{i+h}\right)-\bar{Y}\right]\left[Y\left(x_{i}\right)-\bar{Y}\right]
$$

Se C(h) é normalizada dividindo-se pela variância da população క̌, então o coeficiente $\mathrm{r}(\mathrm{h})$ da função de autocorrelação é obtido por meio da seguinte equação:

$$
\mathrm{r}(\mathrm{h})=\frac{\mathrm{C}(\mathrm{h})}{\mathrm{s}^{2}}
$$

$\mathrm{r}(\mathrm{h})$ assumindo valores entre $+1 \mathrm{e}-1$. É importante notar que para o cálculo de $\mathrm{r}(\mathrm{h})$, as observações $\mathrm{Y}$ tem que ser coletadas em intervalos regulares. Plotando $\mathrm{r}(\mathrm{h})$ como uma função de h, obtém-se o autocorrelogramo da variável Y. O próximo passo é calcular os intervalos de confiança de $r$, para definir o comprimento do intervalo $\alpha$ h no qual a dependência espacial da variável é significante. Uma maneira de calcular o intervalo de confiança IC da função de autocorrelação é, segundo Davis (1986), usar a função de probabilidade acumulada p ( $\pm 1,96$ para um nível de probabilidade de $95 \%)$, e o número de observações (n-h). Desta forma:

$$
\mathrm{IC}= \pm \frac{\mathrm{p}}{\sqrt{\mathrm{n}-\mathrm{h}}}
$$




\subsubsection{A função de crosscorrelação}

Sendo os dois conjuntos de variáveis $\mathrm{Y}\left(\mathrm{x}_{\mathrm{i}}\right)$ e $\mathrm{W}\left(\mathrm{x}_{\mathrm{i}}\right)$ observados em um mesmo local $\mathrm{x}_{\mathrm{i}}$, sua estrutura espacial pode ser analisada calculando os coeficientes de crosscorrelação. Cada variável tem seu autocorrelogramo, contudo, uma análise de sua crosscorrelação indica até que distância uma variável é relacionada com a outra. $\mathrm{O}$ coeficiente $r_{c}(h)$ da função de crosscorrelação será também uma função de $h$, e descreve o grau de associação linear entre ambas variáveis (Davis, 1986; Shumway, 1988; Wendroth et al., 1997).

Considerando que os dados de temperatura do solo e de umidade do solo foram coletados no mesmo tempo e nas mesmas posições $\mathrm{x}_{\mathrm{i}}$, os coeficientes da função de crosscorrelação $r_{c}(h)$, entre as variáveis $Y$ e W, separados por distâncias $\alpha h$, ou por um número de lag h, são calculados por:

$$
\mathrm{r}_{\mathrm{c}}(\mathrm{h})=\frac{\operatorname{cov}_{\mathrm{YW}}(\mathrm{h})}{\mathrm{s}_{\mathrm{Y}} \times \mathrm{s}_{\mathrm{W}}}
$$

sendo $\mathrm{S}_{\mathrm{Y}} \mathrm{e} \mathrm{s}_{\mathrm{W}}$, os desvios padrões das variáveis $\mathrm{Y}$ e W, respectivamente. Neste caso, a covariância entre as variáveis $\mathrm{Y}$ e W (cov Yw) é obtida pela seguinte equação:

$$
\operatorname{cov} Y W(h)=\frac{1}{(n-h)} \sum_{i=1}^{n-h}\left[Y\left(x_{i}\right)-\bar{Y}\right]\left[W\left(x_{i+h}\right)-\bar{W}\right]
$$

Também neste caso, $\mathrm{r}_{\mathrm{c}}(\mathrm{h})$ é obtido normalizando a função de covariância. $\mathrm{O}$ gráfico de $r_{c}(h)$ como uma função de h representa o crosscorrelogramo. Para o caso de 
duas variáveis, cada uma delas tem dois diferentes vizinhos, ou seja, um par $\mathrm{Y}_{\mathrm{i}}$ e $\mathrm{W}_{\mathrm{i}+1} \mathrm{e}$ um par $\mathrm{Y}_{\mathrm{i}}$ e $\mathrm{W}_{\mathrm{i}-1}$. Desta forma, são obtidos valores de $r_{\mathrm{c}}(\mathrm{h})$ e $\mathrm{r}_{\mathrm{c}}(-\mathrm{h})$. Da mesma forma que para o autocorrelogramo, os intervalos de confiança IC de $r_{c}$ podem ser calculados usando a equação (5).

\subsubsection{A representação em espaço de estados}

Um sistema linear pode ser representado na forma de espaço de estados por meio de um sistema de duas equações (Souza, 1989; Shumway, 1988; West \& Harrison, 1997), como segue:

$1^{\mathrm{o}}$ ) - a forma pela qual o vetor das observações $\mathbf{Y}_{\mathbf{j}}\left(\mathbf{x}_{\mathbf{i}}\right)$ do processo é gerado como uma função do vetor de estados $\mathbf{Z}_{\mathbf{j}}\left(\mathbf{x}_{\mathbf{i}}\right)$; (equação das observações ou de medida) $2^{\circ}$ ) - a evolução dinâmica do vetor de estado não-observado $\mathbf{Z}_{\mathbf{j}}\left(\mathbf{x}_{\mathbf{i}}\right)$; (equação do sistema ou do estado)

Analiticamente, estes dois sistemas podem ser representados por:

$$
\begin{aligned}
& \mathbf{Y}_{\mathbf{j}}\left(\mathbf{X}_{\mathbf{i}}\right)=\mathbf{M}_{\mathrm{jj}}\left(\mathbf{X}_{\mathbf{i}}\right) \mathbf{Z}_{\mathbf{j}}\left(\mathbf{X}_{\mathbf{i}}\right)+\mathbf{V}_{\mathbf{j}}\left(\mathbf{X}_{\mathbf{i}}\right) \quad \text { equação de observação } \\
& \mathbf{Z}_{\mathbf{j}}\left(\mathbf{X}_{\mathbf{i}}\right)=\phi_{\mathbf{j i}} \mathbf{Z}_{\mathbf{j}}\left(\mathbf{X}_{\mathbf{i}-\mathbf{1}}\right)+\mathbf{U}_{\mathbf{Z} \mathbf{j}}\left(\mathbf{X}_{\mathbf{i}}\right) \quad \text { equação de estado }
\end{aligned}
$$

onde a matriz $\mathbf{M}_{\mathbf{j j}}$ origina-se das seguintes equações de observação: 


$$
\begin{aligned}
& \mathrm{Y}_{1}\left(\mathrm{x}_{\mathrm{i}}\right)=\mathrm{m}_{11} \mathrm{Z}_{1}\left(\mathrm{x}_{\mathrm{i}}\right)+\mathrm{m}_{12} \mathrm{Z}_{2}\left(\mathrm{x}_{\mathrm{i}}\right)+\ldots \ldots \ldots . .+\mathrm{m}_{1 \mathrm{j}} \mathrm{Z}_{\mathrm{j}}\left(\mathrm{x}_{\mathrm{i}}\right)+\mathrm{V}_{1}\left(\mathrm{x}_{\mathrm{i}}\right) \\
& \mathrm{Y}_{2}\left(\mathrm{Xi}_{\mathrm{i}}\right)=\mathrm{m}_{21} \mathrm{Z}_{\mathrm{i}}\left(\mathrm{x}_{\mathrm{i}}\right)+\mathrm{m}_{22} \mathrm{Z}_{2}\left(\mathrm{x}_{\mathrm{i}}\right)+\ldots \ldots \ldots+\mathrm{m}_{2 \mathrm{j}} \mathrm{Z}_{\mathrm{j}}\left(\mathrm{x}_{\mathrm{i}}\right)+\mathrm{VY}_{2}\left(\mathrm{x}_{\mathrm{i}}\right) \\
& \mathrm{Y}_{\mathrm{j}}\left(\mathrm{x}_{\mathrm{i}}\right)=\mathrm{m}_{\mathrm{j} 1} \mathrm{Z}_{\mathrm{l}}\left(\mathrm{xi}_{\mathrm{i}}\right)+\mathrm{m}_{\mathrm{j} 2} \mathrm{Z}_{2}\left(\mathrm{x}_{\mathrm{i}}\right)+\ldots \ldots \ldots+\mathrm{m}_{\mathrm{j}} \mathrm{Z}_{\mathrm{j}}\left(\mathrm{x}_{\mathrm{i}}\right)+\mathrm{vyj}_{\mathrm{j}}\left(\mathrm{x}_{\mathrm{i}}\right)
\end{aligned}
$$

as quais, de uma forma matricial, podem ser escritas da seguinte forma:

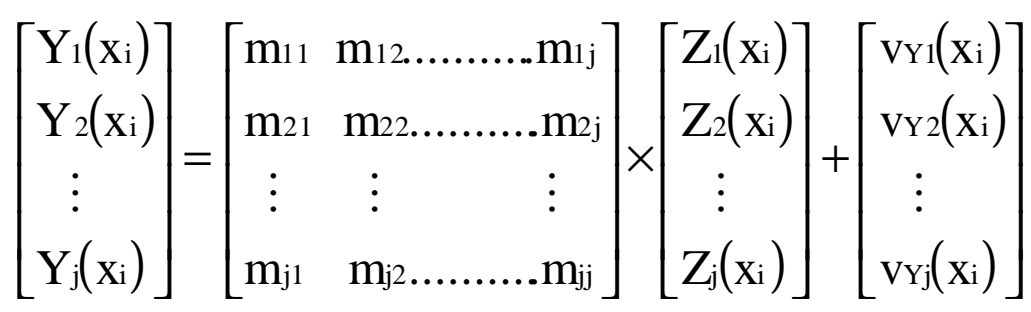

A matriz $\phi_{\mathrm{jj}}$ origina-se das seguintes equações de estado:

$$
\begin{aligned}
& \mathrm{Z}_{1}\left(\mathrm{x}_{\mathrm{i}}\right)=\phi_{11} \mathrm{Z}_{1}\left(\mathrm{x}_{\mathrm{i}-1}\right)+\phi_{12} \mathrm{Z}_{2}\left(\mathrm{x}_{\mathrm{i}}-1\right) \ldots \ldots .+\phi_{1 \mathrm{j}} \mathrm{Z}_{\mathrm{j}}\left(\mathrm{x}_{\mathrm{i}-1}\right)+\mathrm{uzl}\left(\mathrm{x}_{\mathrm{i}}\right) \\
& \mathrm{Z}_{2}\left(\mathrm{xi}_{\mathrm{i}}\right)=\phi_{21} \mathrm{Z}_{1}\left(\mathrm{xi}_{\mathrm{i}-1}\right)+\phi_{22} \mathrm{Z}_{2}\left(\mathrm{x}_{\mathrm{i}-1}\right) \ldots \ldots+\phi_{2 \mathrm{j}} \mathrm{Zj}\left(\mathrm{xi}_{\mathrm{i}-1}\right)+\mathrm{uz}\left(\mathrm{x}_{\mathrm{i}}\right) \\
& Z_{j}\left(x_{i}\right)=\phi_{j} Z_{1}\left(x_{i}-1\right)+\phi_{j 2} Z_{2}\left(x_{i}-1\right) \ldots \ldots .+\phi_{j j} Z_{j}\left(x_{i}-1\right)+u_{j j}\left(x_{i}\right)
\end{aligned}
$$

ou de uma forma matricial: 


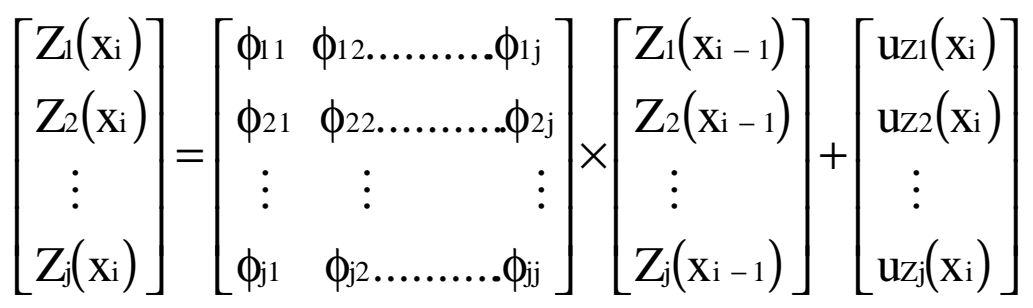

O vetor de observação $\mathbf{Y}_{\mathbf{j}}\left(\mathbf{x}_{\mathbf{i}}\right)$ é relacionado ao vetor de estado não-observável $\mathbf{Z}_{\mathbf{j}}\left(\mathbf{x}_{\mathbf{i}}\right)$ por meio da matriz de observação $\mathbf{M}_{\mathbf{j j}}$ e pelo erro de observação $\mathbf{v}_{\mathbf{Y j}}\left(\mathbf{x}_{\mathbf{i}}\right)$ (equação 8). Por outro lado, o vetor de estados $\mathbf{Z}_{\mathbf{j}}\left(\mathbf{x}_{\mathbf{i}}\right)$, na posição i, é relacionado ao mesmo vetor na posição $\mathrm{i} 1$, por meio da matriz dos coeficientes de estado $\phi_{\mathbf{j j}}$ (matriz de transição), e por um erro associado ao estado $\mathbf{u}_{\mathbf{Z j}}\left(\mathbf{x}_{\mathbf{i}}\right)$ com a estrutura de um modelo autoregressivo de primeira ordem, neste caso. Além da suposição de $\mathbf{V}_{\mathbf{Y j}}\left(\mathbf{x}_{\mathbf{i}}\right)$ e $\mathbf{u}_{\mathbf{Z j}}\left(\mathbf{x}_{\mathbf{i}}\right)$ são normalmente distribuídos e independentes, é assumido também que eles não são correlacionados entre si em qualquer lag.

As equações descritas acima contém distintas perturbações (ruídos): uma associada às observações e outra associada ao estado do sistema. De acordo com Gelb (1974), o desenvolvimento de métodos para processar observações contaminadas com ruídos, pode ser creditado aos trabalhos conduzidos por Gauss e Legendre (por volta de 1800), que desenvolveram independentemente, o método dos quadrados mínimos para modelos lineares. Mais recentemente, Plackett (1950) desenvolveu uma solução recursiva para o método dos quadrados mínimos para modelos lineares. Kalman (1960), usando uma formulação de espaço de estados, desenvolveu um filtro recursivo para estimativas em modelos lineares dinâmicos estocásticos, conhecido atualmente como Filtro de Kalman (KF). Segundo Gelb (1974), um bom estimador é um algoritmo computacional que processa observações para encontrar uma estimativa mínima (seguindo algum critério de otimização) do erro de estado de um sistema, usando: i. o conhecimento da dinâmica das observações e do sistema; ii. assumindo inferências estatísticas para os ruídos associados às observações e ao estado; e iii. conhecimento da condição inicial da informação. Em resumo, dado um sistema dinâmico de equações 
que descreve o comportamento dos vetores das observações e de estado, os modelos estatísticos que caracterizam os erros de observação e de estado, e uma condição inicial da informação, o KF faz a atualização seqüencial do vetor de estado do espaço i-1 para o espaço i, isto é, o KF é essencialmente uma solução recursiva que permite um processamento seqüencial das observações, com o método original dos mínimos quadrados de Gauss. Entretanto, outro algoritmo tem que ser usado [por exemplo, o algoritmo de máxima verossimilhança EM (Dempster et al., 1977), descrito e apresentado por Shumway \& Stoffer (2000)] em conjunto com o KF, para que seja solucionado o problema de observações contaminadas com ruídos, envolvendo a presença de parâmetros de incerteza (Gelb, 1974).

Em síntese, qualquer modelo linear (Dourado-Neto et al., 1999; Timm et al., 2000; Wendroth et al., 2001) ou não- linear (Katul et al., 1993) pode ser representado na formulação de espaço de estados, ou seja, por um sistema de duas equações: uma para o vetor de observações e a outra para a evolução do vetor de estado. 


\section{TEMPERATURA DO SOLO NA CULTURA DA CANA-DE-AÇÚCAR COMO UMA FUNÇÃO DO SISTEMA DE MANEJO}

\section{Resumo}

As temperaturas do ar e do solo são as variáveis mais importantes do agroecossistema. No caso da cana-de-açúcar (Saccharum officinarum L.), elas afetam o desenvolvimento da planta, a maturação e uma série de processos biológicos e físicoquímicos no solo. Este capítulo apresenta um estudo comparativo de três diferentes práticas de manejo na cultura da cana-de-açúcar, conduzido em uma Terra Roxa Estruturada, em Piracicaba, SP, Brasil. As três práticas de manejo são: (i) entrelinhas com solo nu; (ii) superfície do solo coberta com palha e ponteiros deixados após a colheita da cana; (iii) presença de resíduos da queima da cana, antes da colheita, na superfície do solo. A temperatura do solo foi medida com termômetros digitais nas profundidades de 0,03, 0,06 e 0,09 m, metro a metro, próximo a linha da cultura, ao longo das 84 parcelas da transeção experimental em todos os tratamentos e bordaduras. As medidas foram conduzidas a partir de Novembro/1998 (logo após a primeira colheita da cana planta) até Junho/1999. Os efeitos dos tratamentos sobre a temperatura do solo foram, evidentemente, mais pronunciados no período de Novembro/Fevereiro quando as plantas apresentavam um porte pequeno. Os dados foram coletados em dias típicos, escolhidos ao longo do ciclo de desenvolvimento da cultura, sempre das 11:00 h até as 12:00 h, mostram diferenças significativas, principalmente entre os tratamentos com e sem a presença da cobertura vegetal, alcançando diferenças de $7{ }^{\circ} \mathrm{C}$ para a média das três profundidades. Uma análise comparativa é feita entre tratamentos e seus efeitos são discutidos em relação à dados de produção da cultura da cana-de-açúcar. 


\section{SOIL TEMPERATURE IN A SUGAR-CANE CROP AS A FUNCTION OF THE MANAGEMENT SYSTEM}

\section{Summary}

Air and soil temperatures are, by far, the most important state variables of agroecosystems. In the case of sugar-cane (Saccharum officinarum L.) they affect plant development, maturation and a series of biological and physical-chemical soil processes. This paper presents a comparative study of three management practices, applied to the first ratoon of a sugar-cane crop established on a Rhodic Kandiudox (Terra Roxa Estruturada) of Piracicaba, SP, Brazil. The management practices are: i. interrow with bare soil; ii. trash mulching, maintaining harvest residues (straw + tips) on the soil; iii. soil with residues from burning the prior crop. Soil temperature was measured with digital stick thermometers driven into the soil down to the depths of 0.03, 0.06 and $0.09 \mathrm{~m}$, meter by meter, close to the crop row, along an 84-point transect that covered all treatments and borders. The measurements were performed from November 1998 (right after the first harvest of the planted cane) to June 1999. The effects of the treatments on soil temperature were, evidently, more prominent in the period November/February when the plants had a smaller height, not closing interrows. Data that were collected on typical days, chosen along the development cycle of the crop, always from 11:00 to 12:00 a.m., show significant differences, mainly between mulched and non mulched treatments, reaching values as high as $7^{\circ} \mathrm{C}$ for the average of the three depths. A comparative analysis is made between treatments and their effects are discussed in relation to the sugar-cane crop.

\subsection{Introdução}

As temperaturas do ar e do solo são as mais importantes variáveis do agroecossistema, sendo importantes em muitas fases do desenvolvimento da cana-deaçúcar. A introdução de uma nova prática da colheita, a qual deixa uma quantidade 
considerável de palha no campo, a temperatura do solo será severamente afetada. Esta prática de manejo, a qual induz problemas de compactação do solo (Oliveira et al., 1998), substituirá a prática tradicional de colheita que envolve a queima da cana antes da colheita com o objetivo de facilitar o corte manual. A nova prática envolve a colheita mecanizada com todos os resíduos (palha mais ponteiros) sendo cortados e deixados sobre a superfície do solo. Esta cobertura do solo é de fundamental importância para o desenvolvimento da cultura, desde que ela afeta o balanço de radiação devido à modificações na condutividade térmica e nos coeficientes de reflexão e, como consequiência, interfere em todos os outros componentes do balanço de energia. A temperatura do solo, sendo controlada por este balanço (Pezzopane et al., 1996), pode apresentar trocas significativas em relação as práticas tradicionais de colheita, onde a superfície do solo fica exposta a luz solar.

Os efeitos da cobertura vegetal na temperatura do solo têm sido extensamente estudados. Bragagnolo \& Mielniczuk (1990) detectaram uma redução de 8,5 ${ }^{\circ} \mathrm{C}$ na temperatura da superfície do solo, quando palha de trigo foi usada como cobertura vegetal. Derpsch et al. (1985) encontraram temperaturas superiores à $50{ }^{\circ} \mathrm{C}$ na profundidade de $0,03 \mathrm{~m}$, em um solo nu durante o verão, as quais em muitas situações podem causar significativos efeitos. Similares resultados foram também descritos por Lal (1974), Derpsch et al. (1983), Sidiras \& Vieira (1984) e Morote et al. (1990), sendo que os últimos autores estudaram o efeito da cobertura vegetal em áreas irrigadas cultivadas com soja. Eles observaram grandes diferenças nas temperaturas do solo entre áreas irrigadas e não-irrigadas em dias quentes. Sidiras \& Pavan (1986) observaram temperaturas altas na profundidade de $0,03 \mathrm{~m}$ para solos preparados convencionalmente, em relação ao preparo mínimo e ao plantio direto. Outros relevantes trabalhos relacionados à temperatura do solo foram reportados em Diniz \& Bastos (1980) comparando áreas florestadas com áreas sem florestas; Vieira et al. (1991) e Salton \& Mielniczuk (1995), também comparando preparo mínimo com preparo convencional do solo; Olasantam (1999) estudou os efeitos da temperatura do solo na emergência da semente e no crescimento e desenvolvimento das raízes; Caldeira \& Rodella (1997) e 
Parr (1975) descreveram os efeitos da temperatura do solo sobre a degradação de compostos orgânicos.

No caso da cultura da cana-de-açúcar na Austrália, Whitman et al. (1963) estudaram os efeitos da luz, temperatura e da água no brotamento dos ponteiros da cana. Eles enfatizaram que a temperatura ótima de brotamento foi próximo de $30{ }^{\circ} \mathrm{C}$, sendo que uma significante redução ocorreu abaixo de $22{ }^{\circ} \mathrm{C}$, e foi nulo para temperaturas entre 16 e $10{ }^{\circ} \mathrm{C}$. Na Flórida, Gascho et al. (1973) observaram que a temperatura mínima para a emergência da cana é em torno de $12{ }^{\circ} \mathrm{C}$, e que a temperatura teve um efeito marcante sobre o número de ponteiros, no crescimento da cana e na produção de açúcar, sendo que todos estes parâmetros de desenvolvimento da cultura foram maiores para temperaturas em torno de $30{ }^{\circ} \mathrm{C}$.

No Brasil, não existe uma pesquisa específica do efeito da temperatura do solo na cana-de-açúcar. Diversos autores, como por exemplo, Abramo Filho et al. (1993), descreveram os efeitos da temperatura de uma forma indireta, sendo seus principais objetivos sempre relacionados à outros aspectos da cultura. No experimento apresentado aqui, muitos outros aspectos da cultura da cana-de-açúcar serão estudados, principalmente a eficiência do uso do nitrogênio como fertilizante, o destino da matéria orgânica, o balanço hídrico de água no solo, estudos estes que serão publicados posteriormente. Desde que a temperatura do solo é relacionada a todos estes processos, este estudo apresenta dados coletados durante o período da primavera- verão, quando as plantas da cana-de-açúcar são jovens e a superfície do solo está mais intensivamente exposta a radiação solar.

\subsection{Material e Métodos}

O estudo de campo foi conduzido em Piracicaba, SP, Brasil (22 $42^{\circ} 30^{\prime}$ S e $47^{\circ}$ $38^{\prime}$ W) em um solo classificado como Terra Roxa Estruturada, freqüentemente usado no cultivo da cana-de-açúcar. Tabela 1 apresenta algumas características relevantes deste solo. 
Tabela 1. Algumas características do solo Terra Roxa Estruturada na camada de 0 $0,15 \mathrm{~m}$ de profundidade.

\begin{tabular}{cc}
\hline Características & Valor médio (84 pontos) \\
\hline pH em CaCh & 5,0 \\
Matéria orgânica $\left(\mathrm{kg} . \mathrm{m}^{-3}\right)$ & 25,0 \\
Cálcio $\left(\mathrm{mol}_{\mathrm{c}} \cdot \mathrm{m}^{-3}\right)$ & 64,0 \\
Magnésio $\left(\mathrm{mol}_{\mathrm{c}} \cdot \mathrm{m}^{-3}\right)$ & 18,0 \\
Potássio $\left(\mathrm{mol}_{\mathrm{c}} \cdot \mathrm{m}^{-3}\right)$ & 4,3 \\
Densidade do solo $\left(\mathrm{Mg}_{\mathrm{m}} \mathrm{m}^{-3}\right)$ & 1,349 \\
Areia $\left(\mathrm{g} \cdot \mathrm{k}^{-1}\right)$ & 290,0 \\
Silte $\left(\mathrm{g} \cdot \mathrm{kg}^{-1}\right)$ & 160,0 \\
Argila $\left(\mathrm{g} \cdot \mathrm{kg}^{-1}\right)$ & 550,0 \\
\hline
\end{tabular}

$\mathrm{Na}$ área experimental foi plantada cana-de-açúcar (Saccharum officinarum L.) em outubro de 1997, sendo a colheita da cana-planta realizada em Outubro 1998. Logo após, iniciou-se o estudo da temperatura do solo durante o período da primeira soca. Três sistemas de manejo foram comparados: (i) superfície do solo coberta com palha e ponteiros deixados após a colheita da cana $\left(\mathrm{T}_{1}\right.$ e $\left.\mathrm{T}_{2}\right)$; (ii) entrelinhas com solo nu $\left(\mathrm{T}_{3}\right)$; (iii) presença de resíduos da queima da cana, antes da colheita, na superfície do solo $\left(T_{4}\right)$. Os tratamentos $T_{1}$ e $T_{2}$ são similares no que diz respeito à presença da cobertura da superfície do solo e são, desta forma, repetições em termos do estudo da temperatura do solo diferindo somente em termos de ${ }^{15} \mathrm{~N}$ marcado que foi usado em um estudo adicional sobre o destino da matéria orgânica.

A área total $\left(2100 \mathrm{~m}^{2}\right)$ do experimento consistiu de 15 linhas de cana-de-açúcar, cada uma com $100 \mathrm{~m}$ de comprimento, espaçadas entre si de 1,4 m, como mostrado na Figura 1 abaixo. A linha central foi usada para as medidas da temperatura do solo, sendo que cada tratamento tinha um comprimento de $16 \mathrm{~m}$, separados por bordaduras de $4 \mathrm{~m}$ de comprimento. A superfície do solo nas bordaduras entre tratamentos foi mantida 


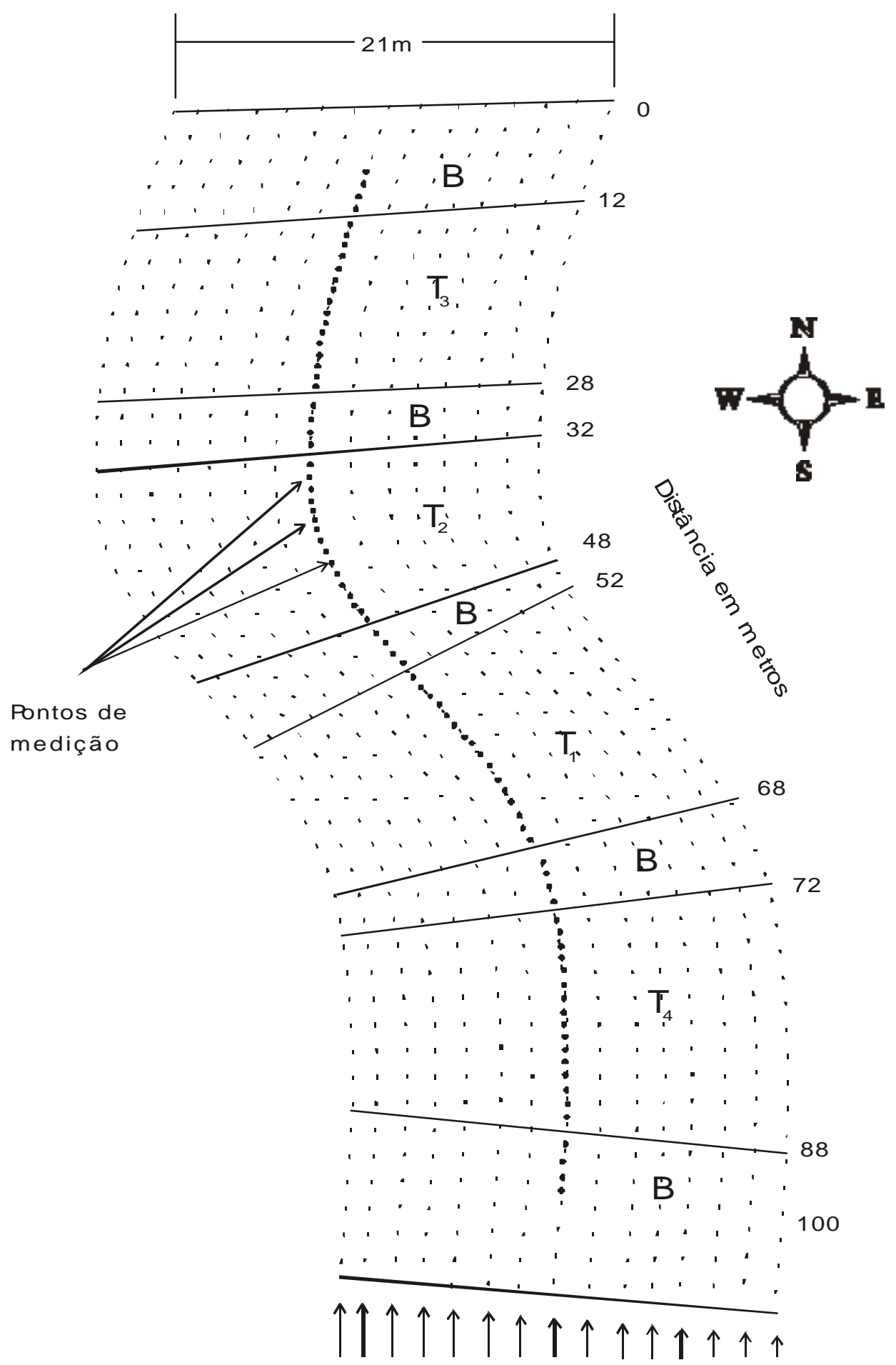

15 linhos do culture

Figura 1 - Esquema experimental da área. $\mathrm{T}_{1}$ e $\mathrm{T}_{2}$ : superfície do solo coberta com palha e ponteiros deixados após a colheita da cana; $\mathrm{T}_{3}$ : entrelinhas com solo nu; $\mathrm{T}_{4}$ : presença de resíduos da queima da cana, antes da colheita, na superfície do solo; B: bordaduras. 
sem cobertura vegetal. A temperatura do solo foi medida ao longo da transeção como mostrado na Figura 1, metro a metro, nos 84 pontos nas profundidades de 0,03, 0,06 e 0,09 $\mathrm{m}$, onde as raízes e o rizoma da cana-de-açúcar predominam e, desta forma, afetados diretamente pelos regimes de temperatura do solo. As medidas foram feitas em datas selecionadas, sempre no período das 11:00 as 12:00 h, com o intuito de detectar as máximas diferenças entre elas.

Termômetros digitais foram inseridos no solo até a profundidade desejada e após alcançado o equilíbrio (em torno de $180 \mathrm{~s}$ ), as leituras eram realizadas. As comparações entre os dados de temperatura do solo coletados ao longo do período deste estudo foram feitas usando análise de variância (ANOVA), por meio do programa estatístico SANEST (Sarriés, 1991), sendo utilizado o delineamento experimental inteiramente ao acaso.

Nos mesmos pontos da transeção, foram feitas leituras de umidade do solo, na faixa de $0-0,15 \mathrm{~m}$ de profundidade, usando uma sonda de superfície nêutron/gama, marca CPN, modelo MC-3. Dados de produção da cana foram avaliados somente na colheita em Outubro/1999.

\subsection{Resultados e Discussão}

As medidas de temperaturas do solo iniciaram-se em 18 de Novembro de 1998. Na Figura 2 são apresentados os valores de temperatura do solo ao longo da transeção para este dia. As diferenças entre os tratamentos com a presença de cobertura vegetal na superfície do solo $\left(\mathrm{T}_{1}\right.$ e $\left.\mathrm{T}_{2}\right)$ e sem a presença da cobertura $\left(\mathrm{T}_{3}\right.$ e $\left.\mathrm{T}_{4}\right)$ pode ser notada muito claramente, mesmo para a profundidade de 0,09 $\mathrm{m}$. No caso da temperatura média entre as três profundidades (valor médio das temperaturas nas profundidades de 0,03, 0,06 e 0,09 m), ANOVA não indicou diferenças entre $T_{1}$ e $T_{2}$, mas significantes diferenças entre estes tratamentos e os tratamentos $\mathrm{T}_{3}$ e $\mathrm{T}_{4}$ (Tabela 2, data: 18/11/1998). Para esta data, quando a cultura não cobre mais do que $10 \%$ da superfície do solo, os resíduos da cinza afetaram significativamente os valores de temperatura do solo em $\mathrm{T}_{4}$ 


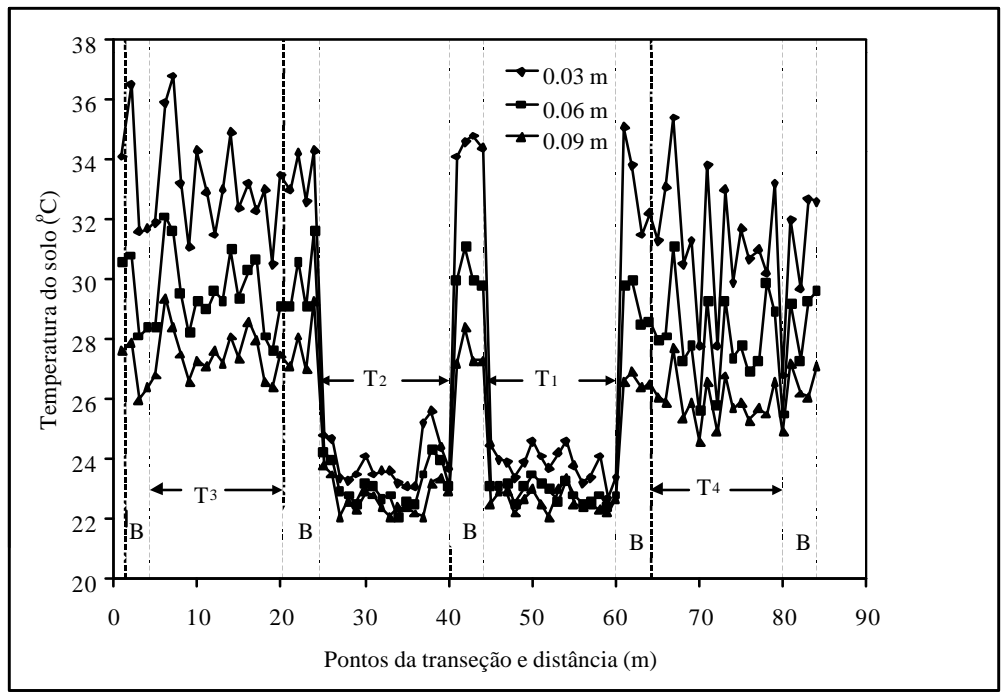

Figura 2 - Valores de temperatura do solo ao longo da transeção de 84 pontos para o dia 18/11/1998. $\mathrm{T}_{1}$ e $\mathrm{T}_{2}$ : superfície do solo coberta com palha e ponteiros deixados após a colheita da cana; $\mathrm{T}_{3}$ : entrelinhas com solo nu; $\mathrm{T}_{4}$ : presença de resíduos da queima da cana, antes da colheita, na superfície do solo; B: bordaduras.

Tabela 2. Valores médios de temperatura do solo (4 repetições, cada uma com 4 pontos de leitura) para a faixa de 0,03 a $0,09 \mathrm{~m}$ de profundidade, em datas selecionadas. $\mathrm{T}_{1}$ e $\mathrm{T}_{2}$ : superfície do solo coberta com palha e ponteiros deixados após a colheita da cana; $\mathrm{T}_{3}$ : entrelinhas com solo nu; $\mathrm{T}_{4}$ : presença de resíduos da queima da cana, antes da colheita, na superfície do solo; B: bordaduras.

\begin{tabular}{cccccccc}
\hline & \multicolumn{3}{c}{ Temperatura do solo média $\left({ }^{\circ} \mathrm{C}\right)$} & \multicolumn{3}{c}{ Temperaturas do ar $\left({ }^{\circ} \mathrm{C}\right)$} \\
\cline { 2 - 7 } Dia & $\mathrm{T}_{1}$ & $\mathrm{~T}_{2}$ & $\mathrm{~T}_{3}$ & $\mathrm{~T}_{4}$ & $\mathrm{~T}$ máx & Tmín & T média \\
\hline $18 / 11 / 1998$ & $23,1 \mathrm{c}$ & $23,3 \mathrm{c}$ & $30,1 \mathrm{a}$ & $28,3 \mathrm{~b}$ & 32,8 & 19,7 & 26,3 \\
$02 / 12 / 1998$ & $23,1 \mathrm{~b}$ & $22,8 \mathrm{~b}$ & $29,8 \mathrm{a}$ & $30,2 \mathrm{a}$ & 35,0 & 18,0 & 26,5 \\
$18 / 12 / 1998$ & $23,9 \mathrm{bc}$ & $23,8 \mathrm{c}$ & $24,5 \mathrm{a}$ & $24,4 \mathrm{ab}$ & 27,6 & 20,8 & 24,2 \\
$12 / 01 / 1999$ & $23,1 \mathrm{~b}$ & $23,3 \mathrm{~b}$ & $23,8 \mathrm{~b}$ & $28,3 \mathrm{a}$ & 29,8 & 20,0 & 24,9 \\
$05 / 02 / 1999$ & $23,8 \mathrm{a}$ & $23,8 \mathrm{a}$ & $23,5 \mathrm{~b}$ & $23,4 \mathrm{~b}$ & 33,7 & 19,8 & 26,8 \\
$04 / 03 / 1999$ & $22,7 \mathrm{a}$ & $22,9 \mathrm{a}$ & $22,7 \mathrm{a}$ & $22,3 \mathrm{~b}$ & 32,0 & 18,4 & 25,2 \\
$07 / 04 / 1999$ & $22,3 \mathrm{~b}$ & $22,6 \mathrm{a}$ & $22,6 \mathrm{a}$ & $22,1 \mathrm{c}$ & 32,2 & 18,4 & 25,3 \\
$14 / 05 / 1999$ & $17,4 \mathrm{a}$ & $17,4 \mathrm{a}$ & $17,7 \mathrm{a}$ & $17,6 \mathrm{a}$ & 22,5 & 9,0 & 15,6 \\
$29 / 06 / 1999$ & $15,5 \mathrm{~b}$ & $15,6 \mathrm{~b}$ & $16,3 \mathrm{a}$ & $15,3 \mathrm{~b}$ & 27,8 & 14,2 & 21,0 \\
\hline
\end{tabular}

Valores médios diários seguidos pela mesma letra não diferem significativamente ao nível de $5 \%$ de probabilidade pelo teste de Tukey. 
quando comparados ao de $\mathrm{T}_{3}$. A situação no dia 02/12/1998 foi muito similar a do dia anterior, exceto pelo fato que para este dia não houve diferença entre os tratamentos $\mathrm{T}_{3}$ e $\mathrm{T}_{4}$, indicando que não houve mais o efeito dos resíduos da queima da cana na temperatura do solo. No dia 18/12/1998 (Figura 3), um dia nublado, as diferenças significativas apresentadas na Tabela 2 não possuem um significado físico visto que os valores médios são muito próximos.

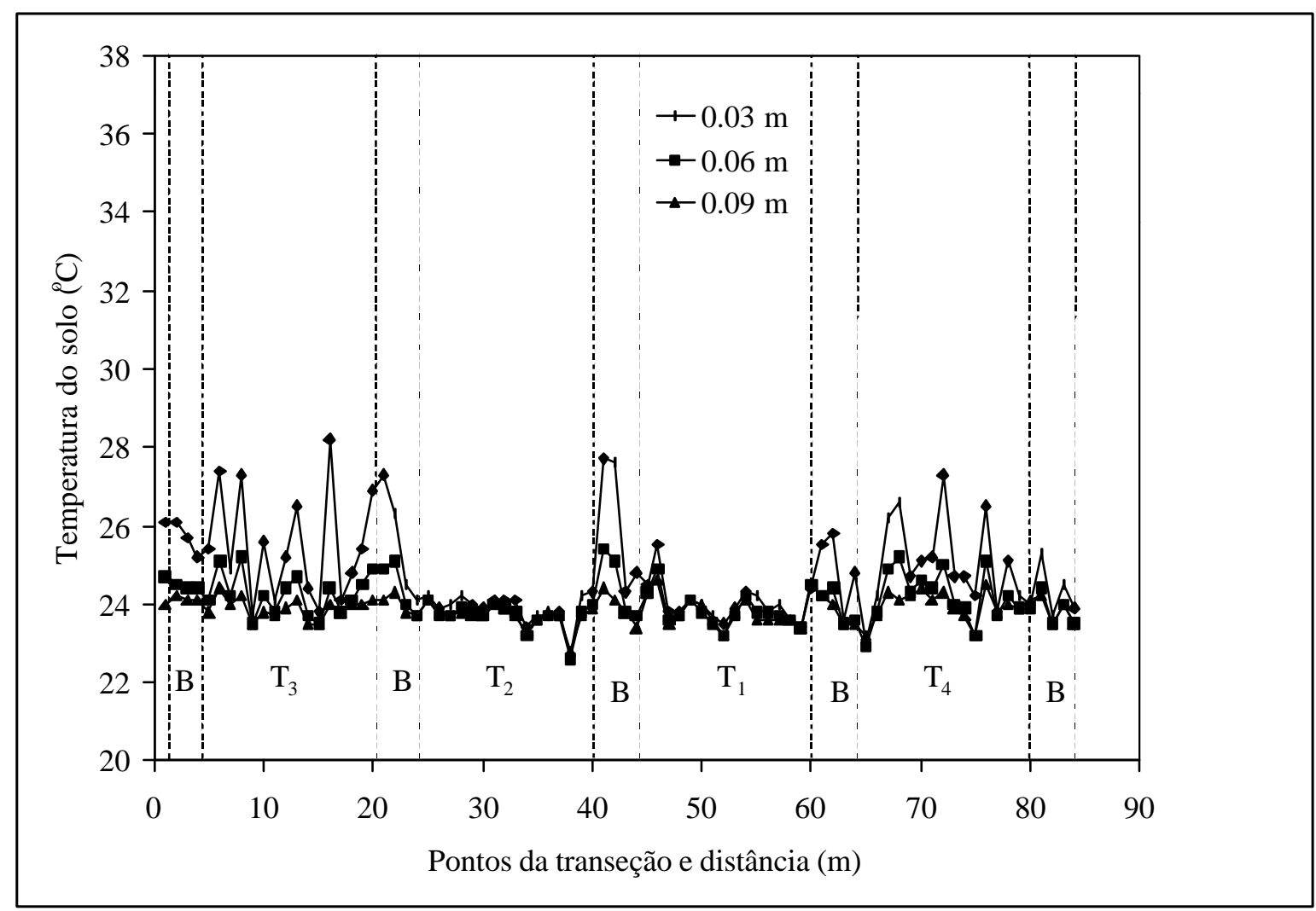

Figura 3 - Valores de temperatura do solo ao bngo da transeção para o dia 18/12/1998. $\mathrm{T}_{1}$ e $\mathrm{T}_{2}$ : superfície do solo coberta com palha e ponteiros deixados após a colheita da cana; $\mathrm{T}_{3}$ : entrelinhas com solo nu; $\mathrm{T}_{4}$ : presença de resíduos da queima da cana, antes da colheita, na superfície do solo; B: bordaduras. 
Analisando a Figura 3, verifica-se que os valores de temperatura do solo na profundidade de $0,03 \mathrm{~m}$ foram os que mais variaram quando comparados às outras profundidades.

Na Figura 4 são encontrados os valores de temperatura do solo para o dia 12/01/1999, quando as plantas tinham em torno de $1 \mathrm{~m}$ de altura. Embora a Tabela 2 não indica diferenças entre $T_{1}, T_{2}$ e $T_{3}$, pode ser visto que a temperatura média no tratamento $\mathrm{T}_{3}$ é ligeiramente maior do que as temperaturas em $\mathrm{T}_{1}$ e $\mathrm{T}_{2}$, no mínimo para as profundidades de 0,06 e 0,09 m. A maior diferença entre estes tratamentos e $\mathrm{T}_{4}$ é provavelmente devido à um retardo no crescimento da planta neste tratamento onde a

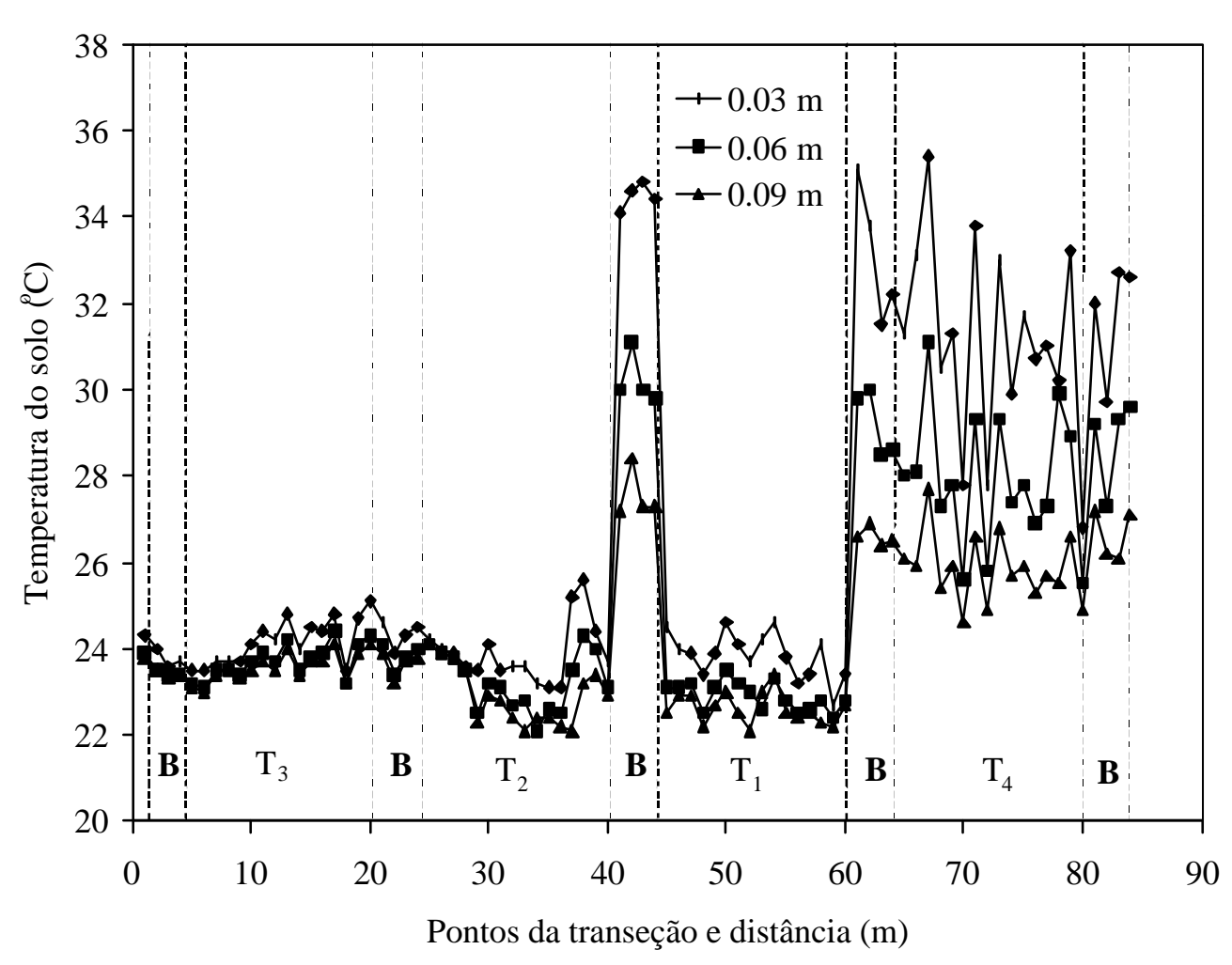

Figura 4 - Valores de temperatura do solo ao longo da transeção para o dia 12/01/1999. $\mathrm{T}_{1}$ e $\mathrm{T}_{2}$ : superfície do solo coberta com palha e ponteiros deixados após a colheita da cana; $\mathrm{T}_{3}$ : entrelinhas com solo nu; $\mathrm{T}_{4}$ : presença de resíduos da queima da cana, antes da colheita, na superfície do solo; B: bordaduras. 
cana foi queimada. Para o dia 05/02/1999, também um dia nublado, as diferenças mostradas na Tabela 2 não tem um significado físico. $\mathrm{O}$ mesmo pode ser dito para os outros dias (04/03, 07/04, 14/05 e 29/06/1999) não nublados. Os valores de temperatura do solo para o dia 29/06/1999 encontram-se na Figura 5. Neste dia as plantas estavam sombreando completamente as entrelinhas, assim sendo, os tratamentos não afetavam mais os valores de temperatura do solo.

Analisando a Figura 5, pode-se verificar que os valores de temperatura do solo são ligeiramente mais altos no início da transeção (faixa de 0-15 m de distância) devido aos clarões formados pelos ventos fortes neste período que derrubaram as canas. $\mathrm{Na}$

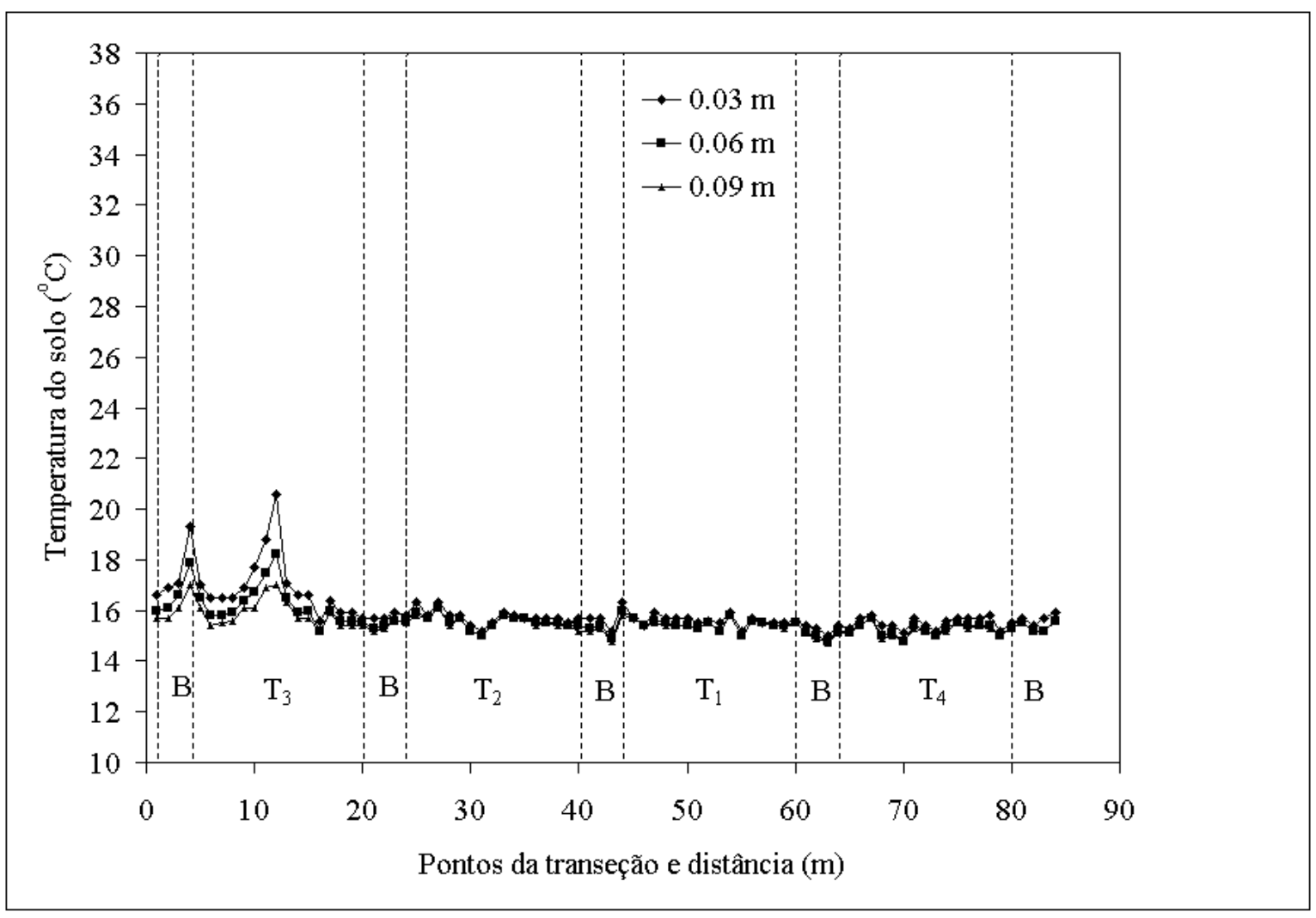

Figura 5 - Valores de temperatura do solo ao longo da transeção para o dia 29/06/1999. $\mathrm{T}_{1}$ e $\mathrm{T}_{2}$ : superfície do solo coberta com palha e ponteiros deixados após a colheita da cana; $\mathrm{T}_{3}$ : entrelinhas com solo nu; $\mathrm{T}_{4}$ : presença de resíduos da queima da cana, antes da colheita, na superfície do solo; B: bordaduras. 
Tabela 2, pode ser verificado que a diferença de temperatura do solo entre os tratamentos sem a presença da cobertura vegetal $\left(\mathrm{T}_{3}\right.$ e $\left.\mathrm{T}_{4}\right)$ e com presença da cobertura vegetal $\left(\mathrm{T}_{1}\right.$ e $\left.\mathrm{T}_{2}\right)$ alcançaram valores na ordem de $7{ }^{\circ} \mathrm{C}$ em Novembro, decrescendo para quase zero em Fevereiro. Os valores máximos (na profundidade de 0,03 m) alcançaram temperaturas na ordem de $37{ }^{\circ} \mathrm{C}$, similares aos encontrados por Derpsch et al. (1985) e, devido ao fato de que os perfis de temperatura do solo são geralmente exponenciais, a temperatura na superfície do solo deve ter alcançado valores bem maiores. O período de primavera-verão no Hemisfério Sul é muito importante para o estabelecimento da soqueira da cultura, sendo esperado que suaves valores de temperatura do solo, devido a presença da cobertura vegetal, favoreçam o desenvolvimento da cultura, como mencionado por Gasho et al. (1973). Embora sendo um período relativamente curto do ciclo da cultura, este é o período no qual o rizoma da cultura é jovem e mais sensível à altas temperaturas. Na Tabela 3, são apresentados os dados de produção da cultura relativos à colheita de Outubro/1999.

Tabela 3. Dados de produção da cultura na colheita de Outubro/1999. NS = número de ponteiros por metro; WS = peso úmido dos ponteiros por metro. Valores médios de 16 repetições por tratamento.

\begin{tabular}{ccc}
\hline Tratamento & NS & WS \\
\hline $\mathrm{T}_{1}$ & $39,7 \mathrm{~b}$ & $51,1 \mathrm{~b}$ \\
$\mathrm{~T}_{2}$ & $40,3 \mathrm{~b}$ & $55,3 \mathrm{ab}$ \\
$\mathrm{T}_{3}$ & $47,8 \mathrm{a}$ & $63,2 \mathrm{a}$ \\
$\mathrm{T}_{4}$ & $45,2 \mathrm{ab}$ & $58,1 \mathrm{ab}$ \\
\hline
\end{tabular}

Médias seguidas pela mesma letra não diferem significativamente ao nível de $5 \%$ de probabilidade pelo teste de Tukey.

Analisando a Tabela 3, pode-se verificar que houve uma resposta negativa da cobertura vegetal no crescimento da planta, daí o fato de que $T_{1}$ e $T_{2}$ tiveram significativamente valores mais baixos de massa úmida e número de ponteiros por metro de linha, em relação à $\mathrm{T}_{3}$ e $\mathrm{T}_{4}$, exceto para o número de ponteiros em $\mathrm{T}_{4}$. Uma explicação para isto é o estabelecimento de um microclima muito úmido devido a presença da cobertura vegetal, que possuía inicialmente uma espessura de 0,20 a 0,30m. 
Este microambiente poderia ter favorecido ao ataque de fungos e microorganismos que afetam o brotamento do rizoma e o desenvolvimento dos ponteiros. A presença desta cobertura também tem um efeito sobre a umidade do solo, que foi estudado com mais detalhes por Dourado-Neto et al. (1999), usando técnicas geoestatísticas e a abordagem em espaço de estados.

A Figura 6 apresenta um gráfico de dispersão mostrando a correlação entre a umidade do solo na camada superficial $(0-0,15 \mathrm{~m})$, medida com uma sonda de superfície nêutron/gama, e o valor médio de temperatura do solo (valor médio entre as profundidades de 0,03, 0,06 e 0,09 m) para o dia 18/11/1998.

A correlação $\left(R^{2}=0,4493\right.$, Figura 6$)$ indica claramente que nos pontos da transeção onde a temperatura é mais baixa, maior é o valor da umidade do solo. Similar estudo foi apresentado por Morkoc et al. (1985).

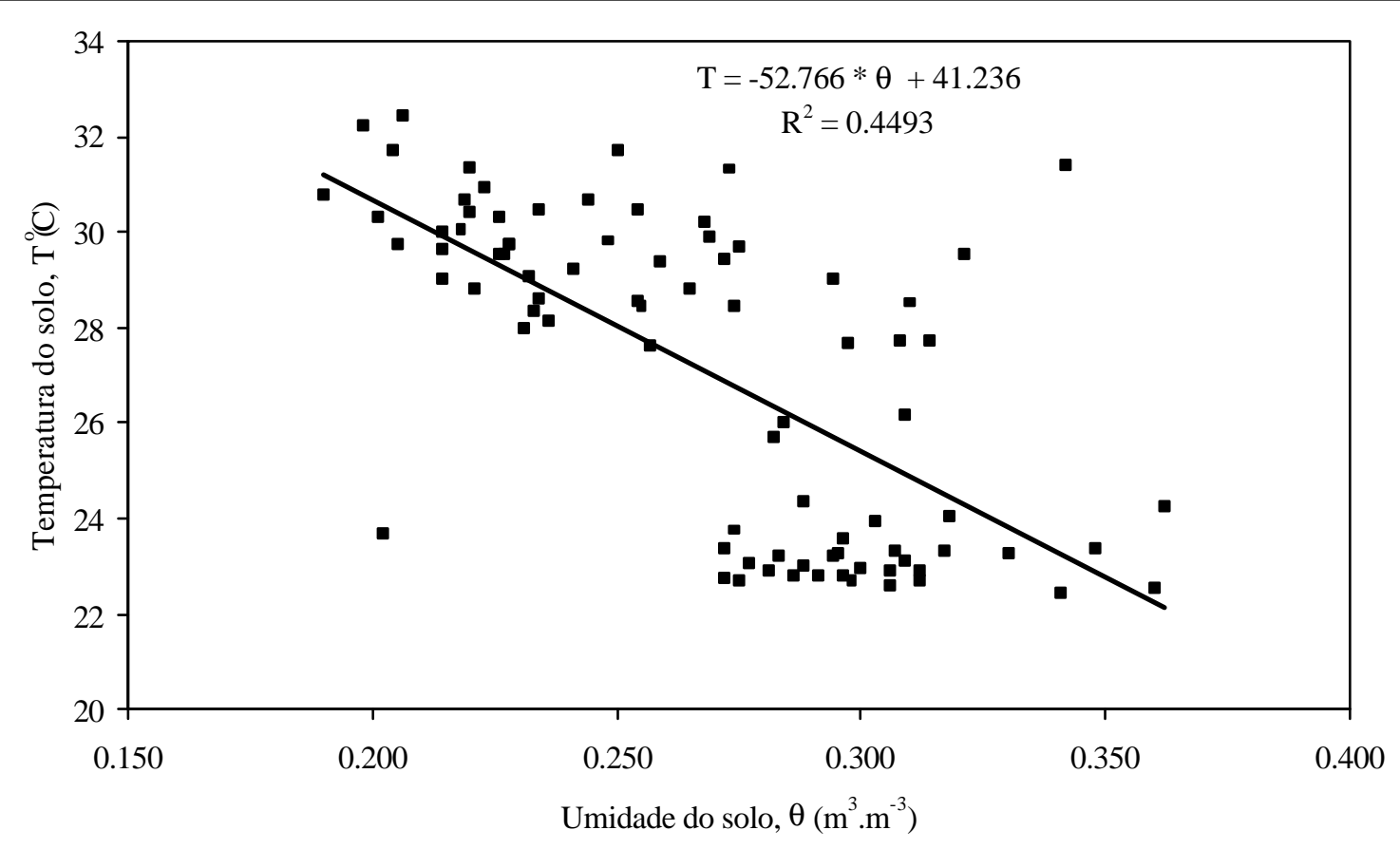

Figura 6 - Diagrama de dispersão mostrando a correlação entre a temperatura média do solo $(0,03-0,09 \mathrm{~m})$ e umidade média do solo (faixa $0-0,15 \mathrm{~m}$ de profundidade) . 


\subsection{Conclusões}

O efeito da presença da cobertura vegetal na superfície do solo na cultura da cana-de-açúcar durante a primeira soca, como uma conseqüência da adoção de uma nova prática de manejo sem a queima prévia da cana antes da colheita, pode reduzir as temperaturas médias na superfície do solo na ordem de $7{ }^{\circ} \mathrm{C}$, evitando picos de temperatura na superfície durante o período inicial da cana soca. A cobertura vegetal, contudo, afetou negativamente o desenvolvimento da cultura reduzindo o número de colmos e seu peso úmido, no presente estudo em torno de $13 \%$. 


\section{BALANÇO DE ÁGUA NO SOLO NA CULTURA DE CANA-DE-AÇÚCAR: ASPECTOS QUANTITATIVOS E QUALITATIVOS DE SUA CONTABILIZAÇÃO}

\section{Resumo}

Os componentes do balanço de água no solo foram quantificados em diferentes práticas de manejo em uma área cultivada com cana-de-açúcar (Saccharum officinarum L.). Também foi feita uma análise qualitativa das metodologias usadas para suas estimativas. O delineamento experimental utilizado foi o de blocos ao acaso, com três tratamentos e 4 repetições em cada tratamento: (i) entrelinhas com solo nu; (ii) superfície do solo coberta com palha e ponteiros deixados após a colheita da cana; (iii) presença de resíduos da queima da cana, antes da colheita, na superfície do solo. O solo da área experimental $(7,4 \%$ de declividade) foi classificado como Terra Roxa Estruturada. O escoamento superficial de água no solo, o fluxo de água no solo no limite inferior do volume de solo estudado e a variação do armazenamento de água no solo não foram afetados pelas diferentes práticas de manejo. Além disso, foi constatado que o escoamento superficial e os fluxos de água no solo são fortemente afetados pela variabilidade espacial das propriedades físicas do solo.

\section{WATER BALANCE OF A SUGARCANE CROP: QUANTITATIVE AND QUALITATIVE ASPECTS OF ITS MEASUREMENT}

\section{Summary}

We studied the quantification of the water balance components of soils differently managed, as well as made a qualitative analysis of the methodologies used 
for their estimation, in a sugarcane (Saccharum officinarum L.) field, using a randomized block design with four replicates and three treatments: bare soil, mulched soil using trash left on the soil surface after harvest, and soil with burned trash. The soil was classified as a Rhodic Kandiudalf, locally called "Terra Roxa Estruturada", the experimental area having a slope of 7.4\%. Run-off, soil water fluxes at the lower soil volume limit, and soil water storage changes were not affected by the different soil management practices. Furthermore, it was found that the evaluation of run-off and soil water fluxes is strongly affected by soil spatial variability of soil physical properties.

\subsection{Introdução}

Existem vários métodos que visam estimar a demanda hídrica para os diferentes estádios de desenvolvimento das culturas, sendo que, cada um deles possui suas características próprias, quanto aos parâmetros necessários para a sua estimativa. Dentre estes métodos, o balanço hídrico em determinada cultura realizado diretamente em condições de campo permite o acompanhamento das relações hídricas durante as distintas fases de crescimento e desenvolvimento da cultura, tornando-o desta maneira uma ferramenta importante para o manejo racional dos recursos hídricos e edáficos com o objetivo de maximizar a produtividade agrícola.

O balanço hídrico, determinado através da quantificação da água em um volume de solo, é baseado na equação geral de conservação da massa, em sua forma integral ou diferencial, para contabilizar os seus diferentes componentes (precipitação, irrigação, escoamento superficial, drenagem profunda, variação do armazenamento de água no solo e evapotranspiração). Diversos autores usaram esta equação, dentre eles Rose \& Stern (1967), Reichardt et al. (1979) e Villagra et al. (1995). A metodologia baseia-se na somatória das quantidades de água que entram e saem de um determinado elemento de volume de solo, num dado intervalo de tempo, fornecendo como resultado a quantidade de água líquida disponível as plantas. Cada componente é determinado através de diferentes técnicas (Moura et al., 1994), e apesar das inúmeras dificuldades e erros experimentais envolvidos na estimativa de cada componente, o balanço hídrico 
completo no campo constitui uma importante forma de ajudar no manejo da cultura, permitindo medir "in situ” os vários processos que envolvem a dinâmica da água no sistema solo-planta-atmosfera. Por outro lado, Reichardt et al. (1990) citam que um fato importante que impõe dificuldades na metodologia do balanço hídrico no campo, é o fato do volume de solo ser aberto no seu limite inferior, o que dificulta a quantificação de sua capacidade de armazenar água que estaria disponível às plantas. Outro problema é a variabilidade espacial das propriedades físicas do solo. Esta variabilidade foi estudada por vários pesquisadores (Greminger et al., 1985; Villagra et al., 1988) que indicaram sua importância mas não discutiram suas implicações no cálculo do balanço hídrico. Villagra et al. (1995) salientaram que tal método exige uma quantidade considerável de instrumentos nos limites superior (superfície do solo) e inferior (zona radicular da cultura) do elemento de volume, o que causa uma significativa limitação no estudo da variabilidade espacial, já que este requer um grande número de repetições. Como consequiência, segundo estes autores, poucos trabalhos discutem as dificuldades impostas pela variabilidade espacial no estudo e no cálculo do balanço hídrico.

Os componentes do balanço hídrico que aparentemente podem ser avaliados mais facilmente são a precipitação e a irrigação. A determinação do armazenamento de água no perfil de solo em estudo é feita pela integração de perfis consecutivos de umidade. Sonda de nêutrons tem sido muito utilizada para a medição da umidade do solo (Greacen, 1981). Dentre os problemas de seu uso, a variabilidade espacial das propriedades do solo e a sua calibração, são apontados como os mais importantes. Turatti \& Reichardt (1991) estudaram a variabilidade espacial e temporal do armazenamento de água em uma Terra Roxa Estruturada, e concluíram que o solo apresentou uma grande variabilidade ao longo da transeção de $125 \mathrm{~m}$ de comprimento, porém se manteve estável no tempo, ou seja, pontos úmidos permanecendo sempre úmidos para diferentes condições do sistema solo-planta, um ponto que é discutido por Reichardt et al. (1997) como sendo relacionado a calibração da sonda.

A medição direta do escoamento superficial no campo é difícil, uma vez que tem que ser levado em consideração sua dependência do tipo de solo, das suas propriedades físicas, da cobertura superficial do solo, do comprimento e declividade da área. Desta 
forma, em muitas situações, o escoamento superficial é deixado como incógnita na equação do balanço, e, neste caso, todos os outros componentes tem que ser conhecidos.

A drenagem profunda e a ascensão capilar são os componentes de grande complexidade no procedimentos de cálculo do balanço hídrico. Para a estimativa deles, utiliza-se comumente, a equação de Buckingham-Darcy, que envolve a função de condutividade hidráulica do solo $\mathrm{K}(\theta)$. A condutividade hidráulica é, desta frma, um parâmetro indispensável para o uso desta equação e, de acordo com van Lier \& Libardi (1999), ela é uma das mais importantes propriedades do solo para estudos que envolvem infiltração da água, movimento de água dentro do perfil do solo e para as raízes da planta. No entanto, a informação a respeito da variabilidade dos parâmetros empíricos que definem as relações de $\mathrm{K}(\theta)$ é escassa. Uma das metodologias mais comumente utilizadas para estimar $\mathrm{K}(\theta)$ é o método do perfil instantâneo (Hillel et al., 1972; Libardi et al., 1980). A vantagem deste método está no fato de basear-se em medições diretas no campo, contudo, isto implica em um grande investimento em equipamentos, tempo e mão-de-obra, especialmente em solos com camadas adensadas e compactadas, onde o processo de drenagem é muito lento. Por esta razão, que existem poucos relatos de determinações de $K(\theta)$ usando o método do perfil instantâneo com um grande número de repetições. É importante salientar que Govindaraju et al. (1992) discutiram o fato de que os métodos baseados na equação de Richards, como é o caso do perfil instantâneo, embora teoricamente corretos, envolvem grandes problemas para sua aplicação em virtude da exigência de dados de entrada difíceis de serem obtidos com precisão. Reichardt et al. (1998) também fizeram uma forte discussão sobre a medição e dificuldades do uso das relações de $K(\theta)$.

A condutividade hidráulica do solo é, entre as propriedades físicas do solo, a que possui a maior variabilidade, seguindo em muitos casos, uma distribuição log-normal. Warrick \& Nielsen (1980) apresentaram dados com coeficientes de variação na ordem de $100 \%$ para a condutividade hidráulica do solo saturado, e de $400 \%$ para a condutividade hidráulica do solo não-saturado em umidades mais baixas. Libardi \& Saad (1994) comentam que é comum encontrar estudos de balanço hídrico que se 
baseiam em apenas uma medida da condutividade hidráulica para a área experimental, o que acarreta erros na estimativa da drenagem profunda ou na ascensão capilar.

Embora tendo em mente o efeito de diferentes coberturas vegetais nos componentes do balanço hídrico, o principal objetivo deste capítulo é mostrar que embora o conceito de balanço hídrico seja simples e direto, sua quantificação para uma dada cultura é extremamente difícil e complicado.

\subsection{Material e Métodos}

O experimento foi conduzido em Piracicaba, SP, em um solo classificado como Terra Roxa Estruturada. De acordo com a classificação de Koeppen, o clima é do tipo Cwa, tropical, mesotérmico com inverno seco, sendo a temperatura média do mês mais frio inferior a $18{ }^{\circ} \mathrm{C}$ e do mês mais quente superior a $22{ }^{\circ} \mathrm{C}$. Os valores médios de temperatura do ar, precipitação e umidade relativa do ar são $21,2{ }^{\circ} \mathrm{C}, 1253 \mathrm{~mm} / \mathrm{ano}$ e $74 \%$, respectivamente. O período seco é de Junho-Agosto, sendo Julho o mês mais seco. Durante o verão, Outubro-Março, valores de precipitação com alta intensidade são eventos comuns, muitos deles alcançando valores de $50 \mathrm{~mm} / \mathrm{h}$ ou até mais.

\subsubsection{Desenho experimental}

O estudo foi conduzido em uma área experimental cultivada com cana-deaçúcar, variedade SP 80-3280 de médio a longo ciclo, tendo um espaçamento de 1,4 m entrelinhas. $\mathrm{O}$ delineamento experimental usado foi o de blocos ao acaso com três tratamentos e 4 repetições cada um. A cana-de-açúcar foi plantada em sulcos nivelados, uma prática que minimiza o escoamento superficial. A declividade da área experimental é de 7,4\%, sendo que todas 15 linhas da cultura foram separadas por terraços para o controle de eventos de alta precipitação. A área experimental total consistiu de 15 linhas de cana, cada uma com $100 \mathrm{~m}$ de comprimento, sendo as três linhas centrais (7, 8 e 9) escolhidas para as medições da umidade do solo e do potencial mátrico da água no solo (Figura 1). 


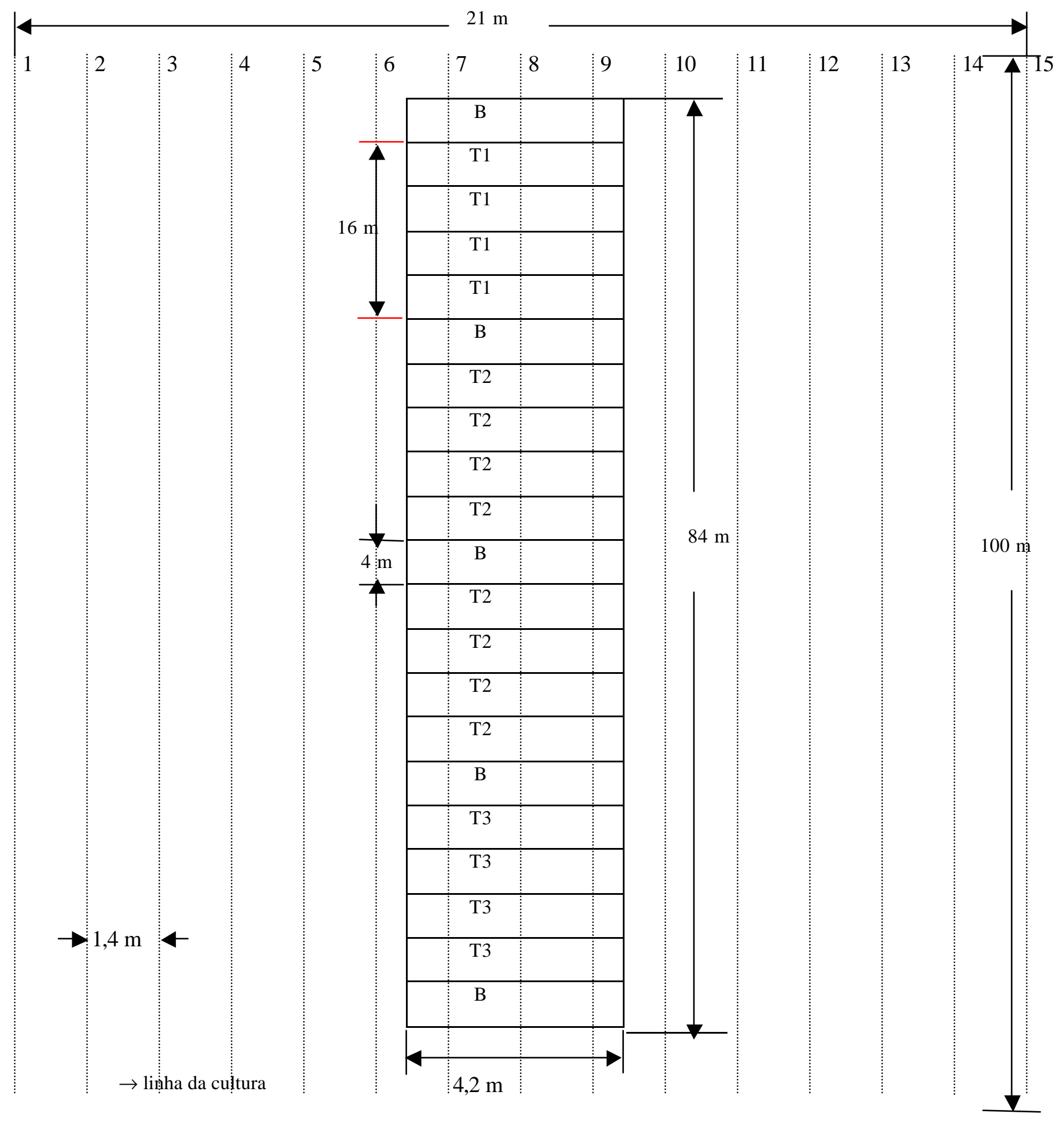

Figura 1 - Esquema da área experimental consistindo de 15 linhas de cana-de-açúcar, espaçadas de $1,4 \mathrm{~m}$, com comprimento de $100 \mathrm{~m}$ cada uma. As três linhas centrais $(7,8 \mathrm{e} 9)$ foram usadas para o estudo do balanço hídrico. $\mathrm{T}_{1}=$ entrelinhas com solo nu; $\mathrm{T}_{2}=$ superfície do solo coberta com palha e ponteiros deixados após a colheita da cana; $\mathrm{T}_{3}=$ presença de resíduos da queima da cana, antes da colheita, na superfície do solo, e $\mathrm{B}=$ bordaduras. 
Os tratamentos consistiram de: $T_{1}=$ entrelinhas com solo nu; $T_{2}=$ superfície do solo coberta com palha e ponteiros deixados após a colheita da cana; $\mathrm{T}_{3}=$ presença de resíduos da queima da cana, antes da colheita, na superfície do solo, e B = bordaduras.

\subsubsection{Balanço hídrico}

Para avaliar o balanço hídrico em todos os tratamentos, a seguinte equação de balanço de massa foi usada:

$$
\mathrm{P}+\mathrm{I}-\mathrm{ET}-\mathrm{R} \pm \mathrm{Q}_{\mathrm{L}}=\ddot{\mathrm{A} S}
$$

onde todas as unidades dos componentes do balanço são dadas em mm e estimadas em intervalos de tempo $\Delta \mathrm{t}$ (dias); $\mathrm{P}$ = precipitação; $\mathrm{I}$ = irrigação; $\mathrm{ET}$ = evapotranspiração; $\mathrm{R}$ = escoamento superficial; $\mathrm{Q}_{\mathrm{L}}=$ fluxo de água no limite inferior do volume de solo, na profundidade $\mathrm{z}=\mathrm{L}$, tomada como o limite da zona radicular; e $\Delta \mathrm{S}=$ a variação do armazenamento de água no solo na camada de 0 - L .

A precipitação foi medida na área experimental, usando o valor médio dos valores de precipitação coletados em dois pluviômetros, tipo "Ville de Paris", localizados no início e no final do experimento (separados de $100 \mathrm{~m}$ ). A irrigação não foi usada, uma prática comum para a cultura da cana-de-açúcar nesta área.

Para períodos sem precipitação, o escoamento superficial foi nulo e a evapotranspiração foi calculada usando a equação (1). Para os períodos chuvosos, devido às dificuldades de estimar o escoamento superficial no experimento, a evapotranspiração foi estimada usando a equação de Penman-Monteith (Pereira et al., 1997), e o escoamento superficial calculado a partir da equação (1). Os dados para calcular a evapotranspiração foram coletados no posto meteorológico localizado a $1 \mathrm{~km}$ da área experimental. Os coeficientes da cultura usados em função dos diferentes tratamentos e dos estádios de desenvolvimento da cultura são apresentados na Tabela 1. As grandes diferenças entre estes coeficientes em relação aos tratamentos, 
corresponderam aos meses de Novembro e Dezembro, quando o dossel da planta não cobria totalmente a superfície do solo e os tratamentos tinham um efeito na evapotranspiração.

Tabela 1. Coeficientes da cultura da cana-de-açúcar utilizados para estimar a evapotranspiração.

\begin{tabular}{cccccc}
\hline & \multicolumn{5}{c}{ Mês } \\
\hline Tratamento & Novembro & Dezembro & Janeiro & Fevereiro & Março \\
\hline $\mathrm{T}_{1}$ & 0,3 & 0,5 & 0,5 & 1 & 1 \\
$\mathrm{~T}_{2}$ & 0 & 0,2 & 0,5 & 1 & 1 \\
$\mathrm{~T}_{3}$ & 0,3 & 0,5 & 0,5 & 1 & 1 \\
& & & & & \\
\hline
\end{tabular}

As densidades de fluxos de água no solo, no limite inferior do elemento de volume de solo considerado, foram estimadas usando a equação de Darcy-Buckingham, integrando esta equação sobre o respectivo intervalo de tempo (dias) do balanço hídrico:

$$
\mathrm{Q}_{\mathrm{L}}=\int_{\mathrm{ti}}^{\mathrm{tf}}[-\mathrm{K} \not \dot{g} \operatorname{grad} \mathrm{H}] \mathrm{tt}
$$

onde $K(\theta)$ é a condutividade hidráulica do solo ( $\mathrm{mm} /$ dia) em função da umidade volumétrica $\theta$; grad $\mathrm{H}$ é o gradiente hidráulico $(\mathrm{m} / \mathrm{m})$; e t o tempo (dias). Os intervalos de tempo $\Delta t=\left(t_{f}-t_{i}\right)$ foram da ordem de 7 a 15 dias.

Os gradientes hidráulicos foram calculados a partir de leituras de tensiômetros (quatro repetições por tratamento). O limite inferior do volume de solo $(\mathrm{z}=\mathrm{L})$ escolhido foi de 1,0 m, desde que a maioria do sistema radicular da cultura está dentro desta camada. Logo, os tensiômetros foram instalados nas profundidades de 0,9 m e 1,1 m, para calcular o gradiente hidráulico por meio da seguinte equação:

$$
\operatorname{grad} \mathrm{H}=\left(\mathrm{H}_{1.10}-\mathrm{H}_{0.90}\right) / 0.20
$$


onde $\mathrm{H}$ é o potencial total da água no solo, tomado como a soma do potencial mátrico e do gravitacional.

A função condutividade hidráulica $\mathrm{K}(\theta)$, para $\mathrm{z}=\mathrm{L}$, foi obtida a partir de dados coletados em uma área de $18 \mathrm{~m}^{2}$ na parte inferior do experimento, usando o método do perfil instantâneo (Hillel et al., 1972 e Libardi et al., 1980), sendo este adaptado à declividade da área. O nivelamento da superfície do solo foi mínimo, sendo a inundação feita em três adjacentes plataformas de 1,4 m x 4,0 m, assegurando somente fluxo vertical (Timm et al., 2000).

Os tubos de acesso para sonda de nêutrons de profundidade foram instalados até a profundidade de $1,2 \mathrm{~m}$, um em cada repetição, totalizando 12 tubos. A calibração da sonda, modelo CPN 503 DR, foi feita em uma área adjacente ao experimento, correlacionando leituras da sonda com valores de umidade volumétrica do solo. As medições da umidade do solo foram feitas nas profundidades de 0,20, 0,40, 0,60, 0,80 e 1,0 m em datas selecionadas, durante o período inicial de desenvolvimento da cultura, quando as plantas não cobriam a superfície do solo completamente e os tratamentos poderiam afetar os componentes do balanço hídrico (Novembro até Março). O armazenamento de água no solo $\mathrm{S}(\mathrm{mm})$ foi calculado usando o método trapezoidal para cada data, e sua variação $\Delta S$ usada na equação (1). Doze períodos durante a estação chuvosa foram escolhidos a partir do dia 27 de Novembro de 1998 até 29 de Março de 1999 para calcular o balanço hídrico em cada tratamento. Durante o período seco, Abril a Setembro, a precipitação é mínima e a cana-de-açúcar começa o período de maturação.

\subsection{Resultados e Discussão}

Somente no primeiro período investigado não houve precipitação, sendo os demais períodos pertencentes a estação chuvosa de Piracicaba. Como já foi dito, na equação do balanço hídrico, a precipitação e a irrigação são, aparentemente, os componentes mais fáceis de serem estimados. Segundo Downey (1972), os erros envolvidos na medição destes componentes podem ser reduzidos à $5 \%$ ou mesmo $1 \%$, 
se técnicas corretas são empregadas. Reichardt et al. (1995) mostraram que a variabilidade espacial da precipitação tem que ser levada em consideração e que ela tem que ser medida o mais próximo possível da área experimental, como foi o caso deste experimento.

Os altos valores de precipitação, em quantidade e intensidade, associada a declividade da área resultaram em valores altos de escoamento superficial apesar do fato do plantio ter sido em sulcos nivelados. O maior evento de precipitação ocorreu no dia 11/03/1999, totalizando 108,2 mm. Outros exemplos são: dia 26/01/1999, 69,3 mm; e dia 05/12/1998, 47,0 mm. Isto confirma o mencionado por Pereira et al. (1974), que em culturas como café, na qual em muitos aspectos é similar a cana-de-açúcar, o escoamento superficial somente poderia ser negligenciado para declividades inferiores à $3 \%$.

A Figura 2 apresenta as variações de armazenamento de água no solo para o período estudado (124 dias, Novembro a Março), mostrando que não houve evidência do efeito dos tratamentos sobre este componente do balanço. Os maiores valores observados de armazenamento de água no solo (camada de 0 a 1,0 m) foram da ordem de $410 \mathrm{~mm}$ e de $310 \mathrm{~mm}$ (período mais seco), mostrando a relativa pequena capacidade de armazenamento de água deste perfil de solo. Embora, sendo um solo argiloso, a fração deste solo é, na maioria das vezes, constituída de argilas minerais 1:1 e óxidos de ferro de muito baixa capacidade de reter água.

Para verificar se haviam diferenças entre os valores de armazenamento de água no solo nos diferentes tratamentos, ANOVA foi calculada usando as datas como repetições. Não foi encontrada diferença ao nível de significância de $1 \%$ entre os tratamentos, ou seja, a cobertura vegetal e a queima da cana não interferiram no armazenamento de água no solo, no mínimo para as condições deste estudo.

Os valores de precipitação ocorridos e o comportamento dos fluxos de água no solo $\mathrm{Q}_{\mathrm{L}}$ no limite inferior do volume de solo considerado $(\mathrm{z}=1,0 \mathrm{~m})$, para os diferentes tratamentos, no período de estudo são mostrados na Figura 3. 


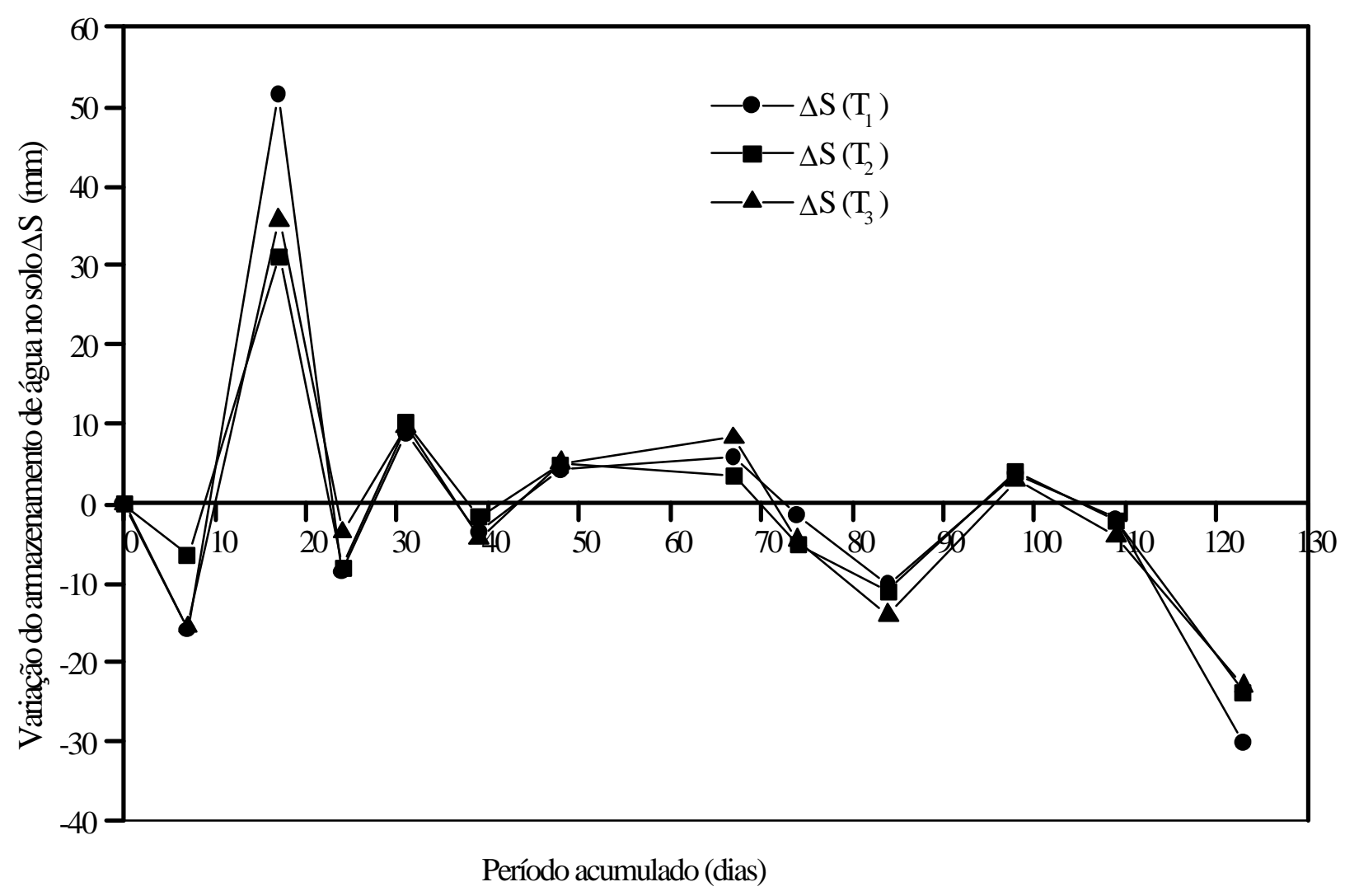

Figura 2 - Variação de armazenamento de água no solo $(\Delta \mathrm{S})$ para o período de estudo do balanço hídrico (124 dias, Novembro a Março). $\mathrm{T}_{1}=$ entrelinhas com solo $\mathrm{nu} ; \mathrm{T}_{2}=$ superfície do solo coberta com palha e ponteiros deixados após a colheita da cana; $\mathrm{T}_{3}=$ presença de resíduos da queima da cana, antes da colheita, na superfície do solo. 


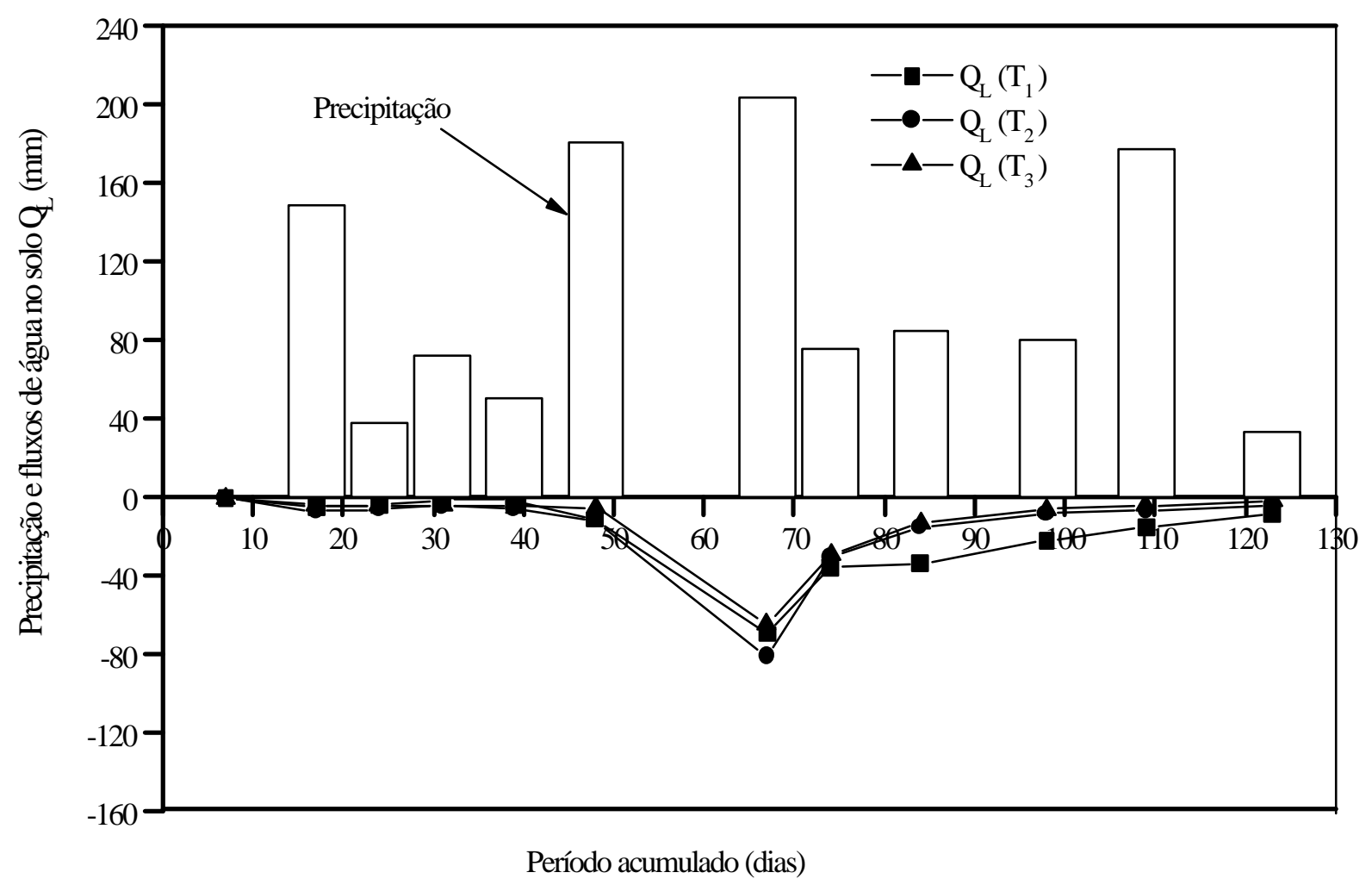

Figura 3 - Precipitação ocorrida e valores dos fluxos de água no solo Q no limite inferior do volume de solo considerado $(\mathrm{z}=1,0 \mathrm{~m})$ para o período de estudo do balanço hídrico (124 dias, Novembro a Março). $\mathrm{T}_{1}=$ entrelinhas com solo $\mathrm{nu} ; \mathrm{T}_{2}=$ superfície do solo coberta com palha e ponteiros deixados após a colheita da cana; $\mathrm{T}_{3}=$ presença de resíduos da queima da cana, antes da colheita, na superfície do solo. 
Analisando a Figura 3, pode-se verificar que os valores de drenagem para os primeiros 40 dias foram pequenos, pelo fato de que o perfil do solo estava em processo de recarga. Após, eles tornaram-se muito altos, assumindo valores da ordem de 80 $\mathrm{mm} /$ dia, devido ao período de altos eventos de precipitação e da baixa capacidade de armazenar água do perfil do solo. Embora altos, estes valores são 24 vezes menores que o valor da condutividade hidráulica do solo saturado $\mathrm{K}_{\mathrm{o}}(1947 \mathrm{~mm} /$ dia $)$ para a mesma profundidade (Timm et al., 2000). Cintra et al. (2000) também encontraram valores de $\mathrm{Q}_{\mathrm{L}}$ desta ordem de magnitude. Como mencionado, esta drenagem interna foi estimada usando a equação de Darcy-Buckingham, envolvendo a estimativa da condutividade hidráulica do solo e do gradiente hidráulico. Os valores individuais de cada repetição diferiram muito entre si, o que tornou proibitivo usar os valores médios para representar todo o processo de drenagem à nível de campo. O uso desta abordagem tem sido criticada extensivamente por diversos pesquisadores, dentre eles podemos destacar Reichardt et al. (1998). Um dos maiores problemas relacionados a esta abordagem é a variabilidade espacial do solo. De acordo com Warrick \& Nielsen (1980), que classificaram os parâmetros do solo em relação à sua variabilidade espacial em baixa, média e alta, a condutividade hidráulica tem uma alta variabilidade, apresentando coeficientes de variação de $170 \%$ a $400 \%$. Por outro lado, Govindaraju et al. (1992) mencionaram que determinações de $K(\theta)$ baseadas na equação de Richards levam à complicações na sua aplicação. A aproximação do gradiente hidráulico unitário usada por Libardi et al. (1980), adotada por Timm et al. (2000) e fortemente criticada por Reichardt (1993) é outro problema a ser levado em consideração.

O modelo mais comum usado para a função condutividade hidráulica é $\mathrm{K}(\theta)=\mathrm{K}_{\mathrm{o}} \exp \left[\gamma\left(\theta-\theta_{\mathrm{o}}\right)\right]$, onde os parâmetros $\mathrm{K}_{\mathrm{o}}$ e $\theta_{\mathrm{o}}$ podem ser vistos como parâmetros de ajuste do modelo (Reichardt et al., 1998). O valor da umidade do solo na saturação $\theta_{\mathrm{o}}$ deveria ser igual ao valor da porosidade total do solo uma vez que o perfil do solo foi completamente saturado até a taxa de infiltração da água no solo tornar-se constante, contudo, diversos trabalhos apresentam valores menores para $\theta_{\mathrm{o}}$. A explicação para isto está na dificuldade de saturar completamente um perfil de solo no campo, um fato que 
leva a erros na determinação de $\theta_{\mathrm{o}}$, e como conseqüência, grandes erros na estimativa de $K$, desde que a relação $K(\theta)$ seja exponencial. Isto é uma evidência da importância de ter valores confiáveis de $\theta_{\mathrm{o}}$, e da dificuldade da escolha do melhor método para sua avaliação, o que indica a possibilidade de uma flexibilização do seu valor, como já mencionado por Reichardt et al. (1998). Estes autores assumiram $\theta_{\mathrm{o}}$ como sendo um parâmetro de ajuste. No presente estudo os melhores valores de $\theta_{\mathrm{o}}$ corresponderam à: 0,540 para $\mathrm{T}_{1} ; 0,483$ para $\mathrm{T}_{2} ; 0,480$ para $\mathrm{T}_{3}$, todos em $\mathrm{m}^{3} / \mathrm{m}^{3}$.

Uma discussão similar pode ser feita a respeito da dificuldade de estimar $\mathrm{K}_{\mathrm{o}}$, principalmente devido à sua variabilidade espacial e a obtenção do estado de equilíbrio dinâmico (taxa de infiltração constante), isto é, a completa saturação do perfil do solo. Para o presente caso, o valor médio (média de 9 medições) de $\mathrm{K}_{\mathrm{o}}$ foi de $1947 \mathrm{~mm} / \mathrm{dia}$, com um coeficiente de variação CV de 41,3\%. O alto valor de CV é também uma evidência da importância de valores confiáveis de $\mathrm{K}_{\mathrm{o}}$ para estimar $\mathrm{Q}_{\mathrm{L}}$.

O gradiente hidráulico, calculado por meio da equação (3) também apresentou uma grande variabilidade entre as repetições, devido às grandes diferenças nas leituras dos tensiômetros. Os coeficientes de variação das 4 repetições de cada tratamento, foram da ordem de 5,9\% a 53,8\%. Esta variabilidade adicionada aquela dos valores de $\mathrm{K}(\theta)$, é de grande importância para o cálculo dos valores de $\mathrm{Q}_{\mathrm{L}}$, usando a equação (2).

Com relação aos tratamentos usados neste estudo, pode ser visto claramente na Figura 3 que os tratamentos não afetaram os valores de fluxos de água no solo na profundidade L, fato este comprovado por meio da ANOVA.

Na Figura 4 são apresentados os valores de precipitação ocorridos e escoamento superficial R, para os diferentes tratamentos, no período de estudo do balanço hídrico. Rose (1966) e Mendes et al. (1992) verificaram que este componente é de difícil estimativa devido às proporções de sua magnitude, do volume de água, da declividade da área e do tipo de solo. Desta forma, neste estudo, o escoamento superficial foi deixado como uma incógnita na equação do balanço hídrico, uma abordagem que demanda o conhecimento dos outros componentes, e que envolve todos os possíveis erros na estimativa dos outros componentes. 


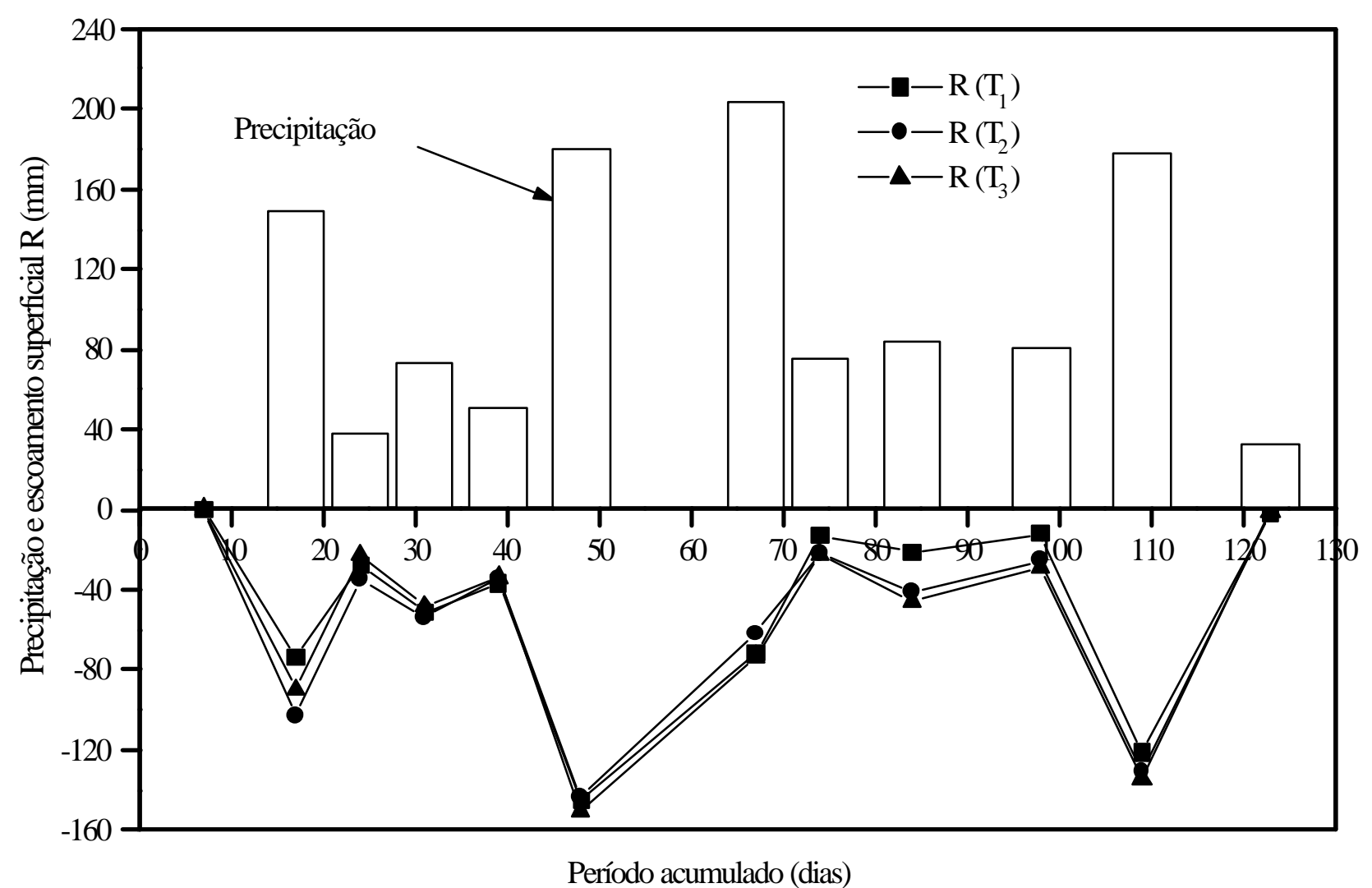

Figura 4 - Precipitação ocorrida e valores do escoamento superficial R para o período de estudo do balanço hídrico (124 dias, Novembro a Março). $\mathrm{T}_{1}=$ entrelinhas com solo nu; $\mathrm{T}_{2}=$ superfície do solo coberta com palha e ponteiros deixados após a colheit a da cana; $\mathrm{T}_{3}=$ presença de resíduos da queima da cana, antes da colheita, na superfície do solo. 
Analisando esta figura, pode-se constatar que foram encontrados altos valores de escoamento superficial, mas que estes valores não apresentaram diferenças significativas entre tratamentos quando comparados por meio da ANOVA. Estes valores de escoamento superficial foram devidos aos altos eventos de precipitação ocorridos durante o período de estudo. Da precipitação que ocorre em uma área, parte da água deixa o sistema pela evapotranspiração, outra parte por drenagem interna e escoamento superficial e o restante permanece armazenado no perfil do solo. Como já discutido, este solo tem uma baixa capacidade de armazenamento de água que pode ser afetada pelas condições da superfície do solo como encrostamento, compactação, rachaduras e tipo de cobertura vegetal. Para períodos muito chuvosos, este fatores conduzem à altos valores de escoamento superficial, como foi o caso deste estudo. Por outro lado, quanto mais úmido o perfil de solo maiores são os valores de $\theta$ e $\mathrm{K}$, implicando em valores maiores de $\mathrm{Q}_{\mathrm{L}}$. Os altos valores de escoamento superficial medidos neste estudo foram devido aos altos valores de precipitação que ocorreram durante todo o período de estudo, à declividade de 7,4 \% da área e ao nível de compactação do solo causado pelo intensivo pisoteio de pessoas durante as medições.

\subsection{Conclusões}

A troca da prática da queima da cultura de cana-de-açúcar antes da colheita para a prática de deixar a palha mais os ponteiros como cobertura vegetal da superfície do solo para o próximo período de cana soca, não afetou nenhum dos seguintes componentes do balanço hídrico: escoamento superficial, fluxo de água no solo no limite inferior do volume de solo em estudo e o armazenamento de água no solo. Isto devido às características da cultura da cana-de-açúcar e da precipitação ocorrida na área experimental. Sendo uma cultura semi-perene que em um período de 60 a 90 dias cobre completamente a superfície do solo, a cobertura vegetal tem efeito somente na evapotranspiração, durante os primeiros 90 dias. Para os altos valores de precipitação, a cobertura vegetal não alterou o processo de infiltração da água no solo e, como conseqüência, os valores do escoamento superficial também não foram alterados. 
O estabelecimento do balanço hídrico da cultura de cana-de-açúcar, prevalecendo estas condições, é problemático principalmente devido ao fato de que o escoamento superficial e os fluxos de água no limite inferior do volume de solo considerado são fortemente afetados pela variabilidade espacial do solo. 


\section{ABORDAGEM DE ESPAÇO DE ESTADOS NA ANÁLISE DA UMIDADE E TEMPERATURA DO SOLO NA CULTURA DE CANA-DE-AÇÚCAR}

\section{Resumo}

Para estudar o comportamento da umidade e da temperatura do solo na camada superficial do solo, a abordagem de espaço de estados ("state-space approach") foi empregada em dados obtidos em uma cultura de cana-de-açúcar submetida à prática distintas de manejo. Os tratamentos constaram de cobertura vegetal (palha e ponteiros), solo nu e palha queimada, todos no início da primeira soca. As amostragens foram realizadas em uma transeção de 84 pontos, metro a metro, cobrindo todos os tratamentos e bordaduras. A metodologia de espaço de estados é descrita em detalhe e os resultados mostram que a umidade do solo pode ser estimada com sucesso a partir de dados de umidade do solo e temperatura observados no primeiro vizinho.

\section{STATE SPACE APPROACH FOR THE ANALYSIS OF SOIL WATER CONTENT AND SOIL TEMPERATURE IN A SUGARCANE CROP}

\section{Summary}

The state space approach is used to describe surface soil water content and temperature behavior, in a field experiment in which sugarcane is submitted to different management practices. The treatments consisted of harvest trash mulching, bare soil, and burned trash, all three in a ratoon crop, after first cane harvest. One transect of 84 points was sampled, meter by meter, covering all treatments and borders. The state space approach is described in detail and the results show that soil water contents 
measured along the transect could be successfully be estimated from water content and temperature observations made at the first neighbor.

\subsection{Introdução}

Existe uma grande classe de fenômenos (físicos, químicos e biológicos), cujo processo observacional e a conseqüente quantificação numérica, produz uma seqüência de dados distribuídos no tempo. A esta seqüência de dados ordenados segundo o parâmetro tempo, denominamos série temporal. A forma mais simples de conceituar uma série temporal, denotada por $\mathrm{Y}_{\mathrm{t}} ; \mathrm{t}=1,2$,.., é de interpretar $\mathrm{Y}_{\mathrm{t}}$ como sendo um conjunto de observações discretas, observadas em tempos eqüidistantes que apresentam uma dependência serial entre as mesmas. O conceito acima, apesar de simples, evidencia de certa forma a "Análise de Séries Temporais" como uma área bem definida dentro da Estatística, visto que estamos claramente descartando aqueles dados independentes e identicamente distribuídos, comumente utilizados nos diversos modelos estatísticos (Souza, 1989). Na ciência do solo este conceito é também aplicado para séries espaciais, correspondendo a um conjunto de observações discretas, obtidas em intervalos iguais ou não, ao longo de transeções ou de malhas ("grids"), e que apresentam uma dependência espacial.

A representação em espaço de estados é uma forma de representar um sistema linear ou não, a partir de um sistema de duas equações: uma equação para um vetor de observações e outra para a evolução do vetor de estados. Uma vez um modelo representado em espaço de estados, o Filtro de Kalman pode ser aplicado, sendo este um algoritmo que permite realizar, entre outras coisas, predição e estimativas (Motta \& Hotta, 1998).

Até recentemente, pesquisadores ligados a área de física dos solos estudavam a variabilidade das propriedades do solo por meio da estatística clássica (análise de variância, média, coeficiente de variação), que pressupõe que as observações de uma dada propriedade são independentes entre si, desconsiderando-se sua localização na área. Entretanto, têm sido enfatizado, que observações adjacentes de uma dada 
propriedade do solo não são completamente independentes e que esta variabilidade espacial deve ser considerada na análise estatística dos dados. Diversas ferramentas estatísticas, tais como: função de autocorrelação, função de crosscorrelação, semivariogramas e espaço de estados ("state-space") têm sido usadas para avaliar a variabilidade espacial (Hui et al., 1998). Segundo Bresler et al. (1981), nas últimas duas décadas, têm-se dado ênfase ao estudo da variabilidade espacial do solo no intuito de um melhor entendimento dos processos que influenciam a variabilidade de produção das culturas. Já Nielsen \& Alemi (1989) comentam que as observações dentro e entre os tratamentos podem não serem independentes entre si, o que torna o arranjo experimental no campo inadequado.

Vauclin et al. (1982) estudaram a variabilidade espacial da umidade do solo e da temperatura do solo usando um modelo autoregressivo de primeira ordem. Shumway (1988) cita que a análise de "state-space" é um tipo especial de modelo autoregressivo. Temperatura do solo e umidade do solo (Morkoc et al., 1985); produção da cultura e nitrogênio no solo (Wendroth et al., 1992); são alguns exemplos de dados modelados usando a abordagem de espaço de estados.

Segundo Morkoc et al. (1985), freqüentemente são utilizados conjunto de dados incompletos por causa das dificuldades que envolvem a aquisição destes dados, como por exemplo, o custo e o tempo requeridos para a sua coleta. Desta forma, são necessárias técnicas para analisar séries com falta de observações. Usando a técnica de espaço de estados, dados de uma série de observações que estão faltando podem ser estimados e valores fora do domínio de observação podem ser preditos.

A análise de espaço de estados pode ser usada, como a krigagem e a cokrigagem, para a interpolação espacial mas a filosofia por trás desta ferramenta é diferente daquela da krigagem.

Neste capítulo, a abordagem de espaço de estados (Shumway, 1988; Shumway $\&$ Stoffer, 2000) foi aplicada no estudo do comportamento de uma série espacial de umidade do solo e de temperatura do solo, coletadas ao longo de uma transeção em um experimento com cana-de-açúcar, submetido à diferentes práticas de manejo, tendo 
como objetivo um melhor entendimento da relação dinâmica entre estas duas variáveis físico-hídricas do solo à nível de campo.

\subsubsection{Aspectos teóricos}

$\mathrm{Na}$ análise de espaço de estados, o estado do sistema, ou seja, o estado de uma variável ou de um conjunto de variáveis em um ponto "i”, é relacionado ao estado do sistema em um ponto "i-h", onde $\mathrm{h}=1,2,3, \ldots ., \mathrm{n} 1$, é a distância ("lag") entre os pontos vizinhos. Este tipo de modelo autoregressivo é usado para vários tipos de previsões, baseados em uma série durante o passado, para identificar os coeficientes que unem estes sistemas de estados (os coeficientes de estados) através do espaço ou do tempo (Wendroth et al., 1997).

A equação básica, denominada de equação de estado, é apresentada da seguinte forma:

$$
\mathrm{X}_{\mathrm{i}}=\phi \mathrm{X}_{\mathrm{i}-1}+\mathrm{W}_{\mathrm{i}}
$$

onde: " $X_{i}$ " é o vetor estado (ou um conjunto de "p" variáveis em um ponto "i"); " $\phi$ " é uma matriz p x p dos coeficientes de estado que indica a medida da regressão espacial, e "Wi" são os erros (ruídos) do sistema de estado para i = 1, 2, 3, ...., n. Assume-se que estes erros possuem média zero, são não-correlacionados e normalmente distribuídos. Esta é a estrutura usual de um modelo autoregressivo comum, onde os coeficientes da matriz $\phi_{p p}$ poderiam ser calculados via regressão múltipla, onde " $\mathrm{X}_{\mathrm{i}}$ " seria a variável dependente e " $\mathrm{X}_{\mathrm{i}-1}$ " a independente. Entretanto, no modelo de espaço de estados, o verdadeiro estado da variável ou do vetor de estado é considerado "embutido" na seguinte equação de observação:

$$
\mathrm{Y}_{\mathrm{i}}=\mathrm{A}_{\mathrm{i}} \mathrm{X}_{\mathrm{i}}+\mathrm{Vi}_{\mathrm{i}}
$$


onde o vetor de observação " $\mathrm{Y}_{\mathrm{i}}$ " está relacionado com o vetor de estado " $\mathrm{X}_{\mathrm{i}}$ " via uma matriz de observação " $\mathrm{A}_{\mathrm{i}}$ " (matriz unitária) e aos erros (ruídos) de observação " $v_{i}$ ". Assume-se que estes erros possuem média zero, são não-correlacionados e normalmente distribuídos. Os ruídos das equações de estado $\left(\mathrm{w}_{\mathrm{i}}\right)$ e de observação ( $\left.\mathrm{v}_{\mathrm{i}}\right)$ são independentes entre si. Em outras palavras, o que é medido não tem que ser tomado como verdadeiro, mas pode ser considerado como uma medida indireta, refletindo o estado verdadeiro da variável mais o ruído (Wendroth et al., 1997).

Considerando neste estudo, $X$ como sendo a umidade do solo $\theta_{\mathrm{i}}\left(\mathrm{m}^{3} . \mathrm{m}^{-3}\right)$ e a temperatura do solo $\mathrm{T}_{\mathrm{i}}\left({ }^{\mathrm{o}} \mathrm{C}\right)$, a equação 1 pode ser escrita da seguinte forma matricial (neste caso um sistema de duas variáveis):

$$
\left[\begin{array}{l}
\theta_{\mathrm{i}} \\
\mathrm{T}_{\mathrm{i}}
\end{array}\right]=\left[\begin{array}{ll}
\phi_{11} & \phi_{12} \\
\phi_{21} & \phi_{22}
\end{array}\right] \times\left[\begin{array}{c}
\theta \mathrm{i}-1 \\
\mathrm{Ti}-1
\end{array}\right]+\left[\begin{array}{c}
\mathrm{W}_{\theta \mathrm{i}} \\
\mathrm{W}_{\mathrm{Ti}}
\end{array}\right]
$$

Os coeficientes de estados $\phi_{\mathrm{pp}}$ e os erros da equação acima são estimados por um procedimento recursivo dado por Shumway \& Stoffer (1982). Eles são otimizados via Filtro de Kalman (Kalman, 1960) dentro de um algoritmo iterativo. Este filtro é um procedimento recursivo para encontrar estimadores ótimos (estimadores com mínimo erro quadrático médio) para o vetor de estados no tempo t (ou espaço i). Motta \& Hotta (1998) citam que este filtro é freqüentemente utilizado em engenharia (Mine, 1984; Gomes \& Mine, 1989; Gomes \& Mine, 1991; Alves et al., 1991); por permitir estimação do vetor de estados com atualização constante deste, conforme novas observações são obtidas, ou seja, o valor atual do vetor de estado é o interesse principal.

Da mesma forma, a equação 2 também pode ser escrita com uma notação matricial da seguinte maneira:

$$
\left[\begin{array}{c}
\theta_{\mathrm{i}}{ }^{\circ} \\
\mathrm{T}_{\mathrm{i}}{ }^{\mathrm{o}}
\end{array}\right]=\left[\begin{array}{cc}
1 & 0 \\
0 & 1
\end{array}\right] \times\left[\begin{array}{c}
\theta_{\mathrm{i}} \\
\mathrm{T}_{\mathrm{i}}
\end{array}\right]+\left[\begin{array}{c}
\mathrm{V}_{\theta i}{ }^{\mathrm{o}} \\
\mathrm{V}_{\mathrm{Ci}^{\mathrm{o}}}
\end{array}\right]
$$


$\theta_{\mathrm{i}}{ }^{\mathrm{e}}$ e $\mathrm{T}_{\mathrm{i}}^{\mathrm{o}}$ são os valores observados de umidade do solo e temperatura do solo no ponto $\mathrm{i}$. A equação 4 indica que as observações de umidade do solo e temperatura do solo consistem de duas partes: $\theta_{\mathrm{i}}$ e $\mathrm{T}_{\mathrm{i}}$ bem como de $\mathrm{v}_{\theta \mathrm{i}} \mathrm{e} \mathrm{v}_{\mathrm{Ti}}$ (ruídos). Os erros observacionais $\mathrm{v}_{\theta \mathrm{i}}$ e $\mathrm{V}_{\mathrm{Ti}}$ podem ser gerados ou por erros nas medidas de $\theta_{\mathrm{i}}{ }^{\mathrm{o}}$ e $\mathrm{T}_{\mathrm{i}}{ }^{\mathrm{o}}$ ou por não serem consideradas outras variáveis que afetam a umidade do solo ou a temperatura do solo (Ex: mineralogia, microtopografia da superfície do solo, radiação solar, etc.) (Morkoc et al., 1985).

\subsection{Material e Métodos}

O experimento de campo foi conduzido em área do Departamento de Produção Vegetal da Escola Superior de Agricultura "Luiz de Queiroz" (ESALQ), Universidade de São Paulo (USP), no município de Piracicaba $\left(22^{\circ} 42^{`}\right.$ de latitude sul e $47^{\circ} 38^{`}$ de longitude oeste), no Estado de São Paulo.

A área experimental total consistiu de 15 linhas de cana, cada uma com $100 \mathrm{~m}$ de comprimento, sendo espaçadas de 1,4 m. O delineamento experimental usado foi o de blocos ao acaso com 3 tratamentos $\left(\mathrm{T}_{3}=\right.$ entrelinhas com solo nu; $\mathrm{T}_{1}$ e $\mathrm{T}_{2}=$ superfície do solo coberta com palha e ponteiros deixados após a colheita da cana; $\mathrm{T}_{4}=$ presença de resíduos da queima da cana, antes da colheita, na superfície do solo). Cada tratamento possuía 4 repetições, sendo que cada repetição foi subdividida em faixas de $1 \mathrm{~m}$, compondo, no total, uma transeção de 84 parcelas, isto incluindo as bordaduras que foram colocadas nas extremidades e entre cada tratamento. Os tratamentos $T_{1}$ e $T_{2}$ são similares no que diz respeito ao uso da cobertura vegetal (palha mais ponteiros) na superfície do solo, sendo diferentes somente em termos de ${ }^{15} \mathrm{~N}$ marcado, que foi usado em um estudo sobre os resíduos de matéria orgânica. A Figura 1 apresenta o esquema experimental utilizado.

Os dados de umidade do solo $(\theta)$ e de temperatura do solo $(\mathrm{T})$ foram coletados durante o primeiro período de cana soca (Outubro/1998 a Outubro/1999). A temperatura 
transeção (TR)

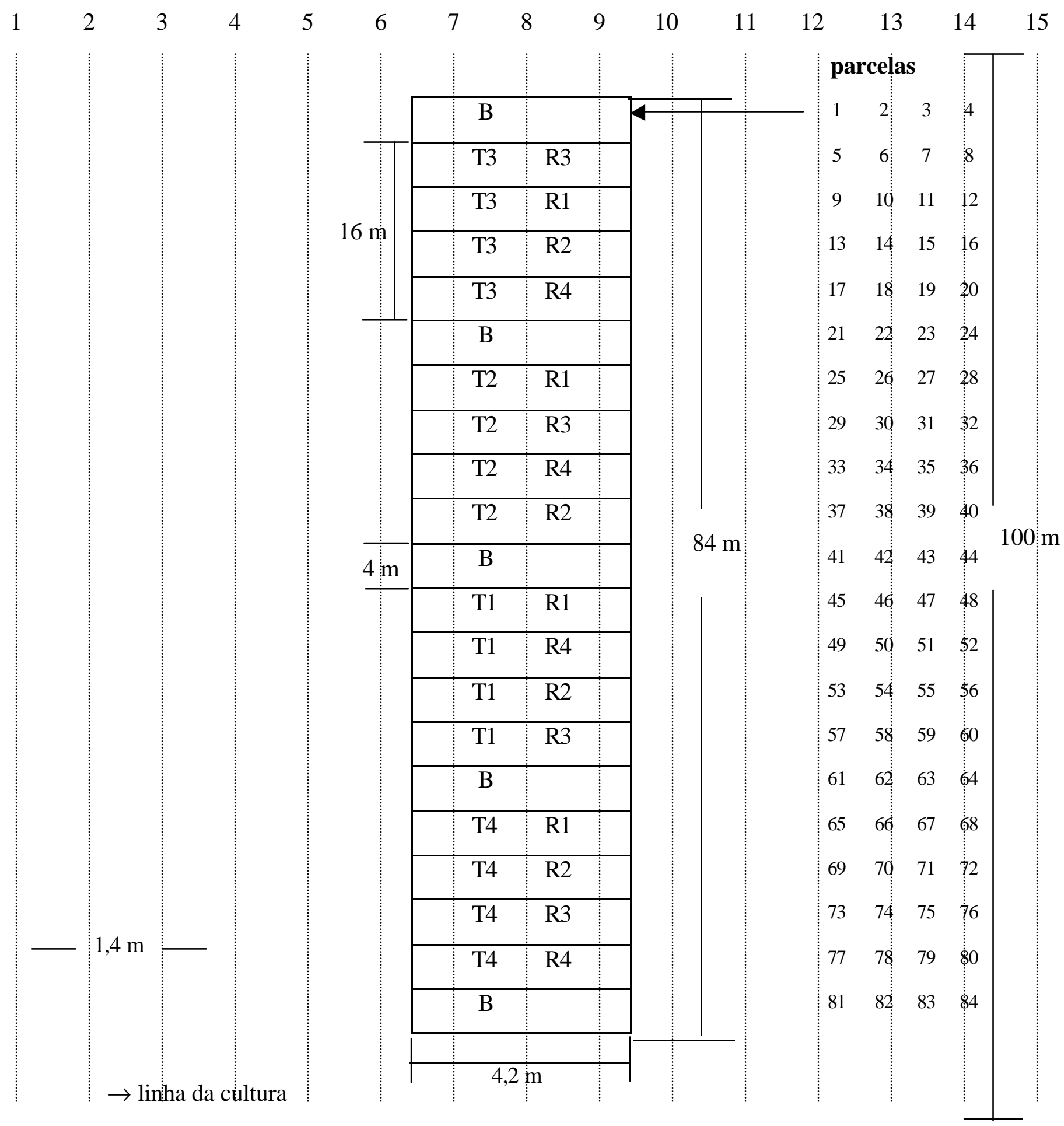

Figura 1 - Esquema experimental da área. $\mathrm{T}_{1}$ e $\mathrm{T}_{2}$ : superfície do solo coberta com palha e ponteiros deixados após a colheita da cana; $\mathrm{T}_{3}$ : entrelinhas com solo nu; $\mathrm{T}_{4}$ : presença de resíduos da queima da cana, antes da colheita, na superfície do solo; B: bordaduras. 
do solo foi medida com um termômetro digital, inserido no solo em três diferentes profundidades: $0,03 \mathrm{~m}, 0,06 \mathrm{~m}$ e $0,09 \mathrm{~m}$, ao longo da transeção dos 84 pontos, sendo neste estudo calculada a média das três leituras de temperatura do solo em cada ponto da transeção. Simultaneamente, os dados de umidade do solo foram coletados usando uma sonda de superfície nêutron/gama, modelo CPN MC-3, ao longo da mesma transeção de 84 parcelas. A umidade do solo é medida pela moderação dos nêutrons, amostrando uma semi-esfera de raio em torno de 0,15 m, assim que os valores obtidos de umidade são uma média da umidade na camada de 0 $0,15 \mathrm{~m}$ de profundidade.

Os dados de umidade e temperatura foram coletados no período das 11:00 as 12:00 h, sendo usado para este estudo o dia 20/11/1998. A análise de espaço de estados foi executada com o auxílio de um software, denominado ASTSA (Applied Statistical Time Series Analysis), desenvolvido por Shumway (1988), com o intuito de obter os coeficientes de estado $\left.\phi_{\mathrm{pp}}\right)$, os valores preditos das variáveis em estudo e os erros padrões das estimativas das variáveis em cada ponto.

Segundo Hui et al. (1998), o uso de dados transformados na análise de espaço de estados (dados com a mesma ordem de magnitude) fornece valores dos coeficientes de estado $\left(\phi_{\mathrm{pp}}\right)$ na equação 1 com magnitudes diretamente proporcionais à contribuição de cada variável de estado na região de estudo. A equação de transformação dos dados sugerida por estes autores foi a seguinte:

$$
X_{i}=\left[\frac{X_{i}-(m-2 s)}{4 s}\right]
$$

onde:

$\mathrm{X}_{\mathrm{i}}$ : são os valores transformados de $\mathrm{X}_{\mathrm{i}}$, que têm média 0,5 ;

$\mathrm{X}_{\mathrm{i}}$ : são os valores observados da variável; 
m: média dos valores observados de $\mathrm{X}_{\mathrm{i}}$;

$\mathrm{s}$ : desvio padrão dos valores observados de $\mathrm{X}_{\mathrm{i}}$.

\subsection{Resultados e Discussão}

Na Figura 2 são apresentados os dados observados de umidade do solo e temperatura do solo (dia 20/11/98) distribuídos espacialmente ao longo da transeção dos 84 pontos.

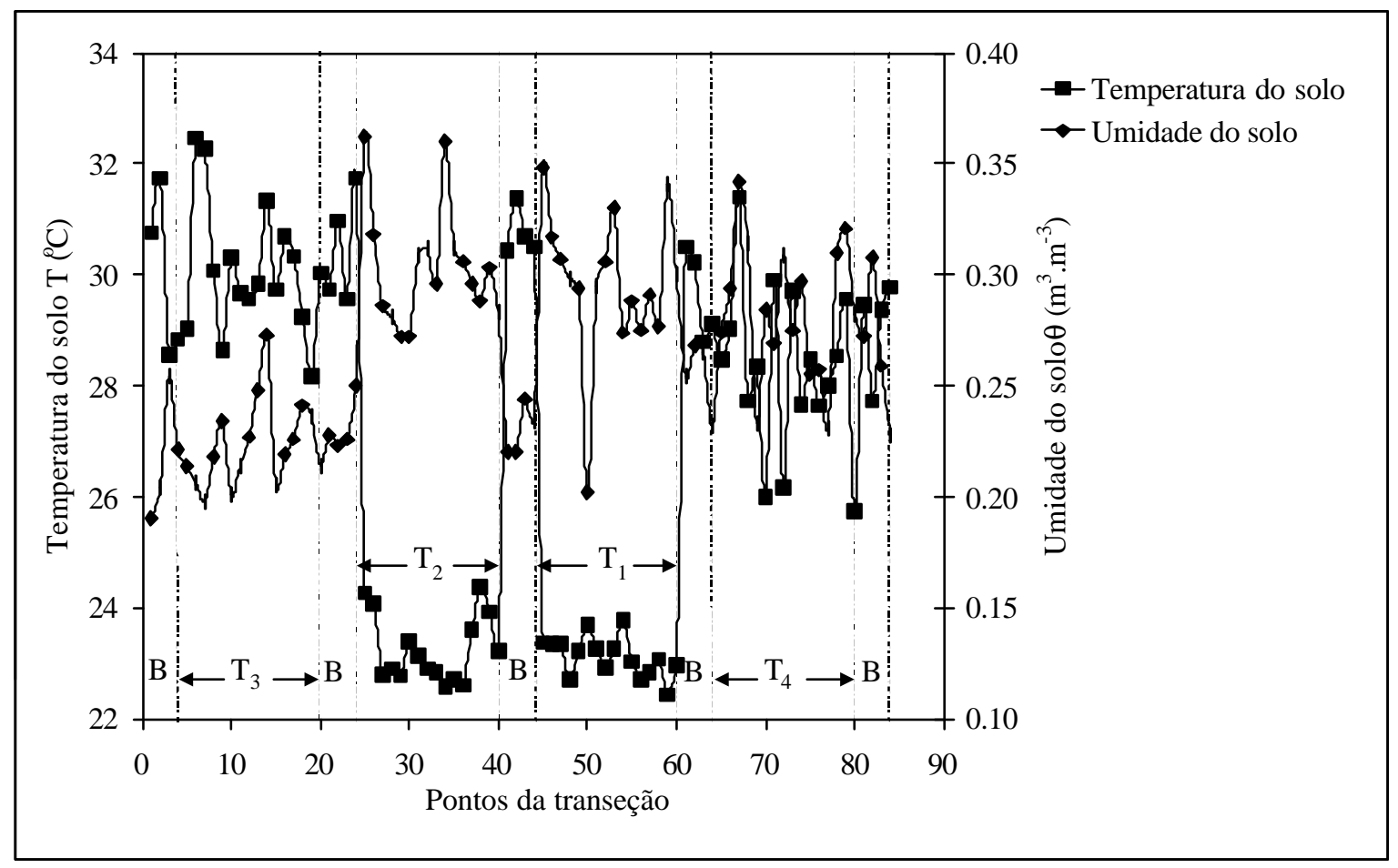

Figura 2 - Dados de umidade do solo $(\theta)$ e temperatura do solo $(\mathrm{T})$ distribuídos ao longo da transeção dos 84 pontos no dia 20/11/1998 (11:00 h - 12:00 h). T e $\mathrm{T}_{2}$ : superfície do solo coberta com palha e ponteiros deixados após a colheita da cana; $\mathrm{T}_{3}$ : entrelinhas com solo nu; $\mathrm{T}_{4}$ : presença de resíduos da queima da cana, antes da colheita, na superfície do solo; B: bordaduras. 
Analisando-se conjuntamente as Figuras 1 e 2, percebe-se claramente o efeito dos tratamentos no valor médio da temperatura do solo na camada de $0-0,09 \mathrm{~m}$ de profundidade. Os tratamentos $\mathrm{T}_{1}$ e $\mathrm{T}_{2}$ apresentando valores menores de temperatura (média geral de $23,2{ }^{\circ} \mathrm{C}$ ), devido à presença da cobertura vegetal na superfície do solo $\left(\right.$ palha + ponteiros $=127 \mathrm{~kg} \cdot \mathrm{ha}^{-1}$ de matéria seca); $\mathrm{T}_{3}$ (superfície do solo sem cobertura vegetal) apresentando um valor médio de temperatura de $30,1{ }^{\circ} \mathrm{C}$; e $\mathrm{T}_{4}$ (presença de resíduos na superfície do solo, devido à queima da cana antes da colheita) com um valor médio de temperatura de $28,3{ }^{\circ} \mathrm{C}$. As diferenças de temperatura são devido ao fato de que as medidas foram executadas duas semanas após a colheita da cana-planta, quando a soca da cultura estava começando a brotar, ou seja, a área estava completamente exposta a luz solar no dia 20/11/1998, após uma seqüência de 6 dias sem chuva.

Os dados de umidade do solo, coletados no mesmo dia, apresentam uma relação inversa, isto é, os tratamentos $\mathrm{T}_{1}$ e $\mathrm{T}_{2}$ mostram valores relativamente mais altos de umidade do solo em relação aos de $\mathrm{T}_{3}$ e $\mathrm{T}_{4}$. Isto é demonstrado na Figura 3, mostrando a relação inversa (coeficiente angular da reta negativo) entre os valores de umidade e temperatura do solo com um coeficiente de ajuste da regressão linear $\left(R^{2}\right)$ igual a $0,4491)$.

Quando uma variável é amostrada no campo, sua média e variância são calculadas para refletir a população, assumindo que as observações são independentes entre si. Em muitos casos, as observações não são independentes entre si existindo uma dependência espacial entre observações adjacentes, que pode ser verificada plotando o coeficiente de autocorrelação em função da distância entre observações, sendo denominado de autocorrelogramo. As Figuras 4A e 4B apresentam os autocorrelogramos da umidade do solo (4A) e da temperatura do solo (4B). Analisando estas figuras, pode-se verificar que tanto a umidade do solo como a temperatura apresentam uma dependência espacial de até 8 "lags", ao nível de $5 \%$ de significância pelo teste t. Isto indica que existe uma dependência espacial, neste caso, de até 8 metros entre as observações adjacentes de ambas variáveis. 


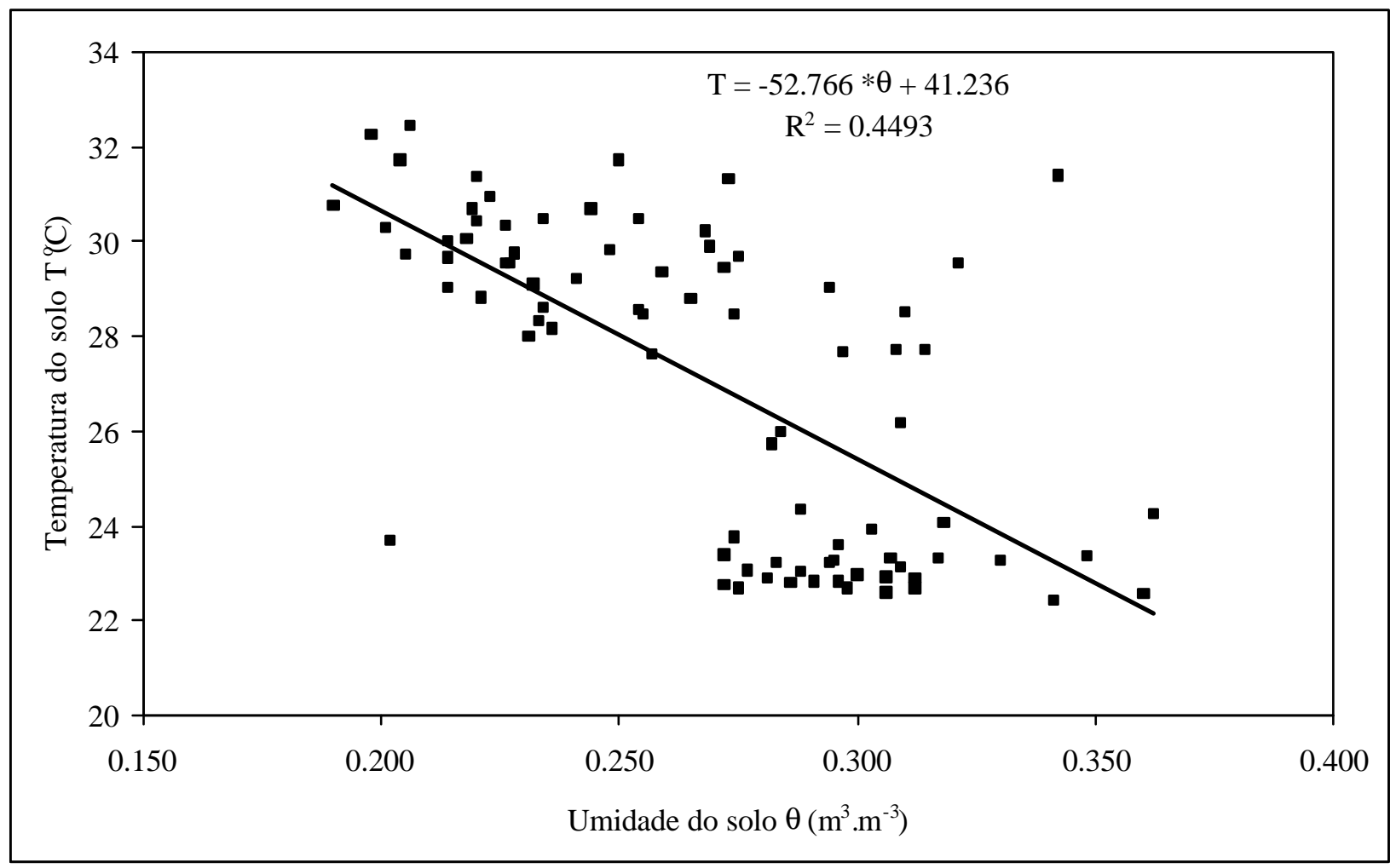

Figura 3 - Diagrama de dispersão entre os dados de umidade e temperatura do solo, apresentando a relação inversa entre os dados com um coeficiente de ajuste da regressão $\left(R^{2}\right)$ de 0,4493 . 

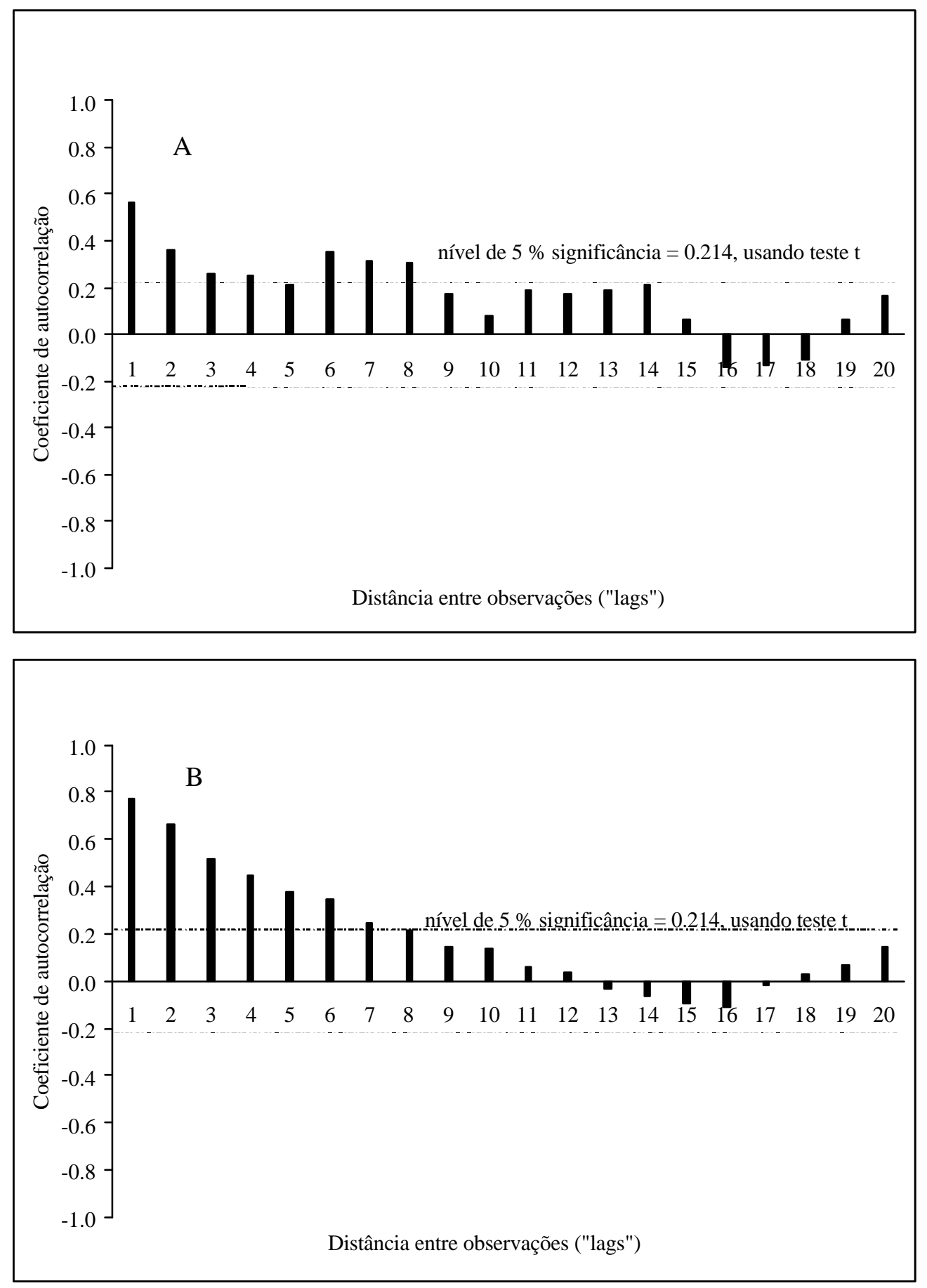

Figura 4 - Autocorrelogramo da umidade do solo (A) e da temperatura do solo (B), indicando a auto-dependência espacial de cada variável com as observações adjacentes. 
O crosscorrelogramo entre a umidade do solo e a temperatura é mostrado na Figura 5, mostrando a forte dependência espacial entre estas variáveis até a distância de 6 metros, em ambas direções neste estudo.

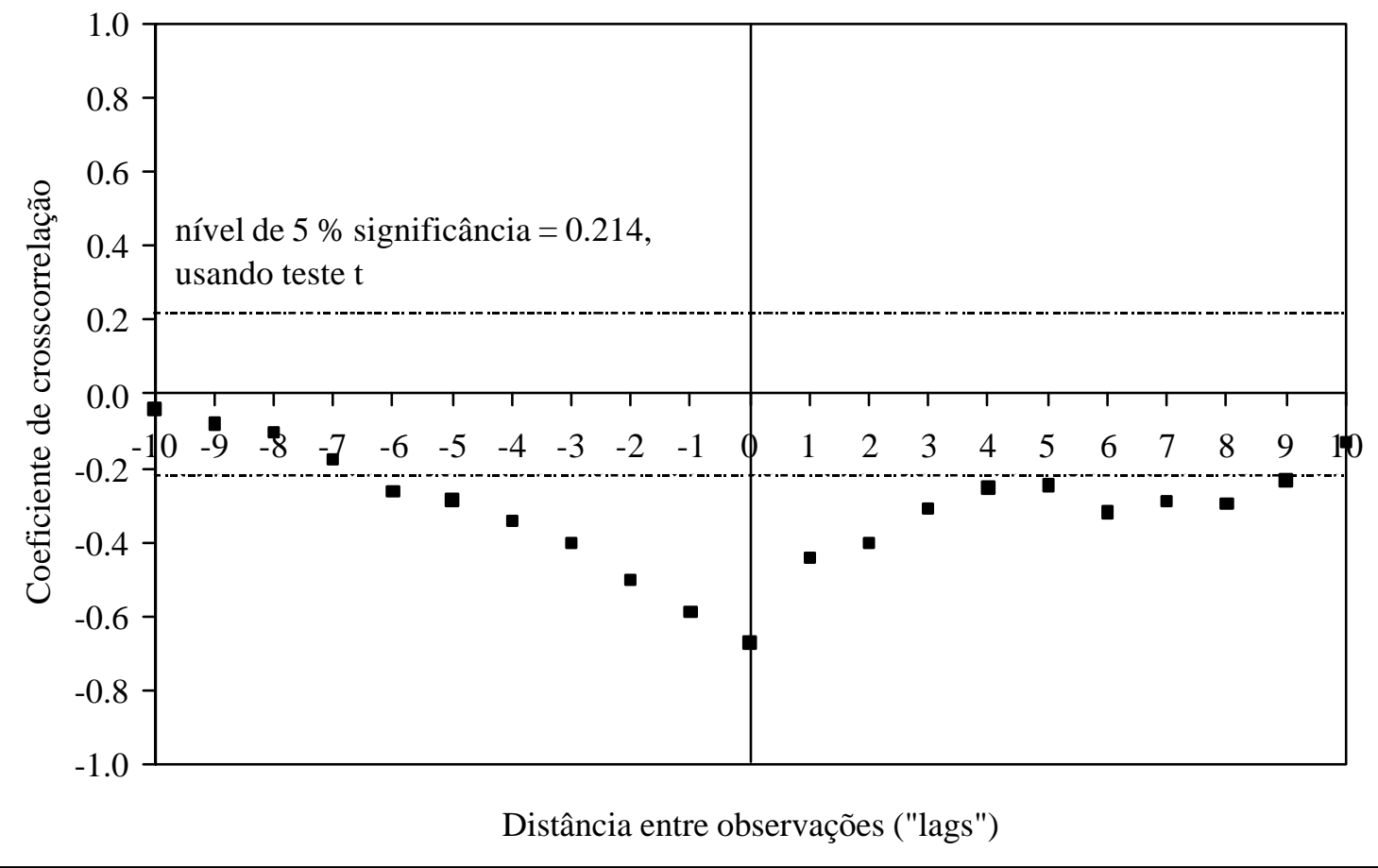

Figura 5 - Crosscorrelogramo entre a umidade do solo e a temperatura do solo, indicando a forte dependência espacial entre estas variáveis. 
A análise de espaço de estados aplicada aos dados de umidade do solo e a temperatura do solo, justificada pelas Figuras 4A, 4B e 5, é apresentada nas Figuras 6 e 7 , respectivamente.

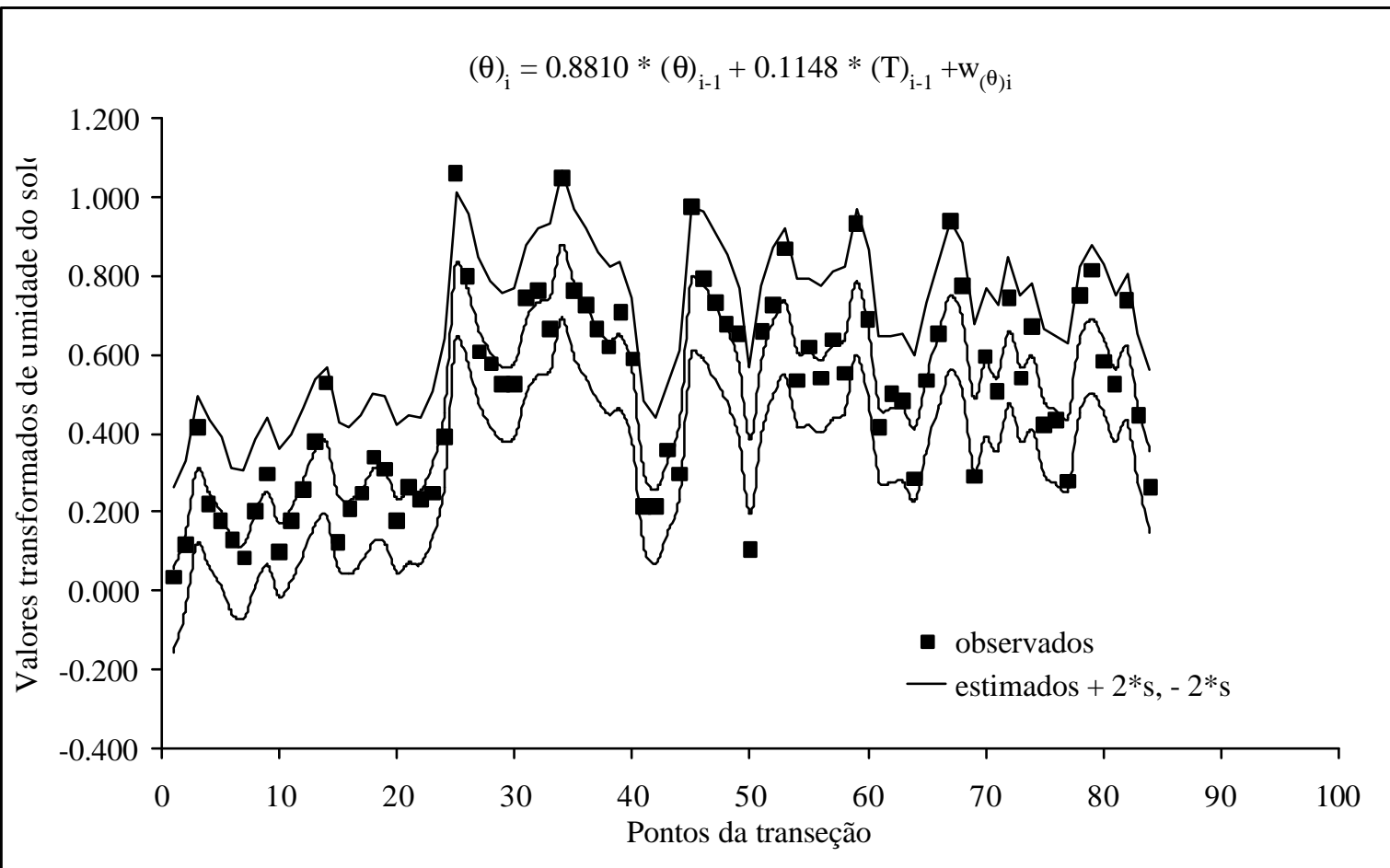

Figura 6 - Análise de espaço de estados aplicada aos dados transformados (equação 5) de umidade do solo. 


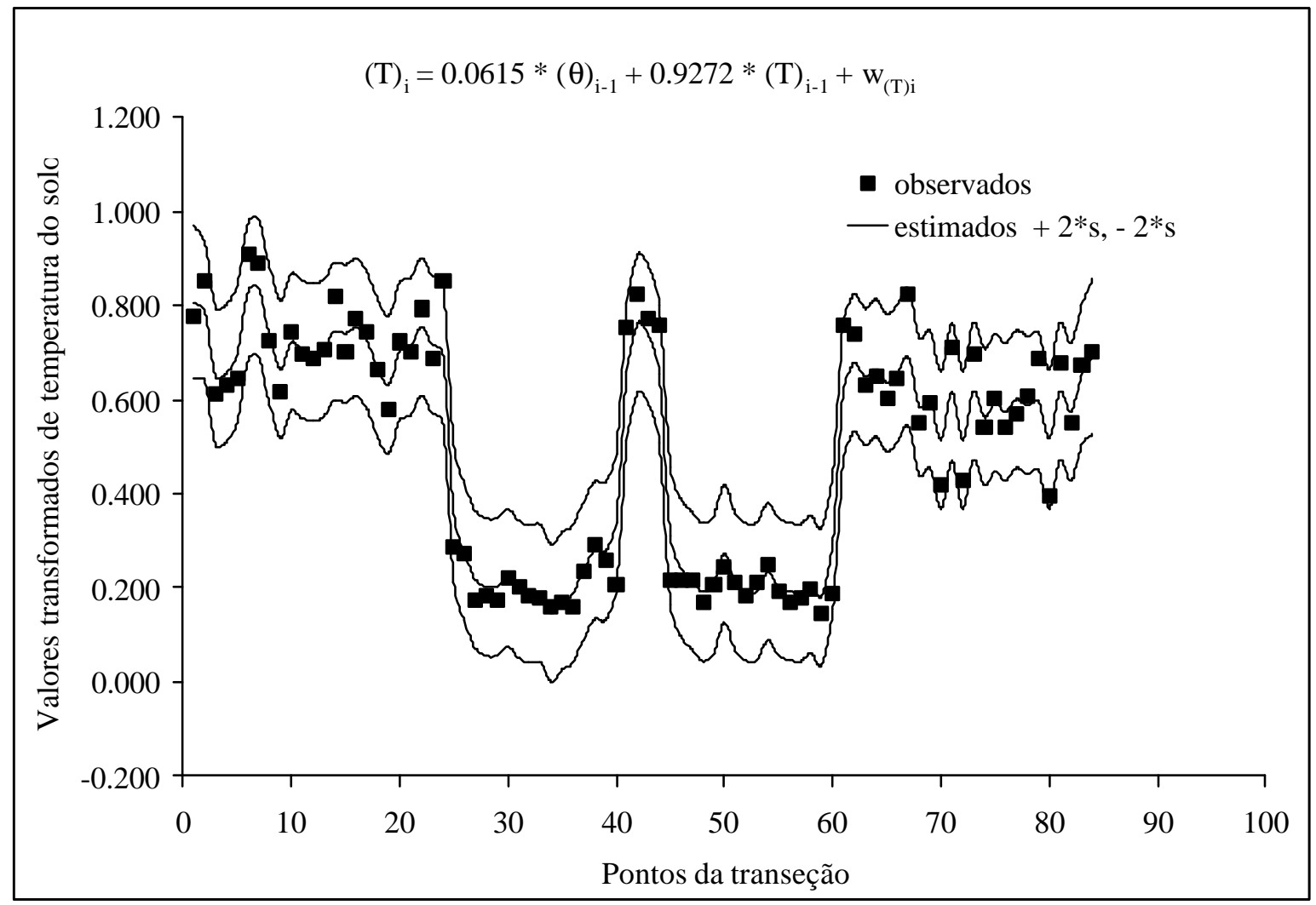

Figura 7 - Análise de espaço de estados aplicada aos dados transformados (equação 5) de temperatura do solo. 
Na Figura 6, os valores (transformados por meio da equação 5) observados de umidade do solo são representados através do símbolo quadrado. Já os valores estimados de umidade do solo usando a análise de espaço de estados são representados pela linha do meio. Os valores estimados de umidade do solo mais duas vezes o erro padrão e menos duas vezes o erro padrão são representados pelas linhas superior e inferior, respectivamente. A equação de estado obtida foi a seguinte:

$$
\theta_{\mathrm{i}}=0.8810 \times \theta_{\mathrm{i}-1}+0.1148 \times \mathrm{T}_{\mathrm{i}-1}+\mathrm{W} \theta \mathrm{i}
$$

A equação 6 indica que a umidade do ponto i- 1 contribui com $88,1 \%$ na estimativa da umidade no ponto i. Já a temperatura do ponto i 1 contribui com 11,48\% na estimativa da umidade no ponto $i$, ou seja, a contribuição da umidade do primeiro vizinho é bem maior que a da emperatura. Morkoc et al. (1985), verificaram que a contribuição da umidade e da temperatura do ponto i1 foram de $98,9 \%$ e de $0,3 \%$, respectivamente, na estimativa da umidade no ponto $i$.

Na Figura 7 (mesmas notações da figura anterior) é apresentada a análise de espaço de estados aplicada aos dados transformados (equação 5) de temperatura do solo ao longo da transeção, sendo obtida a seguinte equação de estado:

$$
\mathrm{T}_{\mathrm{i}}=0.0615 \times \theta_{\mathrm{i}-1}+0.9272 \times \mathrm{T}_{\mathrm{i}-1}+\mathrm{WTi}
$$

Analisando-se a equação 7 , verifica-se que a umidade do ponto $\dot{\mathrm{i}} 1$ contribui com $6,15 \%$ na estimativa da temperatura no ponto i. Já a temperatura do ponto ł1 contribui com $92,72 \%$ na estimativa da temperatura no ponto i, ou seja, a contribuição da temperatura do primeiro vizinho é bem maior que a da umidade. Morkoc et al. (1985), verificaram que a contribuição da umidade e da temperatura do ponto i 1 foram de $11 \%$ e de $96,4 \%$, respectivamente, na estimativa da temperatura no ponto $\mathrm{i}$. 
As Figuras 8 e 9 apresentam o desempenho da equação de estado em estimar a umidade do solo (equação 6, Figura 8) e em estimar a temperatura do solo (equação 7, Figura 9), usando um diagrama de dispersão. O coeficiente de ajuste dos dados $\left(\mathrm{R}^{2}\right)$ foi de 0,9063 no caso da umidade do solo e de 0,9587 para a temperatura.

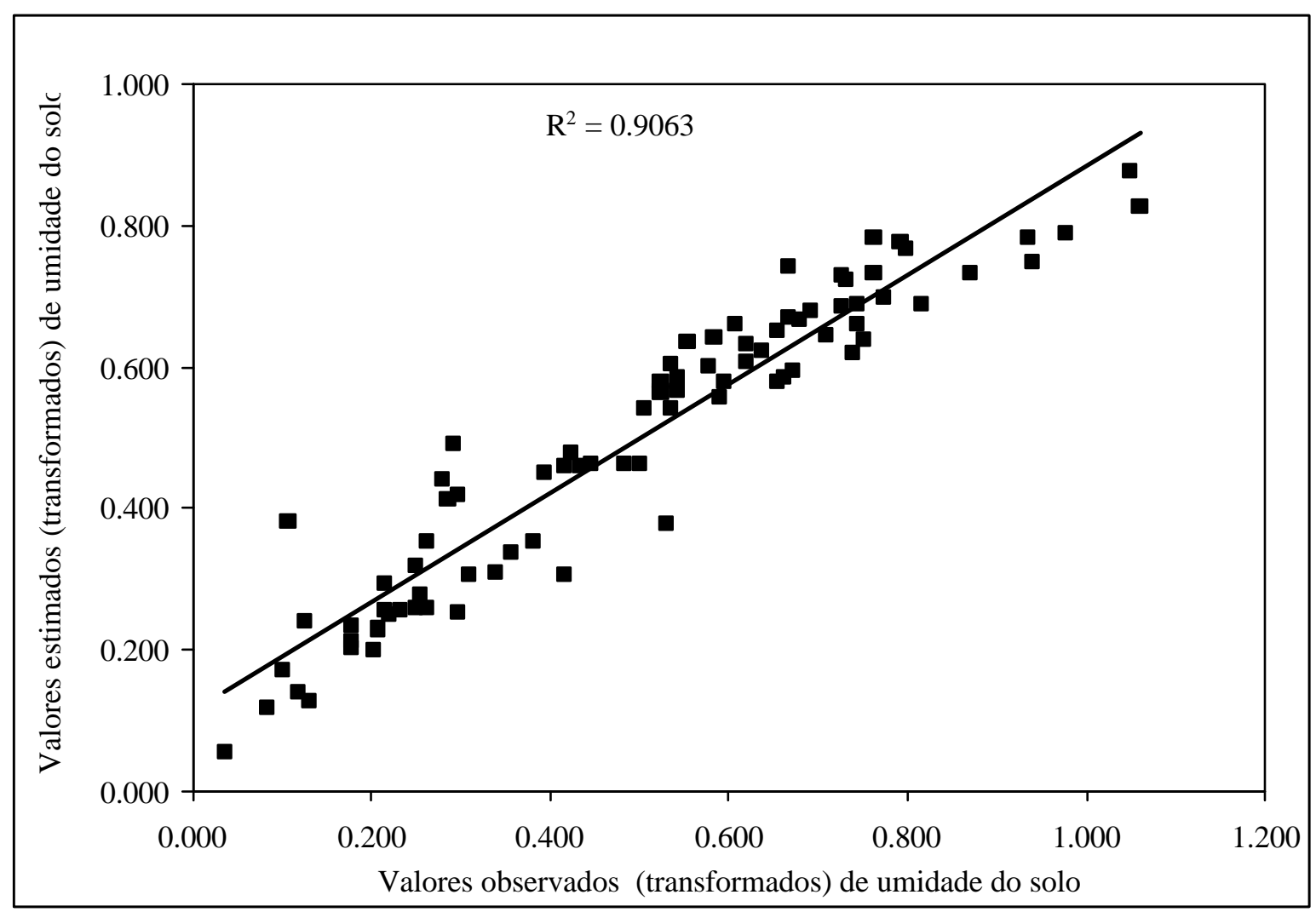

Figura 8 - Diagrama de dispersão dos valores observados (transformados usando equação 5) e estimados de umidade do solo (equação 6), apresentando um coeficiente de ajuste $\mathrm{R}^{2}$ de 0,9063 . 


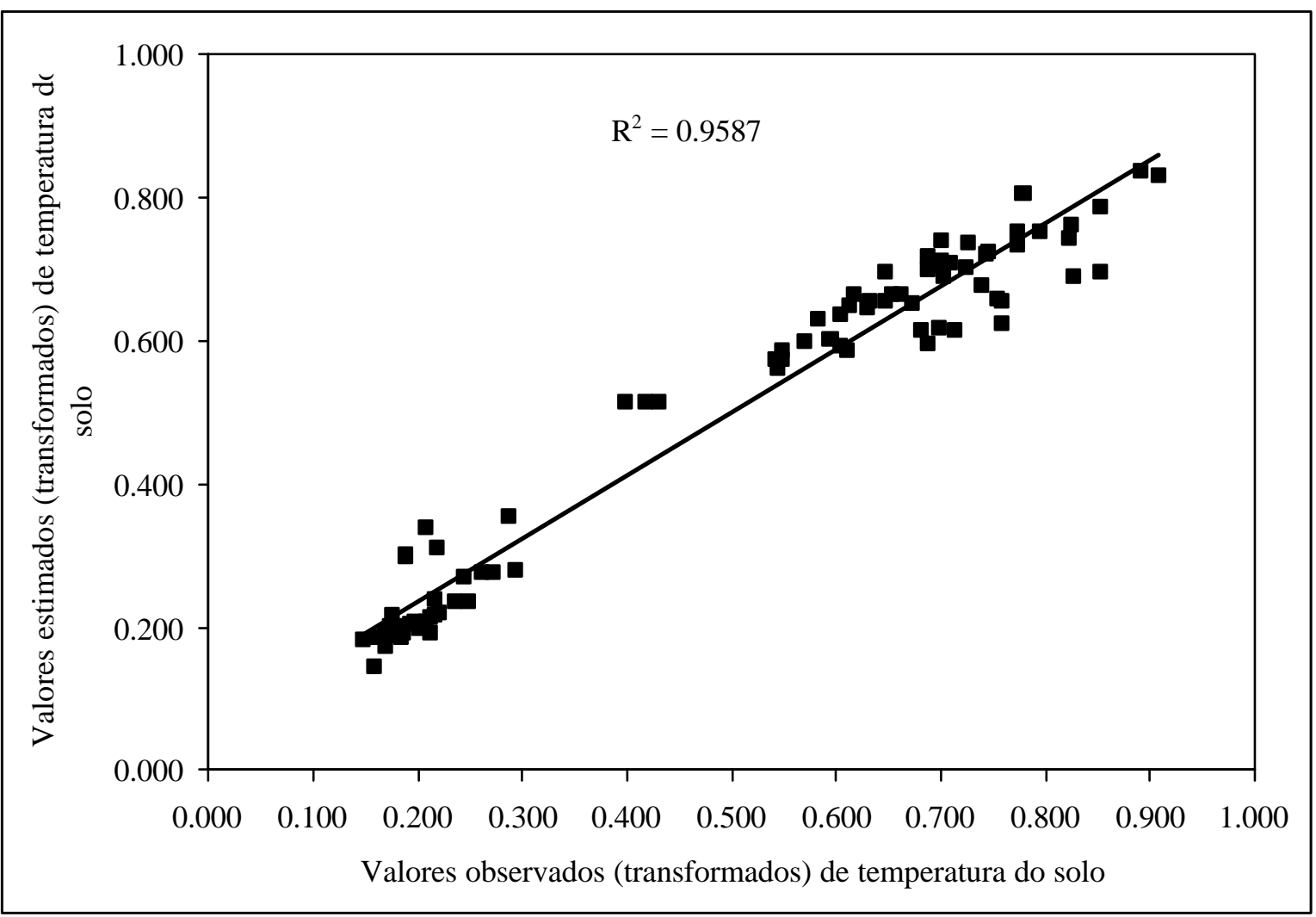

Figura 9 - Diagrama de dispersão dos valores observados (transformados usando equação 5) e estimados de temperatura do solo (equação 7), apresentando um coeficiente de ajuste $\mathrm{R}^{2}$ de 0,9587 .

É importante salientar que esta é a primeira contribuição em termos da análise de espaço de estados aplicada à séries espaciais coletados ao longo de uma transeção na área agronômica no Brasil. Um dos objetivos é sua introdução na literatura brasileira e, como já foi salientado anteriormente, contribuir para um melhor entendimento da relação dinâmica entre a umidade do solo e a temperatura do solo.

Os dados mostram claramente (Figura 3) a relação inversa entre a umidade e a temperatura do solo. Adicionado a isto, Figuras 4A, 4B e 5 apresentam a forte dependência espacial entre os dados, o qual justifica a aplicação da metodologia de 
espaço de estados. Desta forma a umidade do solo em um ponto i pode ser estimada a partir dos valores de umidade e temperatura do solo no primeiro vizinho.

Cabe ressaltar que neste trabalho o objetivo de aplicar a abordagem de espaço de estados foi à dados de umidade e temperatura utilizando-se um modelo de primeira ordem, mas também poderia ser aplicada utilizando-se modelos de ordem superior. Hui et al. (1998), aplicaram esta análise em um modelo de segunda ordem relacionando a taxa de infiltração $\left(v_{0}\right)$ no ponto i, com a taxa de infiltração e condutividade elétrica do extrato do primeiro vizinho (i-1) e a taxa de infiltração do segundo vizinho (i-2).

Neste estudo utilizourse um sistema de duas variáveis (umidade do solo e temperatura do solo), mas poderia ser utilizado um sistema com mais variáveis que de certa forma possuem relação com estas duas variáveis, como por exe mplo, teor de argila, densidade do solo, radiação solar incidente, mineralogia e microtopografia da superfície do solo.

\subsection{Conclusões}

Neste capítulo a análise de espaço de estados foi aplicada à dados de umidade e temperatura do solo coletados ao longo de uma transeção espacial de 84 pontos. Desde que os dados de temperatura do solo são mais fáceis e mais rápidos de serem obtidos no campo de que os de umidade, a análise apresentada aqui sugere que, em muitas situações, uma medida poderia substituir a outra. Por outro lado, relacionar propriedades do solo medidas em um ponto i à um ponto i 1 (modelo autoregressivo de primeira ordem) também é importante do ponto de vista prático para os agricultores. Neste estudo, a distância ("lag") de $1 \mathrm{~m}$ é pequena em termos práticos, contudo torna-se importante a aplicação da análise de espaço de estados quanto tem-se o objetivo de avaliar o quão distante um determinado atributo seja do solo ou da planta medido em um ponto i é afetado pelo seu valor no primeiro vizinho (neste caso) para um melhor uso e manejo racional dos recursos naturais no sentido de maximização da produtividade agrícola, por exemplo, aplicando o conceito de agricultura de precisão. 


\section{ABORDAGEM DE ESPAÇO DE ESTADOS PARA AVALIAR A RELAÇÃO ENTRE AS PROPRIEDADES QUÍMICAS E FÍSICAS DO SOLO}

\section{Resumo}

A abordagem de espaço de estados é usada para um melhor entendimento da relação entre as propriedades químicas e físicas em uma área cultivada com cana-deaçúcar. O experimento foi conduzido em uma Terra Roxa Estruturada em Piracicaba, SP, Brasil. A cana-de-açúcar foi plantada em uma área de 0,21 ha (15 linhas de $100 \mathrm{~m}$ de comprimento, espaçadas de 1,4 m entre si) sendo submetida a três diferentes práticas de manejo: i. superfície do solo coberta com palha e ponteiros deixados após a colheita da cana; ii. entrelinhas com solo nu; (iii) presença de resíduos da queima da cana, antes da colheita, na superfície do solo. Medidas de umidade do solo, matéria orgânica, conteúdo de argila e estabilidade de agregados foram feitas ao longo de uma transeção de 84 pontos, metro a metro. A abordagem de espaço de estados é usada para avaliar como a umidade do solo em um ponto i é afetada pela umidade do solo, pela matéria orgânica, conteúdo de argila e estabilidade de agregados em um ponto i-1, usando diferentes combinações, com o objetivo de um melhor entendimento da relação entre estas variáveis no solo. Os resultados mostram que a umidade do solo pode ser estimada, usando esta abordagem, sendo a melhor performance obtida quando a estimativa da umidade do solo na posição i foi relacionada com a umidade do solo, conteúdo de argila e estabilidade de agregados na posição i1. Os resultados conduzem a possibilidade de destacar as influências que causam as trocas das relações entre as variáveis, quantificando estocasticamente o comportamento local, levando em consideração os erros associados as observações e ao modelo e o relacionamento espacial destas variáveis. Esta variabilidade espacial é um fator importante que afeta a 
produção da cultura e deveria ser considerado no planejamento das práticas de manejo do solo.

\section{STATE-SPACE APPROACH TO EVALUATE THE RELATION BETWEEN SOIL PHYSICAL AND CHEMICAL PROPERTIES}

\section{Summary}

The state-space approach is used to better understand the relation between soil physical and chemical properties in an area cultivated to sugarcane. The experiment was carried out on a Rhodic Kandiudalf at Piracicaba, State of Sao Paulo, Brazil. The sugar cane crop was planted on an area of 0.21 ha, i.e., 15 rows $100 \mathrm{~m}$ long, spaced $1.4 \mathrm{~m}$, submitted to three management treatments: i. mulching the ratoon crop with trash (cane tips and straw from the last harvest); ii. bare soil between rows after harvest; iii. soil surface covered by residues left by the traditional practice of straw burning before harvest. Measurements of soil water content, soil organic matter, clay content and aggregate stability were sampled along one transect of 84 points, meter by meter. The state-space approach is used to evaluate how soil water content is affected by itself and by soil organic matter, clay content and aggregate stability at neighbor locations, in different combinations, aiming to contribute for a better understanding of the relation between these variables in the soil. The results show that soil water contents could successfully be estimated using this approach, the best performance being found when the estimate of soil water content at locations $\mathrm{i}$ was related to soil water content, clay content and aggregate stability at locations i-1. Results open the possibility of underlining influences that cause changes in their relations, stochastically quantifying in a state-space model their changing local behavior, accounting for both, measurement and model errors and the spatial relationships of these variables. This spatial variability is an important factor that affects crop yield and should be considered in planning soil management practices. 


\subsection{Introdução}

Durante a última década, tecnologias para estudar o comportamento local das variáveis à nível de campo tem sido desenvolvidas e podem ajudar potencialmente os agricultores para um manejo diferenciado no campo de acordo com as necessidades e deficiências levando em consideração a variabilidade espacial das propriedades do solo. Relações entre as variáveis ligadas ao solo, planta e atmosfera podem ser caracterizadas com a quantificação dos erros envolvidos nas medições e no modelo usando a análise de espaço de estados. Intuitivamente os agricultores tomam suas decisões de uma maneira similar ao conceito desta análise, focando a atenção em respostas da cultura associadas às variações das condições locais predominantes em diferentes pontos dentro e entre cada área (Nielsen et al., 1998). Um sistema linear pode ser visto como uma representação espacial de diferentes estados por meio de duas equações: uma sendo formada pelo vetor das observações e a outra pela evolução do vetor de estados. As

estimativas das variáveis são obtidas quando o filtro de Kalman é aplicado ao modelo, representando os estados distribuídos no espaço (West \& Harrison, 1997; Motta \& Hotta, 1998). A estatística clássica ignora a posição de amostragem, desconsiderando a dependência espacial das observações adjacentes ao longo de uma transeção. Por outro lado, estes novos métodos que estão sendo aplicados na área de ciência do solo, tomam vantagem da dependência espacial usando as características de cada ponto onde uma observação é medida. Ferramentas estatísticas como a função de autocorrelação, semivariogramas e análise de espaço de estados, tem sido recentemente usadas para definir a estrutura de distribuição espacial das propriedades do solo (Wendroth et al., 1992; Katul et al., 1993; Wendroth et al., 1997; Hui et al., 1998; Dourado et al., 1999; Timm et al., 2000). De acordo com Bresler et al. (1981), a pesquisa nas últimas duas décadas tem sido focada no estudo da variabilidade espacial do solo com o objetivo de um melhor entendimento dos processos que influenciam a variabilidade de produção de uma cultura. Nielsen \& Alemi (1989) comentam que em diversos estudos usando estatística clássica, as observações dentro e entre tratamentos não são sempre independentes, tornando o desenho experimental inadequado. 
Neste capítulo, um modelo de espaço de estados foi aplicado à dados de umidade do solo, matéria orgânica, conteúdo de argila e estabilidade de agregados, coletados em uma área cultivada com cana-de-açúcar, submetida à diferentes práticas de manejo, com o intuito de melhor entender a relação entre estas propriedades do solo.

\subsubsection{Aspectos teóricos}

$\mathrm{Na}$ análise de espaço de estados, o estado do sistema de uma variável ou de um conjunto de variáveis medidas em uma posição i, está relacionada ao estado da mesma variável e de outras variáveis em uma posição ì h, onde $h(=1,2,3, \ldots, n)$ é a distância (número de "lags") entre as observações adjacentes. Este modelo autoregressivo é aplicado para diversos tipos de estimativas (e previsões futuras) baseado em séries temporais/espaciais, para identificar os coeficientes que unem os estados do sistema (Wendroth et al., 1997). A equação básica, denominada equação de estado, pode ser escrita para $\mathrm{h}=1$ como:

$$
\mathrm{X}_{\mathrm{i}}=\phi \mathrm{X}_{\mathrm{i}-1}+\mathrm{w}_{\mathrm{i}}
$$

onde $\mathrm{X}_{\mathrm{i}}$ é o vetor de estado (de um conjunto de $\mathrm{p}$ variáveis) na posição i; $\phi$ é uma matriz p x p dos coeficientes de estado que indica a medida da regressão; e wi é o vetor de erros do sistema para $\mathrm{i}=1,2,3, \ldots, \mathrm{n}$. Assume-se que este erro tem média zero, não é correlacionado e normalmente distribuído. Esta é a estrutura usual de um modelo autoregressivo comum, no qual os coeficientes da matriz $\phi$ poderiam ser calculados usando regressão múltipla, tomando $X_{i}$ e $X_{i-1}$ como variáveis dependente e independente, respectivamente. No caso do modelo de espaço de estados, contudo, o verdadeiro estado da variável é considerado embutido na seguinte equação de observação:

$$
Y_{i}=A_{i} X_{i}+v_{i}
$$


onde o vetor das observações $Y_{i}$ está relacionado ao vetor de estados $X_{i}$ por uma matriz de observação $A_{i}$ (matriz unitária, $\mathrm{p}$ x p) e por um vetor de erros associados às observações $\mathrm{v}_{\mathrm{i}}$, também considerado de média zero, não correlacionado e normalmente distribuído. Além disso, assume-se que os erros $\mathfrak{W}_{1}$ e $v_{i}$ são independentes entre si, as observações não necessitam serem consideradas verdadeiras, mas podem serem vistas como medidas indiretas refletindo o verdadeiro estado da variável adicionando um erro (Wendroth et al., 1997).

Os coeficientes de estado $\phi_{\mathrm{pp}}$ e os erros da equação (1) são estimados por meio de um procedimento recursivo dado por Shumway \& Stoffer (1982). Eles são otimizados usando o filtro de Kalman (Kalman, 1960; Gelb, 1974) com um algoritmo interativo.

\subsection{Material e Métodos}

As observações de umidade do solo $(\theta)$, matéria orgânica do solo (MO), conteúdo de argila (CC) e estabilidade de agregados (AS) foram coletadas em uma área cultivada com cana-de-açúcar, Piracicaba, SP, em um solo classificado como Terra Roxa Estruturada (Figura 1). A cultura foi plantada em Outubro de 1997, sendo a área submetida à três diferentes práticas de manejo: i. superfície do solo coberta com palha e ponteiros deixados após a colheita da cana $\left(\mathrm{T}_{1}\right.$ e $\left.\mathrm{T}_{2}\right)$; ii. entrelinhas com solo nu $\left(\mathrm{T}_{3}\right)$; (iii) presença de resíduos da queima da cana, antes da colheita, na superfície do solo $\left(\mathrm{T}_{4}\right)$.

A umidade do solo foi medida ao longo de uma transeção de 84 pontos usando uma sonda de superfície nêutron/gama (modelo CPN, MC-3) no dia 06/09/1999. Esta sonda mede a umidade do solo pelo princípio de moderação de nêutrons dentro de uma semi-esfera com raio de aproximadamente $0,15 \mathrm{~m}$, portanto, representando o valor médio de umidade do solo na faixa de $0-0,15 \mathrm{~m}$ de profundidade. Detalhes da calibração desta sonda podem ser encontrados em Cássaro et al. (2000). 
transeção (TR)

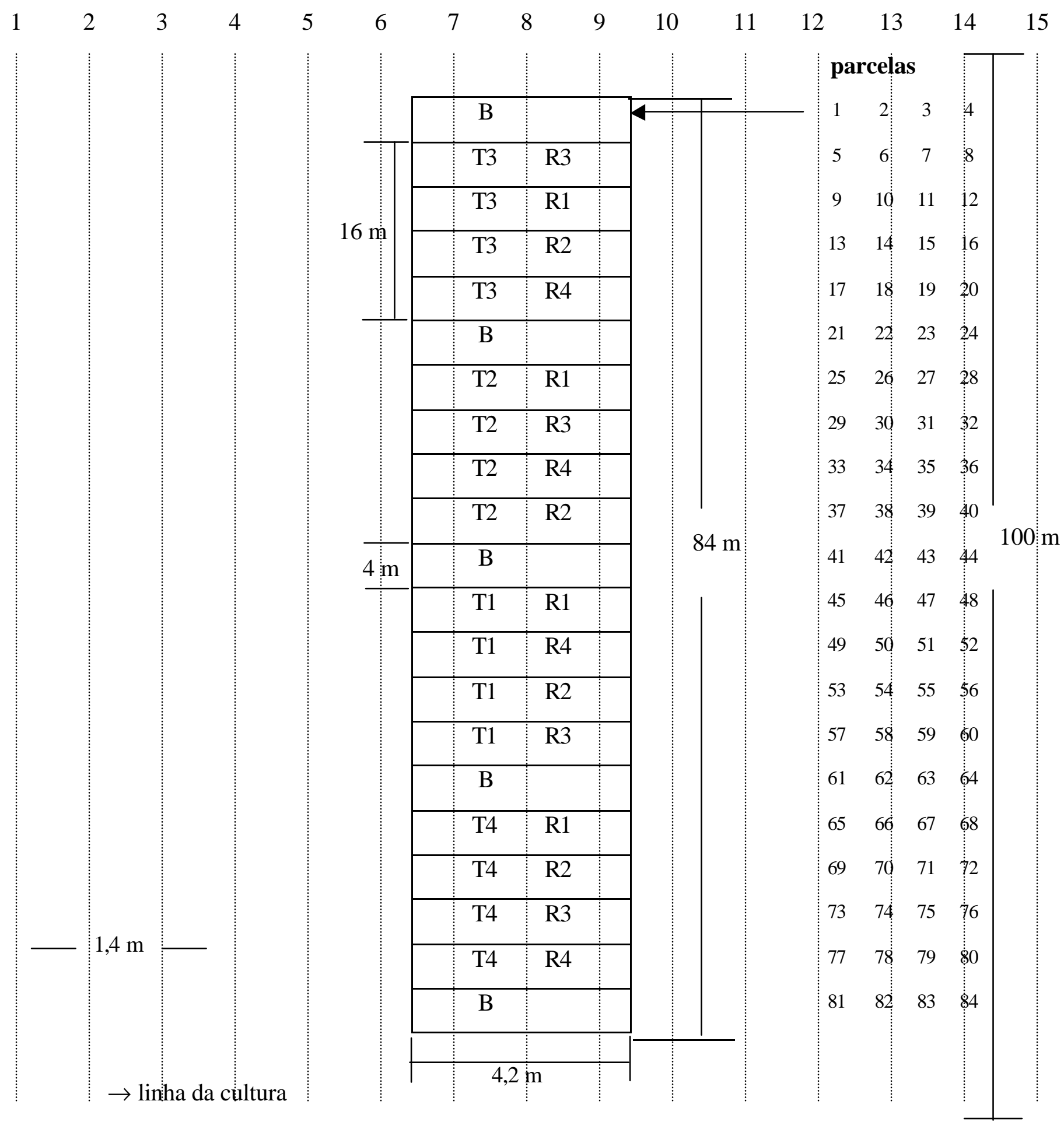

Figura 1 - Esquema experimental da área cultivada com cana-de-açúcar, indicando as três linhas centrais (7, 8 e 9) usadas para medir as propriedades químicas e físicas do solo. $T_{1}$ e $T_{2}$ : superfície do solo coberta com palha e ponteiros deixados após a colheita da cana; $\mathrm{T}_{3}$ : entrelinhas com solo nu; $\mathrm{T}_{4}$ : presença de resíduos da queima da cana, antes da colheita, na superfície do solo; B: bordaduras. 
Para determinar o conteúdo de matéria orgânica do solo, de argila e a estabilidade de agregados, amostras de solo foram coletadas na faixa de $0-0,15 \mathrm{~m}$ de profundidade, ao longo da mesma transeção de 84 pontos. O conteúdo de matéria orgânica foi medido em 1997, 1998 e 1999, e uma média destes valores em cada ponto da transeção foi usada nesta análise. Detalhes a respeito da metodologia usada podem ser encontrado em Embrapa (1997). O conteúdo de argila e a estabilidade de agregados foram medidas durante o ano de 2000. Detalhes a respeito da metodologia usada podem ser encontrados em Gee \& Bauder (1986) e Kemper \& Rosenau (1986).

Os dados foram analisados usando o software ASTSA (Applied Statistical Time Series Analysis) desenvolvido por Shumway (1988), após a seguinte transformação:

$$
\mathrm{X}_{\mathrm{i}}=\left[\mathrm{X}_{\mathrm{i}}-(\mathrm{m}-2 \mathrm{~s})\right] / 4 \mathrm{~s}
$$

sendo $\mathrm{m}$ e s a média e o desvio padrão dos valores observados $\mathrm{X}_{\mathrm{i}}$, respectivamente. Esta transformação permite que os coeficientes de estado $\phi_{p}$ na equação (1) terem magnitudes diretamente proporcional a contribuição de cada variável de estado usada na análise (Hui et al., 1998).

\subsection{Resultados e Discussão}

O comportamento da umidade do solo ao longo da transeção é mostrado na Figura 2. O coeficiente de variação $(\mathrm{CV}=13,4 \%)$ das observações indica que a variação dos dados em relação a média é relativamente pequeno. Entretanto, as flutuações ponto a ponto são grandes quando comparadas a variação total. Usando o teste $t$ ao nível de $5 \%$ de probabilidade, a função de autocorrelação (ACF) da umidade do solo é apresentada na Figura 3, manifestando uma significante correlação espacial até 14 "lags" (14 m neste estudo).

Figura 4 apresenta a variabilidade espacial das observações de matéria orgânica nos 84 pontos da transeção, com um valor baixo do coeficiente de variação $(\mathrm{CV}=$ 
$7,8 \%$ ) e flutuações ponto a ponto sendo grandes. A dependência espacial entre as observações de matéria orgânica (Figura 5) sendo significante até $10 \mathrm{~m}$.

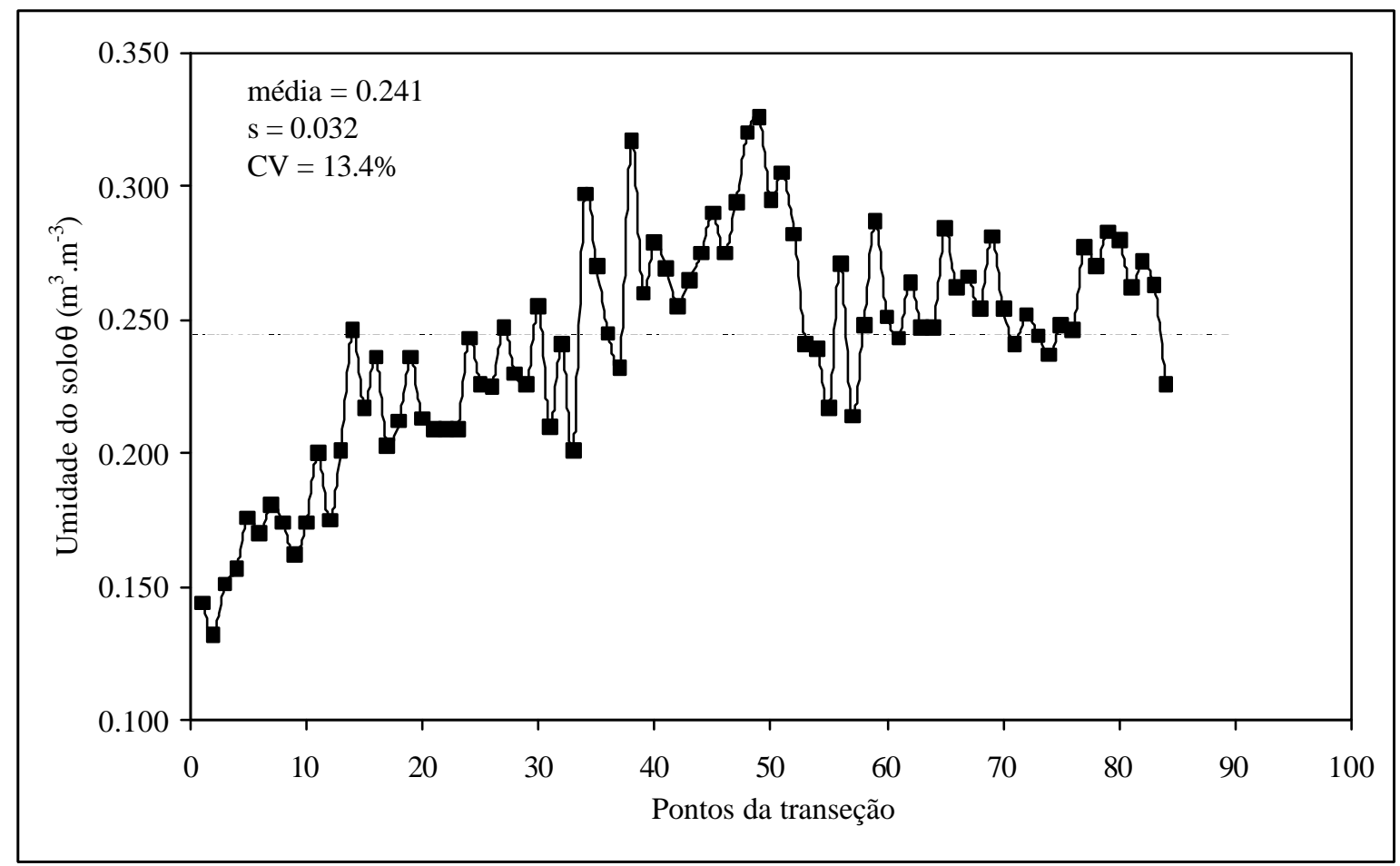

Figura 2 - Distribuição da umidade do solo $(\theta)$, metro a metro, ao longo dos 84 pontos da transeção, no dia 06/09/1999. 


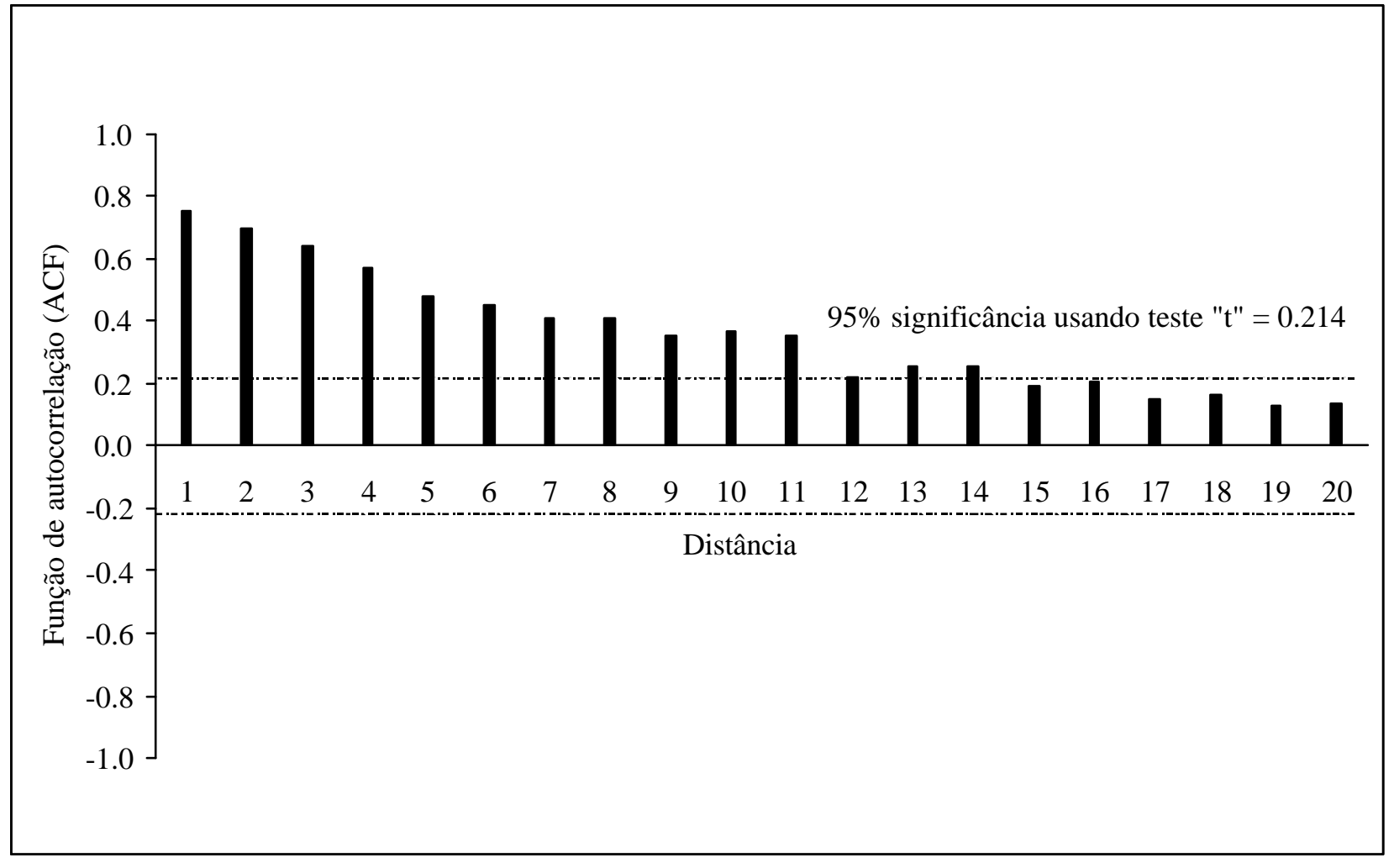

Figura 3 - Função de autocorrelação (ACF) para os dados de umidade do solo $(\theta)$ da Figura 2. 


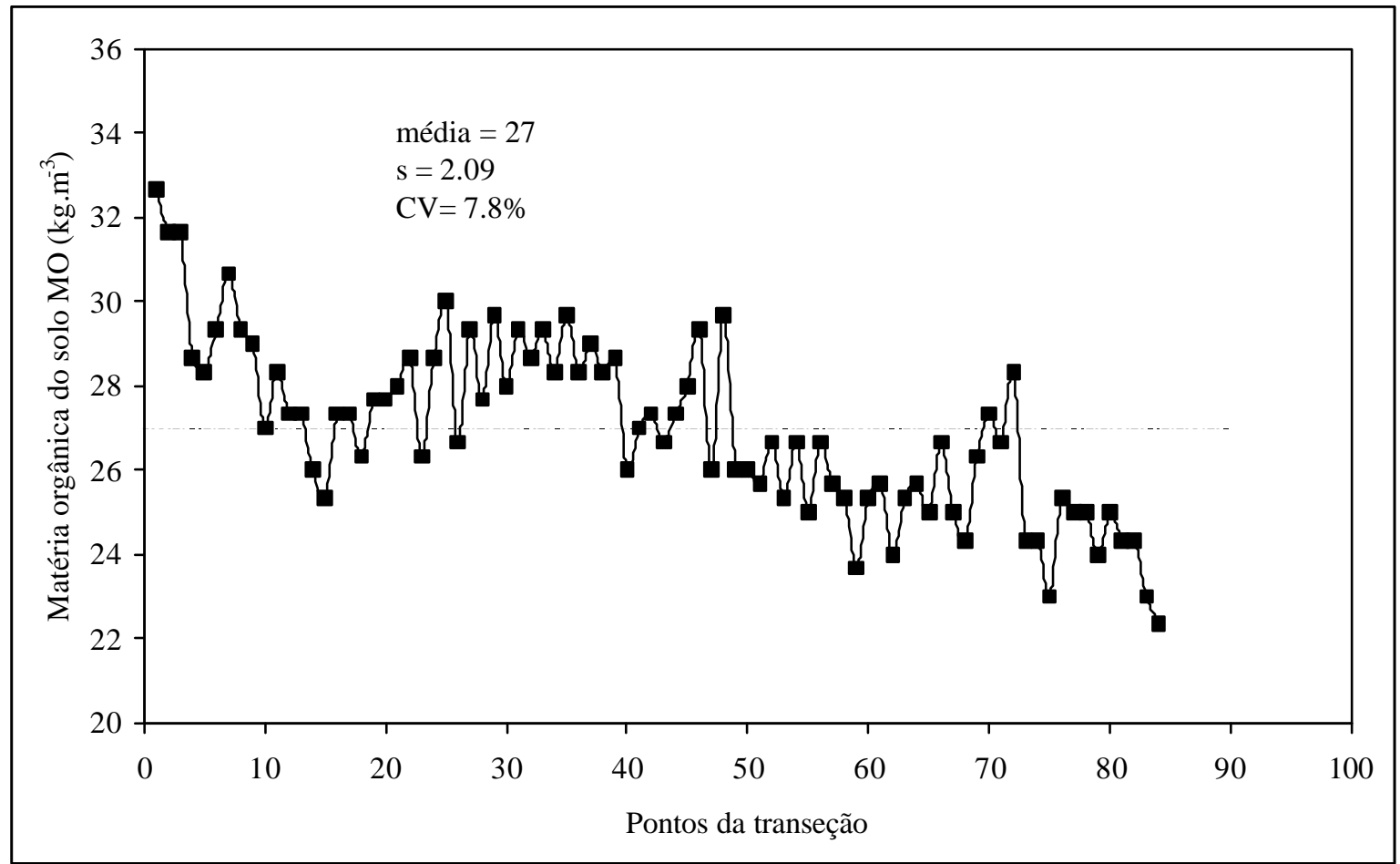

Figura 4 - Distribuição da matéria orgânica do solo (MO), metro a metro, ao longo dos 84 pontos da transeção. 


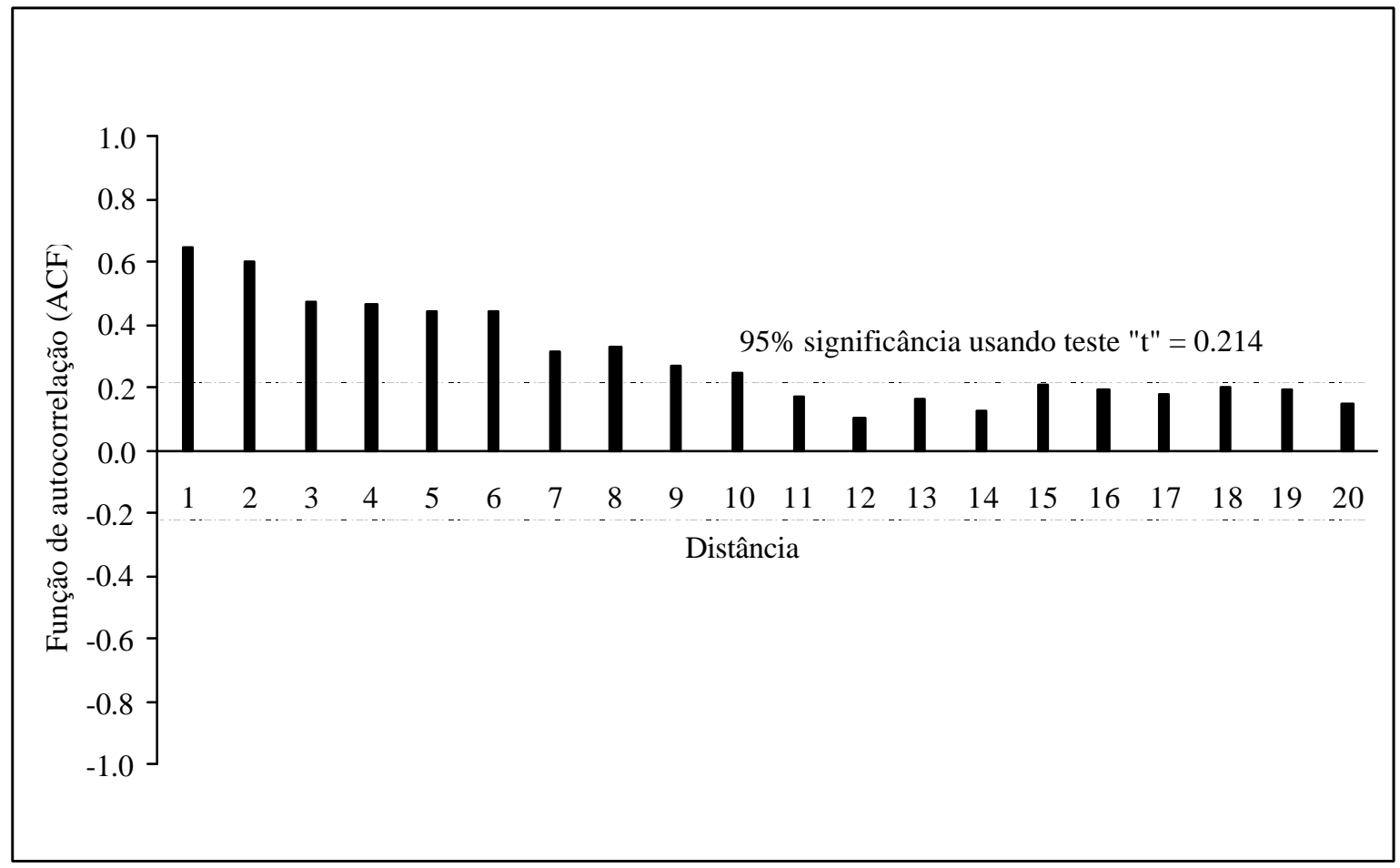

Figura 5 - Função de autocorrelação (ACF) para os dados de matéria orgânica do solo MO da Figura 4. 
A distribuição do conteúdo de argila (CC) ao longo dos 84 pontos da transeção e a função de autocorrelação são apresentadas nas Figuras 6 e 7, respectivamente. Novamente, as flutuações ponto a ponto das observações de CC são grandes quando comparadas ao coeficiente de variação $\mathrm{CV}$ de $8,7 \%$.

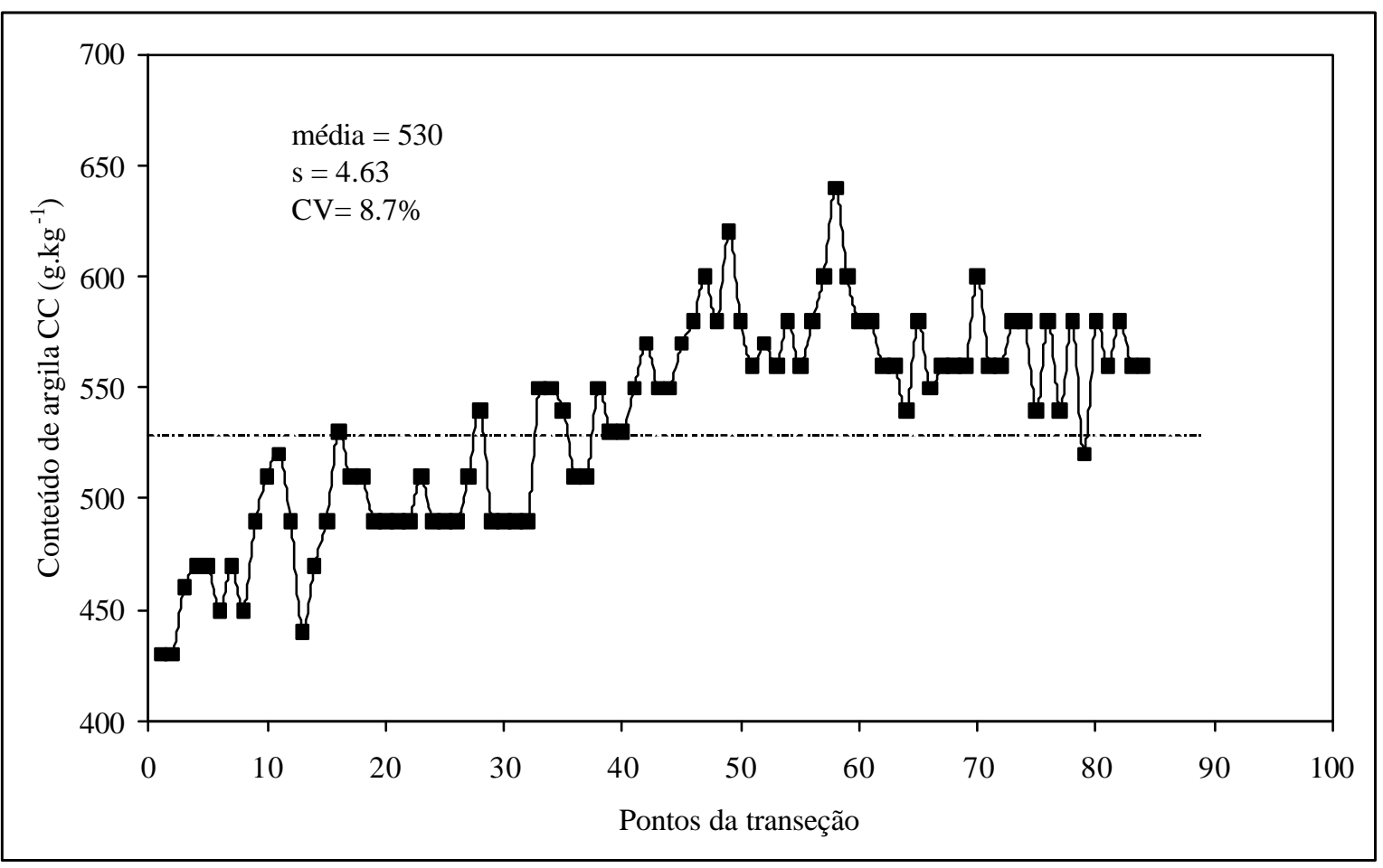

Figura 6 - Distribuição do conteúdo de argila (CC), metro a metro, ao longo dos 84 pontos da transeção. 


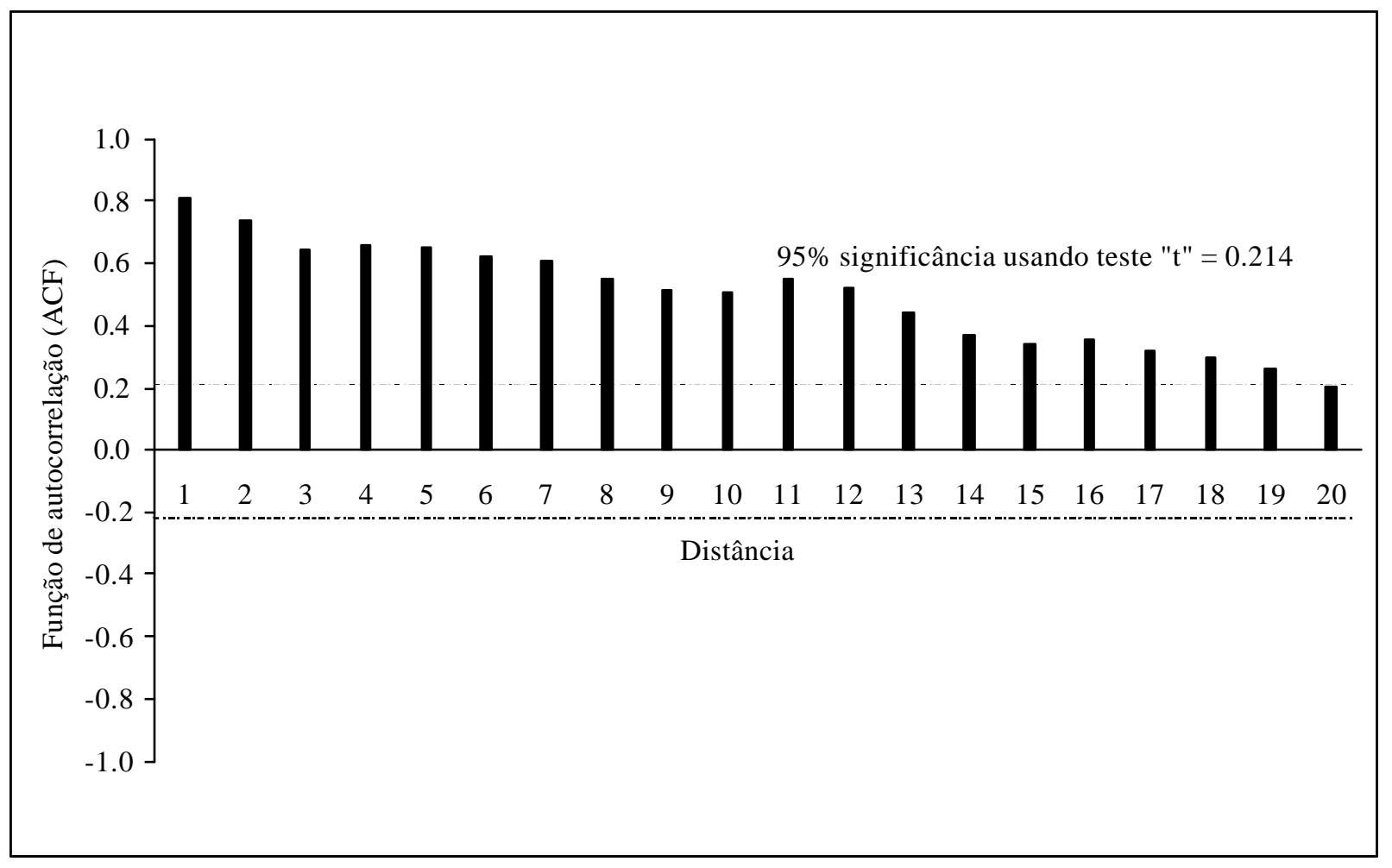

Figura 7 - Função de autocorrelação (ACF) para os dados de conteúdo de argila $\mathrm{CC}$ da Figura 6. 
Analisando as Figuras 2, 4 e 6, pode ser verificado que a distribuição espacial das observações de umidade do solo, matéria orgânica e conteúdo de argila manifestam uma tendência ao longo da transeção. Esta tendência causa uma forte dependência espacial de cada variável como evidenciado pela função de autocorrelação nas Figuras 3, 5 e 7. As Figuras 8 e 9 apresentam a variabilidade espacial e a autocorrelação para as observações de estabilidade de agregados ao longo da transeção. Ao contrário das outras três séries de dados, a estabilidade de agregados não tem uma tendência, e manifesta dependência espacial até 3 m (Figura 9).

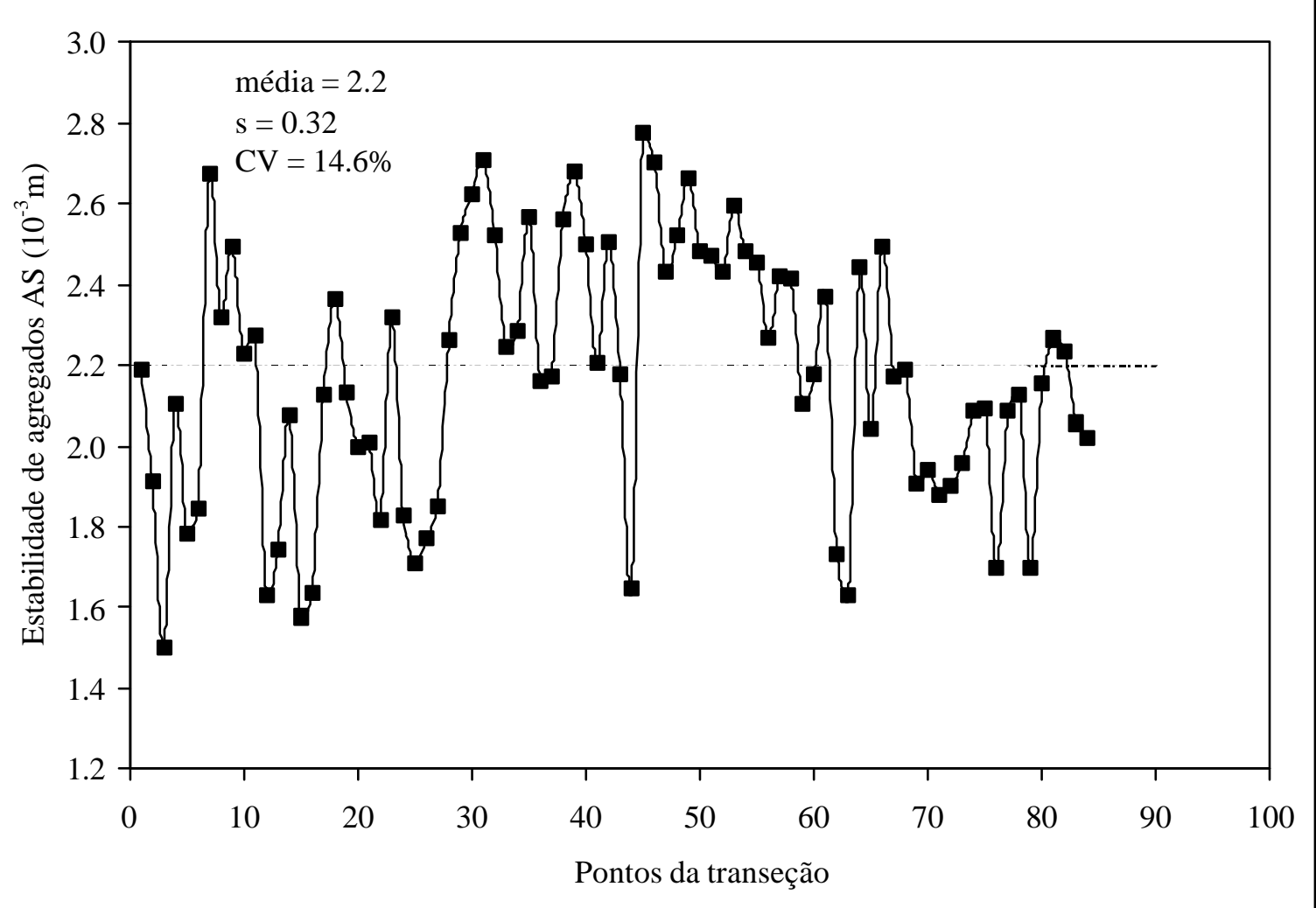

Figura 8 - Distribuição da estabilidade de agregados (AS), metro a metro, ao longo dos 84 pontos da transeção. 


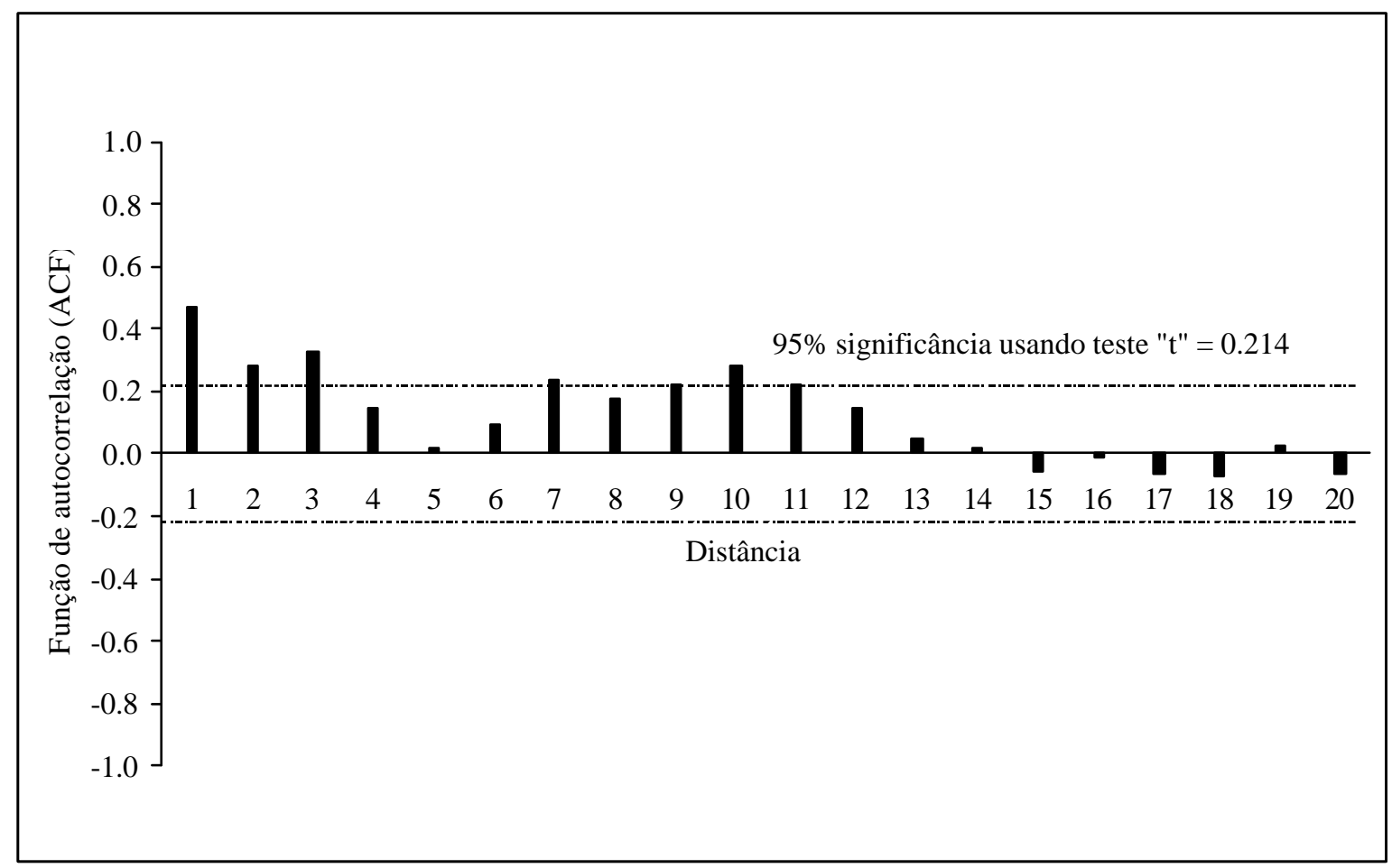

Figura 9 - Função de autocorrelação (ACF) para os dados de estabilidade de agregados AS da Figura 8. 
Sobre condições de campo, os efeitos dos diferentes tratamentos em qualquer das variáveis medidas não são facilmente verificados usando a estatística clássica (ignora as correlações espaciais locais) devido à heterogeneidade do solo. Em tais condições, de acordo com Wendroth et al. (1998), o uso de análises que levam em consideração as tendências locais são mais adequadas e fornecem melhores resultados.

Tradicionalmente, a maioria das investigações agronômicas tem usado técnicas de amostragem ao acaso e assumido que as amostras são independentes entre si. Desta forma, as análises de estatística clássica são usadas, tais como análise de variância (ANOVA) e análises de regressão, para descrever as trocas observadas dentro e entre diferentes tratamentos. Neste estudo, tais análises foram usadas para determinar como os dados de umidade do solo medidos ao longo da transeção são descritos pelas equações clássicas de regressão.

Devido a tendência de comportamento ao longo do espaço de três das quatro séries estudadas, é esperado que as variáveis sejam relacionadas entre si. Não levando em consideração as posições das observações, não mais do que 55\% da variância da umidade do solo é explicado pela análise de regressão linear e múltipla usando qualquer combinação das séries observadas. Na Tabela 1, pode ser notado que o melhor resultado da regressão foi obtido usando as séries de matéria orgânica, conteúdo de argila e estabilidade de agregados, e o pior é obtido usando somente estabilidade de agregados. Usando conteúdo de argila e estabilidade de agregados foi obtido um coeficiente de determinação $\left(\mathrm{R}^{2}\right)$ próximo aquele usando as três séries como variáveis dependentes.

Estas análises clássicas de regressão são baseadas nas hipóteses de que cada série manifesta uma média constante ao longo da transeção e ignora a crosscorrelação espacial local na transeção. Devido as observações de AS manifestarem somente uma autocorrelação espacial local e não possuírem uma tendência de correlacionar com as outras séries, foi encontrado o menor valor de $\mathrm{R}^{2}$.

Para verificar que o uso da análise de séries temporais conduz a uma informação adicional sobre a variabilidade espacial das propriedades do solo e, juntamente, com a análise de estatística clássica (média, desvio padrão e coeficiente de variação) propicia um melhor manejo do solo e o uso dos recursos naturais mais prudentemente. 
Tabela 1. Regressão linear e múltipla usando as quatro séries de observações.

\begin{tabular}{|c|c|}
\hline Equação & $\mathrm{R}^{2}$ \\
\hline \multicolumn{2}{|l|}{ Regressão Múltipla } \\
\hline$\theta=-0,073-0,00128 * \mathrm{MO}+0,000591 * \mathrm{CC}+0,0150 * \mathrm{AS}$ & 0,544 \\
\hline$\theta=-0,096-0,000322 * \mathrm{MO}+0,000645^{*} \mathrm{CC}$ & 0,534 \\
\hline$\theta=0,397-0,00942 * \mathrm{MO}+0,0448 * \mathrm{AS}$ & 0,321 \\
\hline$\theta=-0,124+0,000632 * \mathrm{CC}+0,0122 * \mathrm{AS}$ & 0,542 \\
\hline \multicolumn{2}{|l|}{ Regressão Linear } \\
\hline$\theta=0,474-0,0087 * \mathrm{MO}$ & 0,205 \\
\hline$\theta=-0,109+0,000655^{*} \mathrm{CC}$ & 0,534 \\
\hline$\theta=0,159+0,375 * A S$ & 0,082 \\
\hline
\end{tabular}

Os crosscorrelogramas apresentados nas Figuras 10 e 11 mostram a forte dependência espacial entre a umidade do solo e a matéria orgânica e conteúdo de argila, respectivamente, do que entre a umidade do solo e a estabilidade de agregados (Figura 12). Com tais magnitudes para as funções de crosscorrelação, é reconhecido o potencial para descrever as distribuições das séries ao longo da transeção usando a análise de espaço de estados. Inicialmente, na presença das tendências notadas acima, foi avaliado quão bem a aplicação da análise de séries temporais pode descrever a série de umidade do solo usando várias combinações entre as séries de matéria orgânica, conteúdo de argila e estabilidade de agregados. Cada série foi transformada para a mesma média usando a equação (3).

A Figura 13a apresenta a análise de espaço de estados aplicada a umidade do solo, matéria orgânica, conteúdo de argila e estabilidade de agregados com o símbolo quadrado representando os valores medidos de umidade do solo. A linha do meio representa os valores estimados de umidade do solo usando a equação de estado. As linhas superior e inferior representam os limites de confiança considerando mais ou menos dois desvios padrões, respectivamente. Pode ser visto a partir da equação de estado na figura, que a umidade do solo na posição i 1 contribui com aproximadamente 91\% na estimativa da umidade no ponto i, enquanto que, a matéria orgânica, o conteúdo 
de argila e a estabilidade de agregados na posição i 1 contribuem com 7\%, $6 \%$ e 2,4\%, respectivamente. Figura $13 \mathrm{~b}$ indica que este modelo de espaço de estados usando todas quatro séries descreve a umidade do solo $\left(\mathrm{R}^{2}=0,797\right)$ melhor do que o equivalente usando a equação de regressão múltipla $\left(\mathrm{R}^{2}=0,544\right)$.

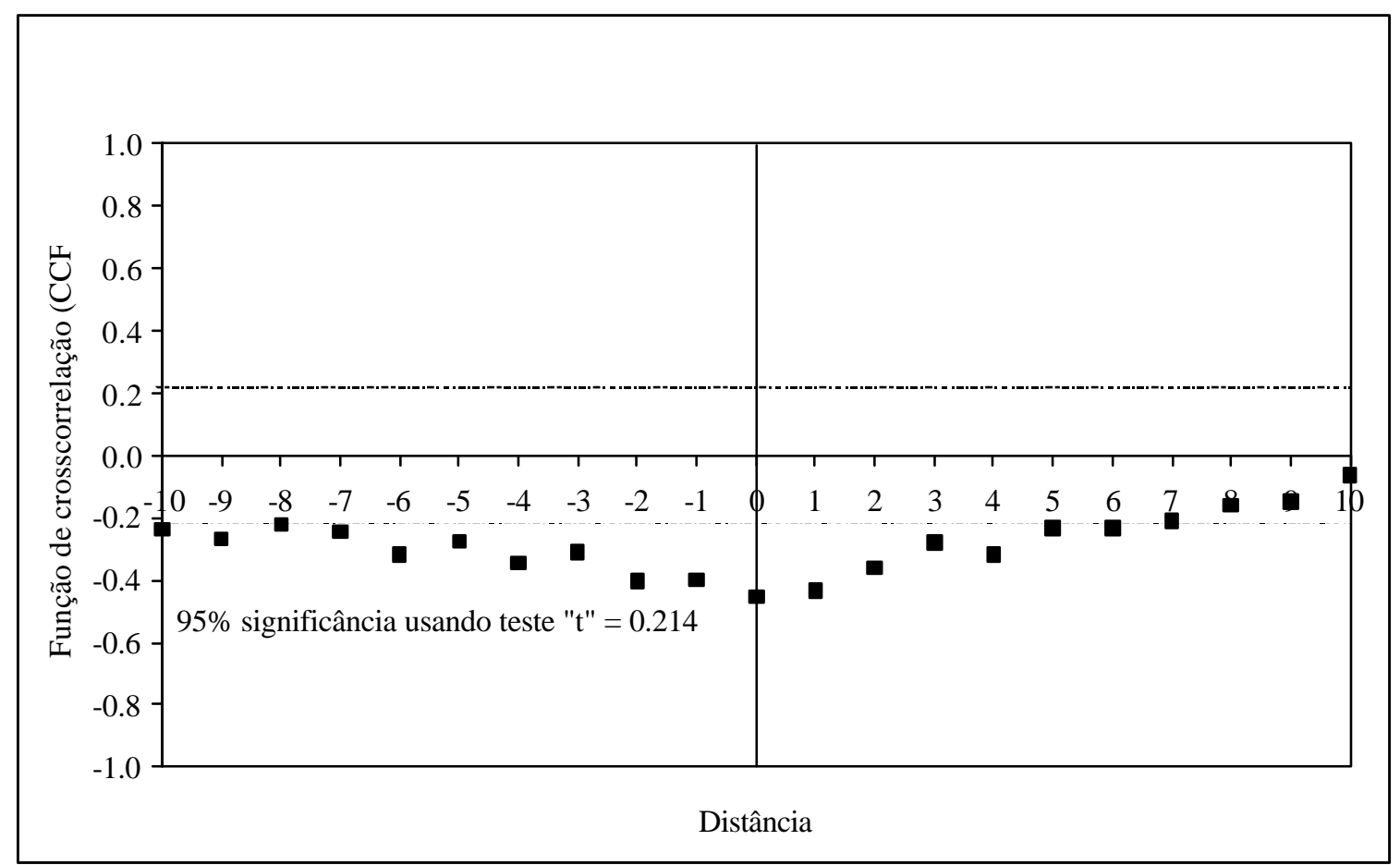

Figura 10 - Função de crosscorrelação (CCF) entre a umidade do solo e a matéria orgânica do solo, indicando a forte dependência espacial entre estas variáveis. 


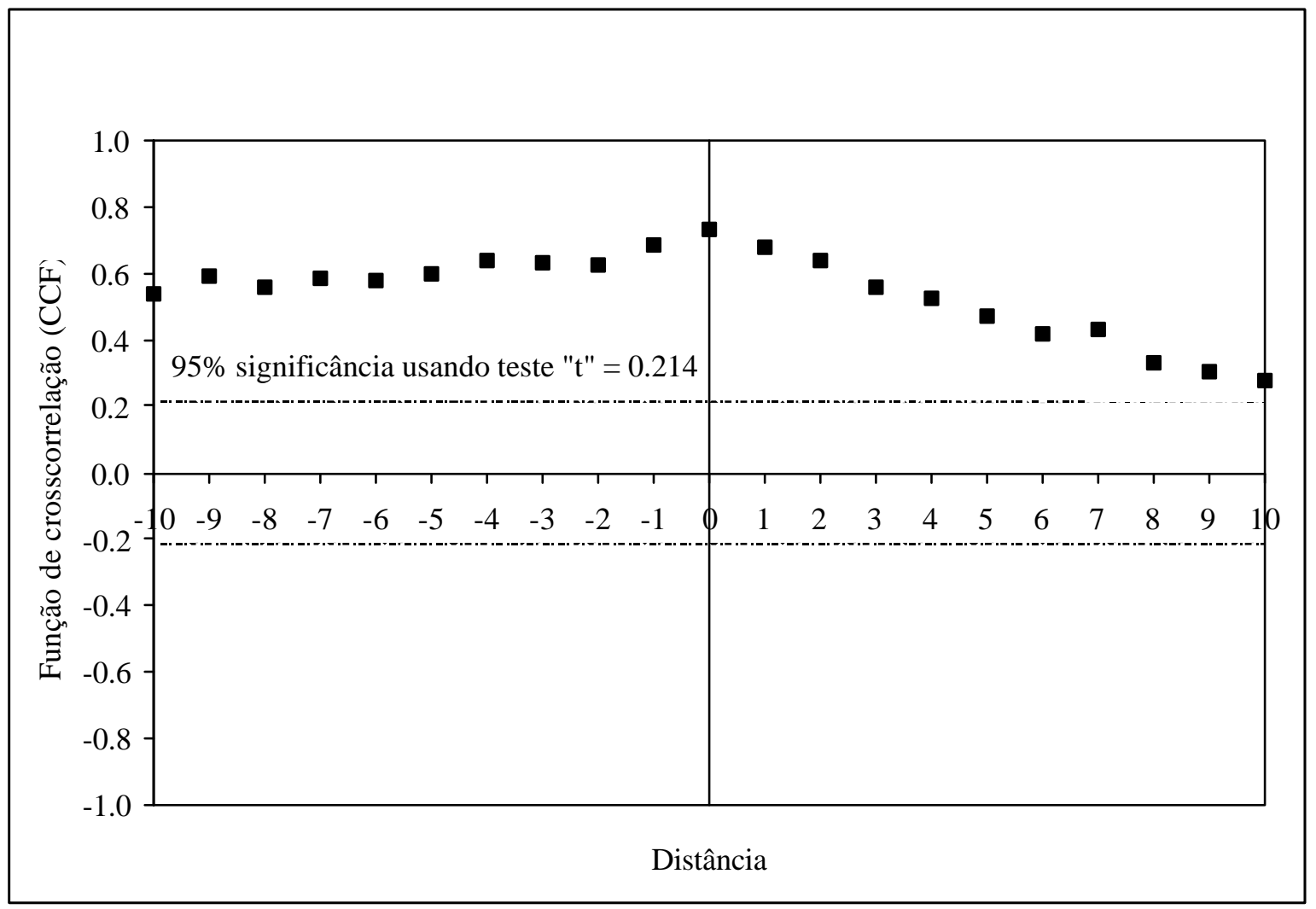

Figura 11 - Função de crosscorrelação (CCF) entre a umidade do solo e o conteúdo de argila, indicando a forte dependência espacial entre estas variáveis. 


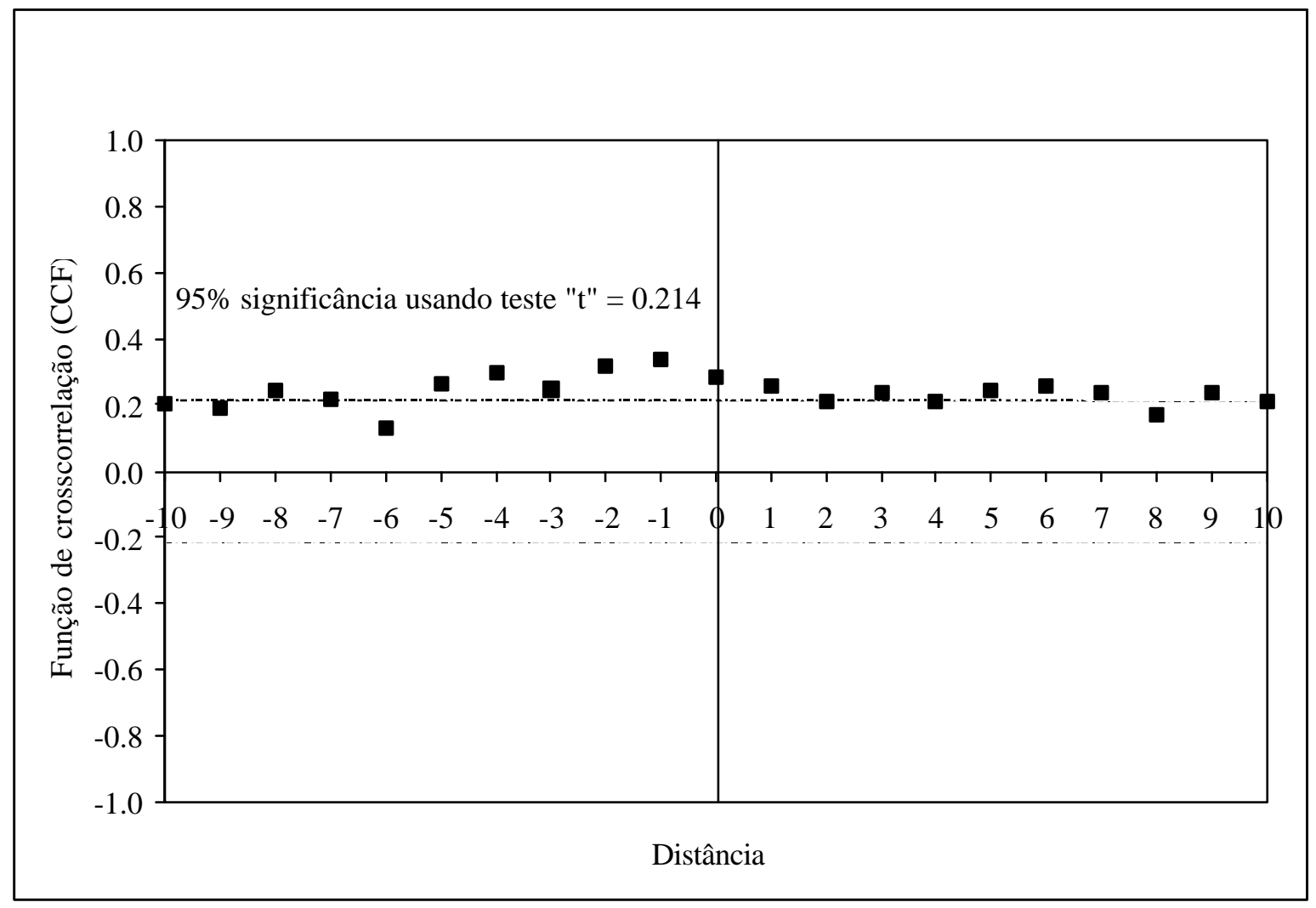

Figura 12 - Função de crosscorrelação (CCF) entre a umidade do solo e a estabilidade de agregados, indicando a fraca dependência espacial entre estas variáveis. 


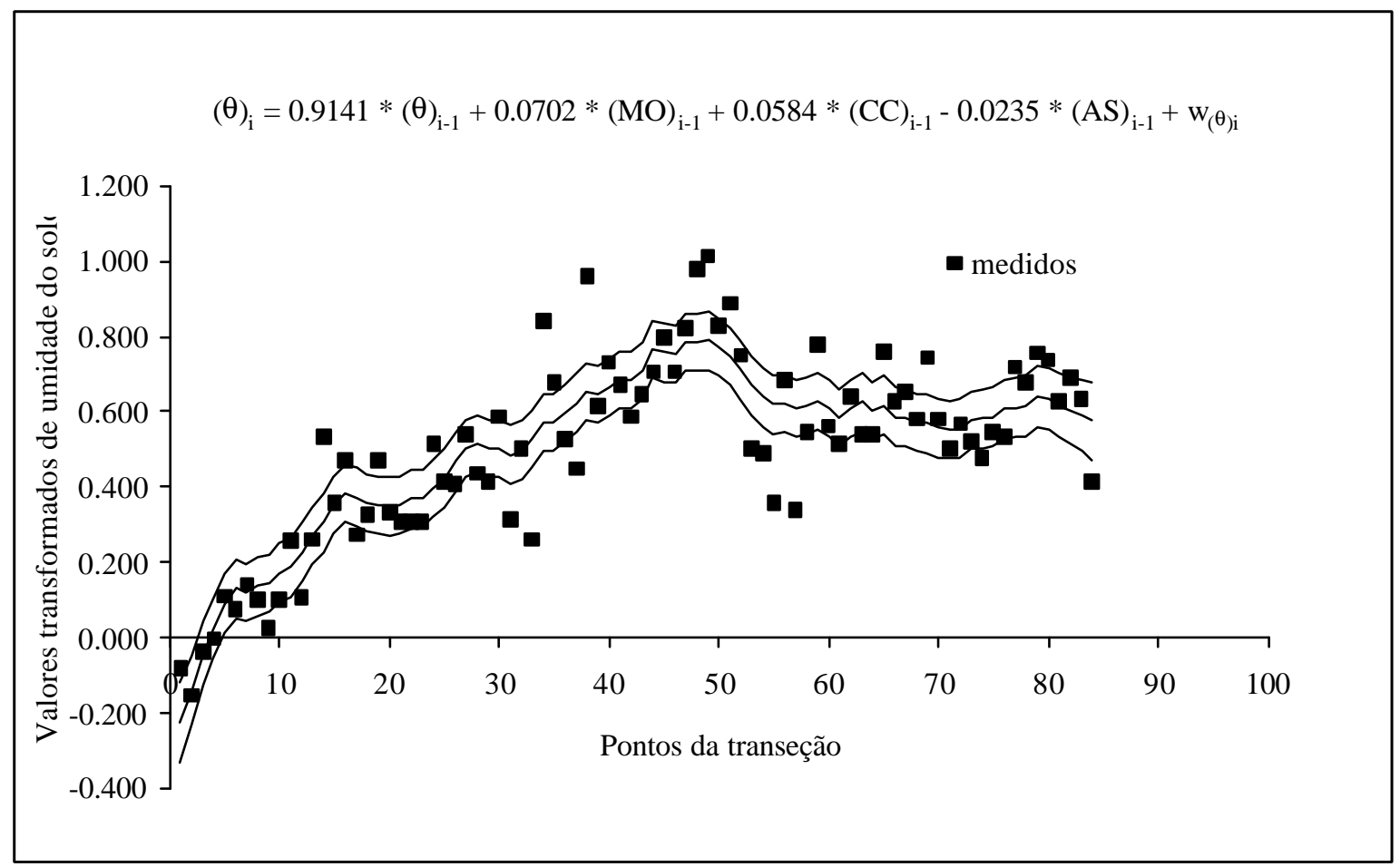

Figura 13a - Análise de espaço de estados aplicada à umidade do solo na posição i como uma função da umidade do solo, de matéria orgânica do solo, de conteúdo de argila e de estabilidade de agregados na posição i-1 (séries transformadas usando equação 3). 


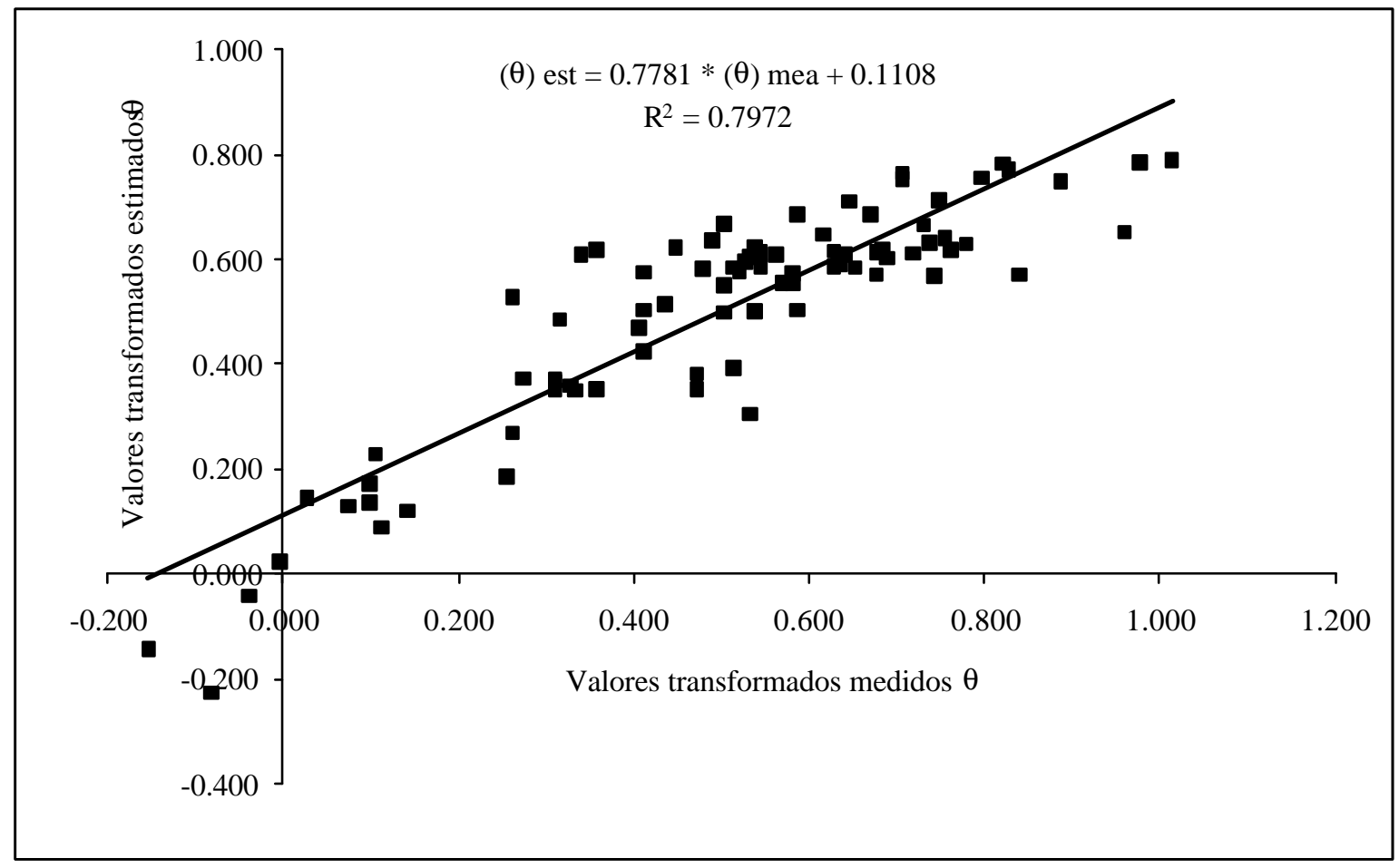

Figura 13b - Correlação entre os valores transformados estimados e medidos de umidade do solo da Figura 13a. 
As Figura 14a e 14b apresentam a análise de espaço de estados aplicada a umidade do solo sem a série de estabilidade de agregados. Comparando com os gráficos na Figura 13, a contribuição da umidade do solo na posição ił1 é menor, os limites de confiança são maiores e $\mathrm{R}^{2}$ é maior $(0,836)$.

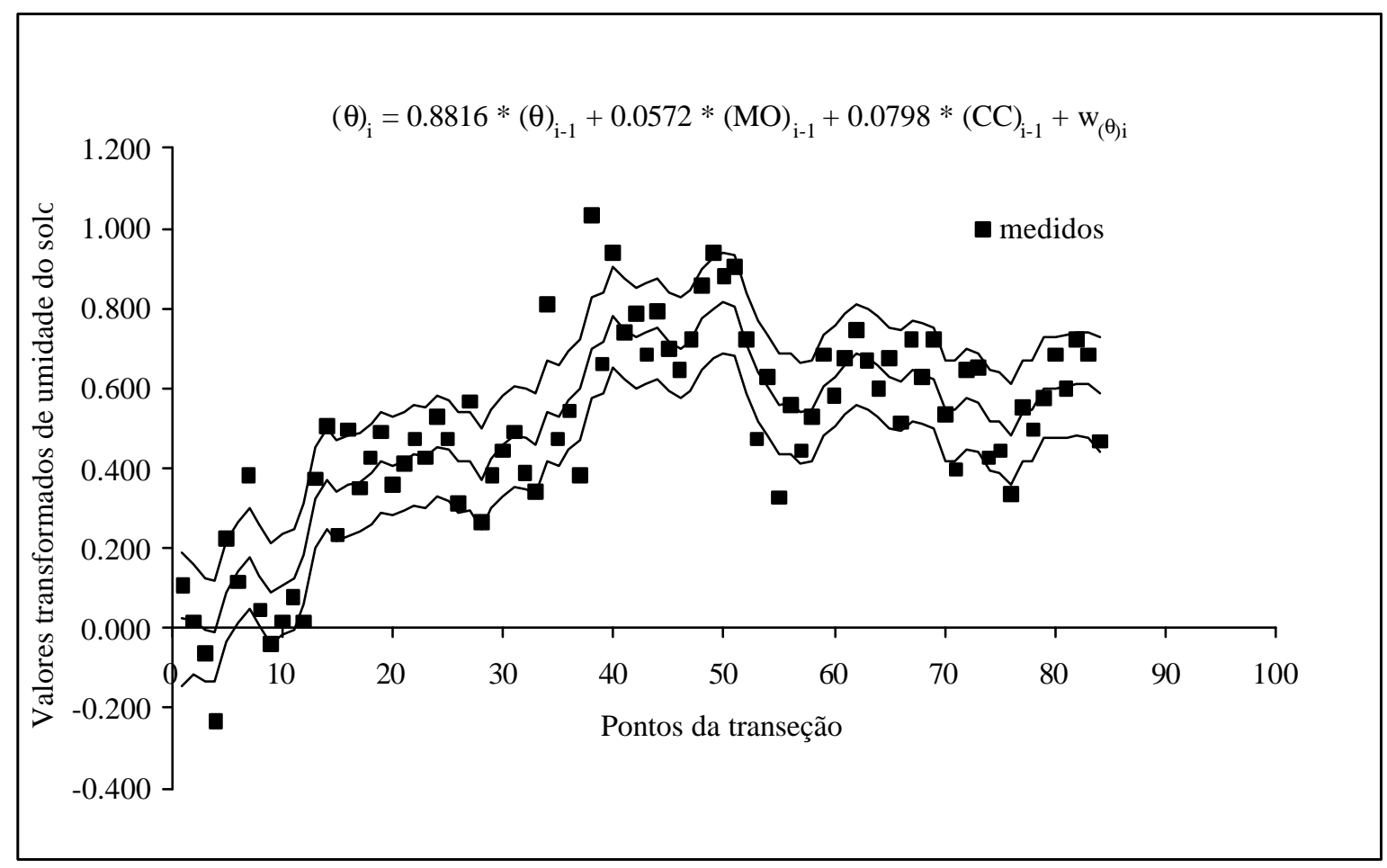

Figura 14a - Análise de espaço de estados aplicada à umidade do solo na posição i como uma função da umidade do solo, de matéria orgânica do solo e de conteúdo de argila na posição i-1 (séries transformadas usando equação 3). 


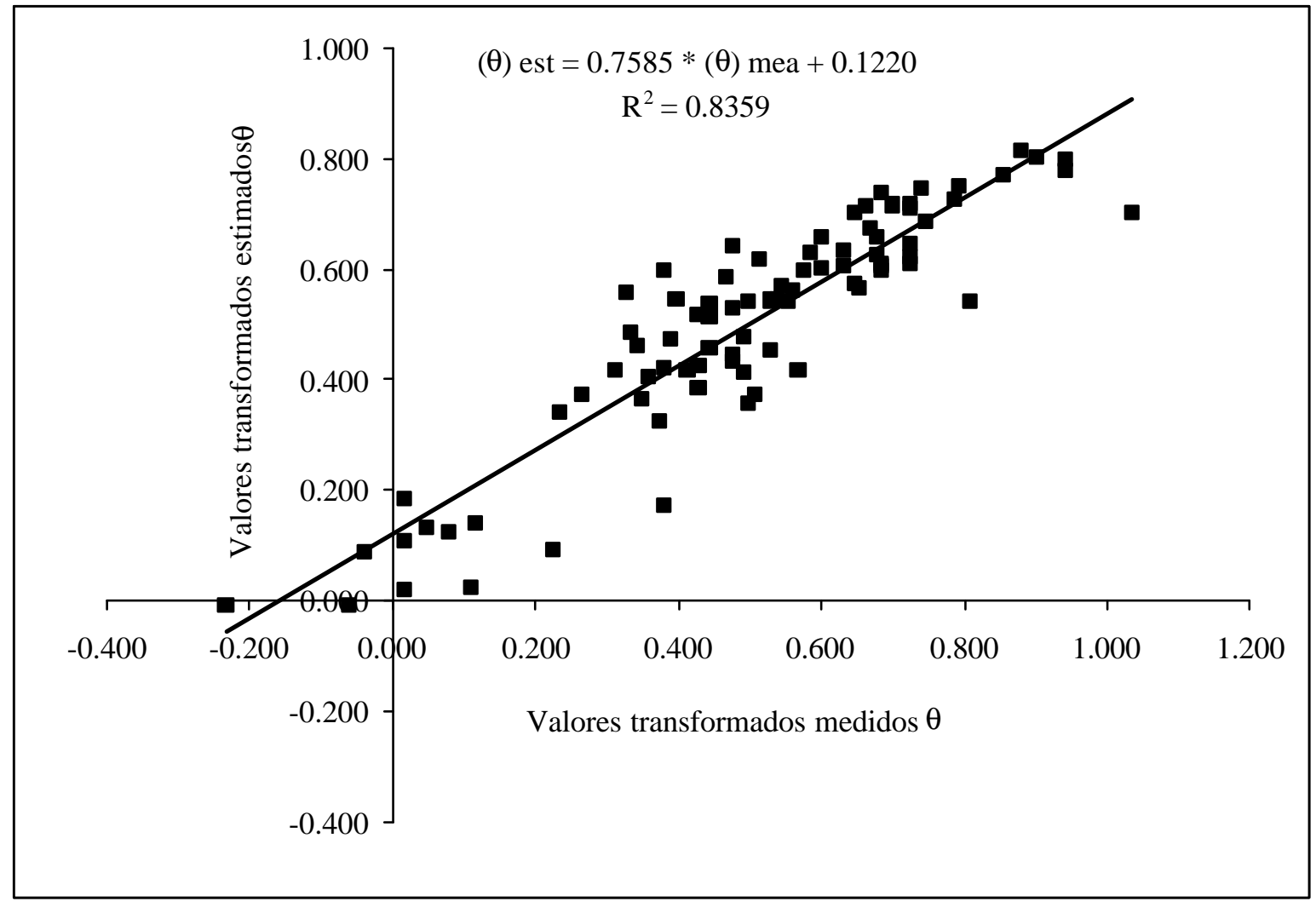

Figura 14b - Correlação entre os valores transformados estimados e medidos de umidade do solo da Figura 14a. 
A Tabela 2 mostra que as equações de espaço de estados descrevem a umidade do solo melhor do que qualquer equivalente equação de regressão clássica (Tabela 1).

Tabela 2. Equações de espaço de estados de umidade do solo (Figura 2) usando os dados apresentados nas Figuras 4, 6 e 8, e valores do coeficiente de regressão linear $\mathrm{R}^{2}$ entre os valores estimados e medidos de $\theta$. Todas as observações foram transformadas usando equação (3).

\begin{tabular}{|c|c|}
\hline Equação & $\mathrm{R}^{2}$ \\
\hline$\theta_{\mathrm{i}}=0,914 * \theta_{\mathrm{i}-1}+0,070 * \mathrm{MO}_{\mathrm{i}-1}+0,058 * \mathrm{CC}_{\mathrm{i}-1}-0,024 * \mathrm{AS}_{\mathrm{i}-1}+\mathrm{w}_{\mathrm{i}}$ & 0,797 \\
\hline$\theta_{\mathrm{i}}=0,882 * \theta_{\mathrm{i}-1}+0,057 * \mathrm{MO}_{\mathrm{i}-1}+0,080 * \mathrm{CC}_{\mathrm{i}-1}+\mathrm{w}_{\mathrm{i}}$ & 0,836 \\
\hline$\theta_{\mathrm{i}}=0,971 * \theta_{\mathrm{i}-1}+0,061^{*} \mathrm{MO}_{\mathrm{i}-1}-0,014 * \mathrm{AS}_{\mathrm{i}-1}+\mathrm{w}_{\mathrm{i}}$ & 0,803 \\
\hline$\theta_{\mathrm{i}}=0,768^{*} \theta_{\mathrm{i}-1}+0,146^{*} \mathrm{CC}_{\mathrm{i}-1}-0,096^{*} \mathrm{AS}{ }_{\mathrm{i}-1}+\mathrm{w}_{\mathrm{i}}$ & 0,907 \\
\hline$\theta_{\mathrm{i}}=0,961 * \theta_{\mathrm{i}-1}+0,053^{*} \mathrm{MO}_{\mathrm{i}-1}+\mathrm{w}_{\mathrm{i}}$ & 0,854 \\
\hline$\theta_{\mathrm{i}}=0,900 * \theta_{\mathrm{i}-1}+0,100 * \mathrm{CC}_{\mathrm{i}-1}+\mathrm{w}_{\mathrm{i}}$ & 0,887 \\
\hline$\theta_{\mathrm{i}}=0,924 * \theta_{\mathrm{i}-1}+0,083 * \mathrm{AS}_{\mathrm{i}-1}+\mathrm{w}_{\mathrm{i}}$ & 0,882 \\
\hline
\end{tabular}

Examinando os resultados dados na Tabela 2, verifica-se que a melhor performance de todas as equações de espaço de estados foi usando o conteúdo de argila e a estabilidade de agregados. Para esta equação, a contribuição da umidade do solo na posição $\mathrm{i} 1$ foi a menor e $\mathrm{R}^{2}$ foi o maior, ou seja, as variações locais e regionais de CC e AS ao longo da transeção foram as mais importantes variações relacionadas a distribuição espacial de $\theta$.

As tendências espaciais (notadas nas Figuras 2, 4 e 6) foram removidas usando uma regressão polinomial de segunda ordem em cada uma das séries. Subtraindo estas tendências de cada respectiva série de observações, foram obtidos os resíduos ao longo da transeção (Figuras 15, 16 e 17). As funções de autocorrelação destes resíduos (Figuras 18, 19 e 20) revelam que a dependência espacial ao longo da transeção persiste no mínimo de 2 "lags" após retirada a tendência, isto é, as observações ainda estão relacionadas as observações adjacentes. 


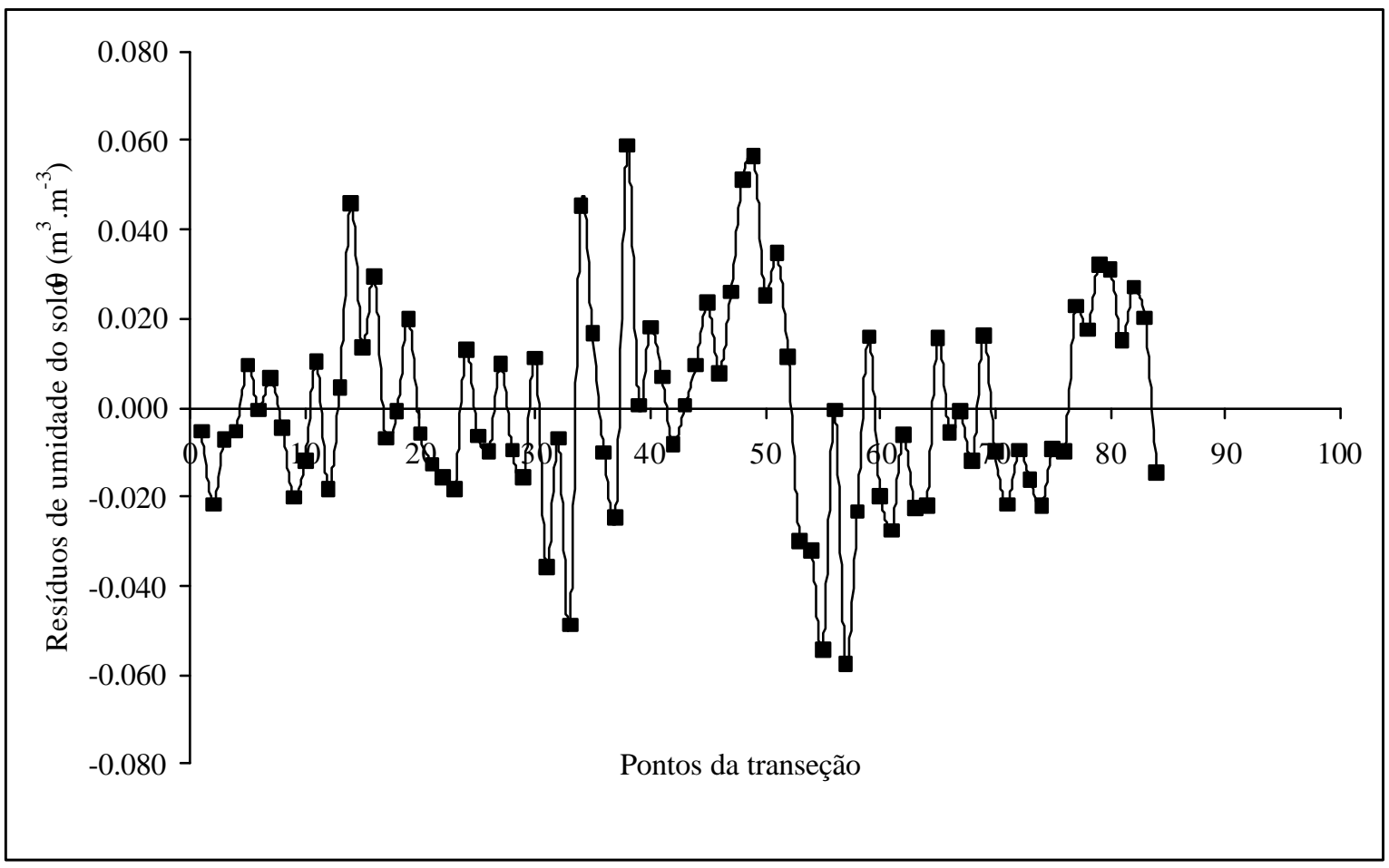

Figura 15 - Distribuição dos resíduos de umidade do solo, metro a metro, ao longo dos 84 pontos da transeção. 


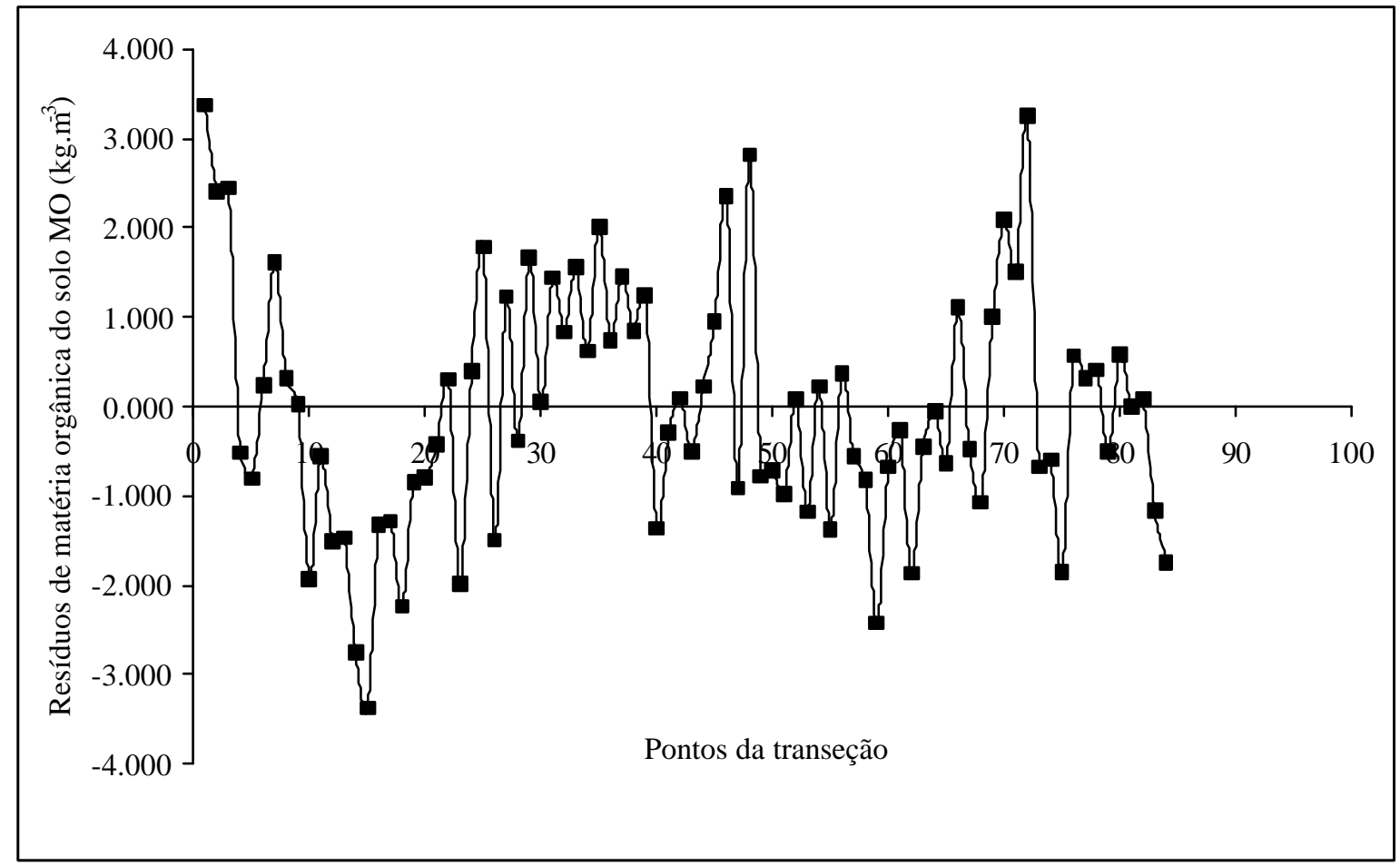

Figura 16 - Distribuição dos resíduos de matéria orgânica do solo, metro a metro, ao longo dos 84 pontos da transeção. 


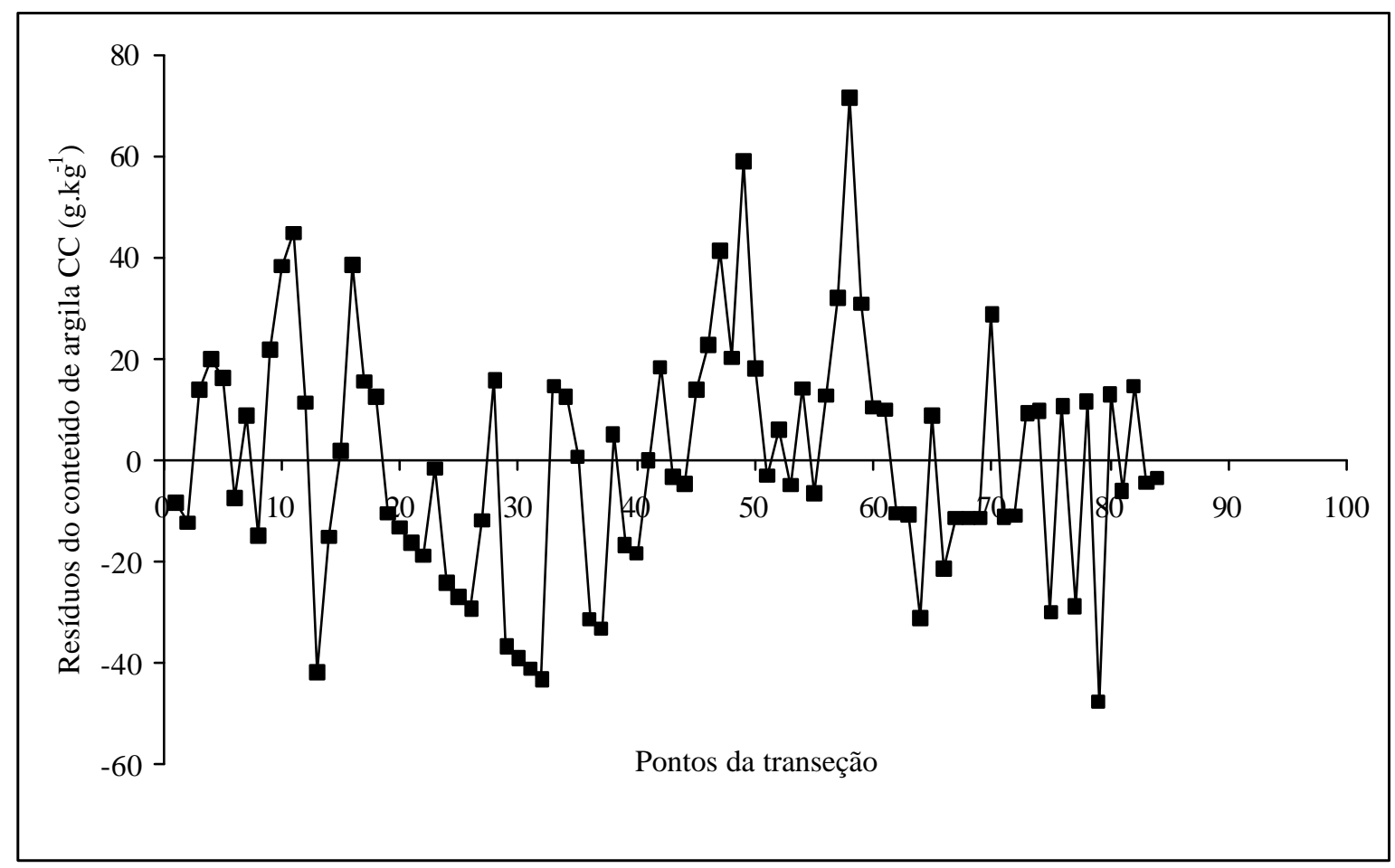

Figura 17 - Distribuição dos resíduos de conteúdo de argila, metro a metro, ao longo dos 84 pontos da transeção. 


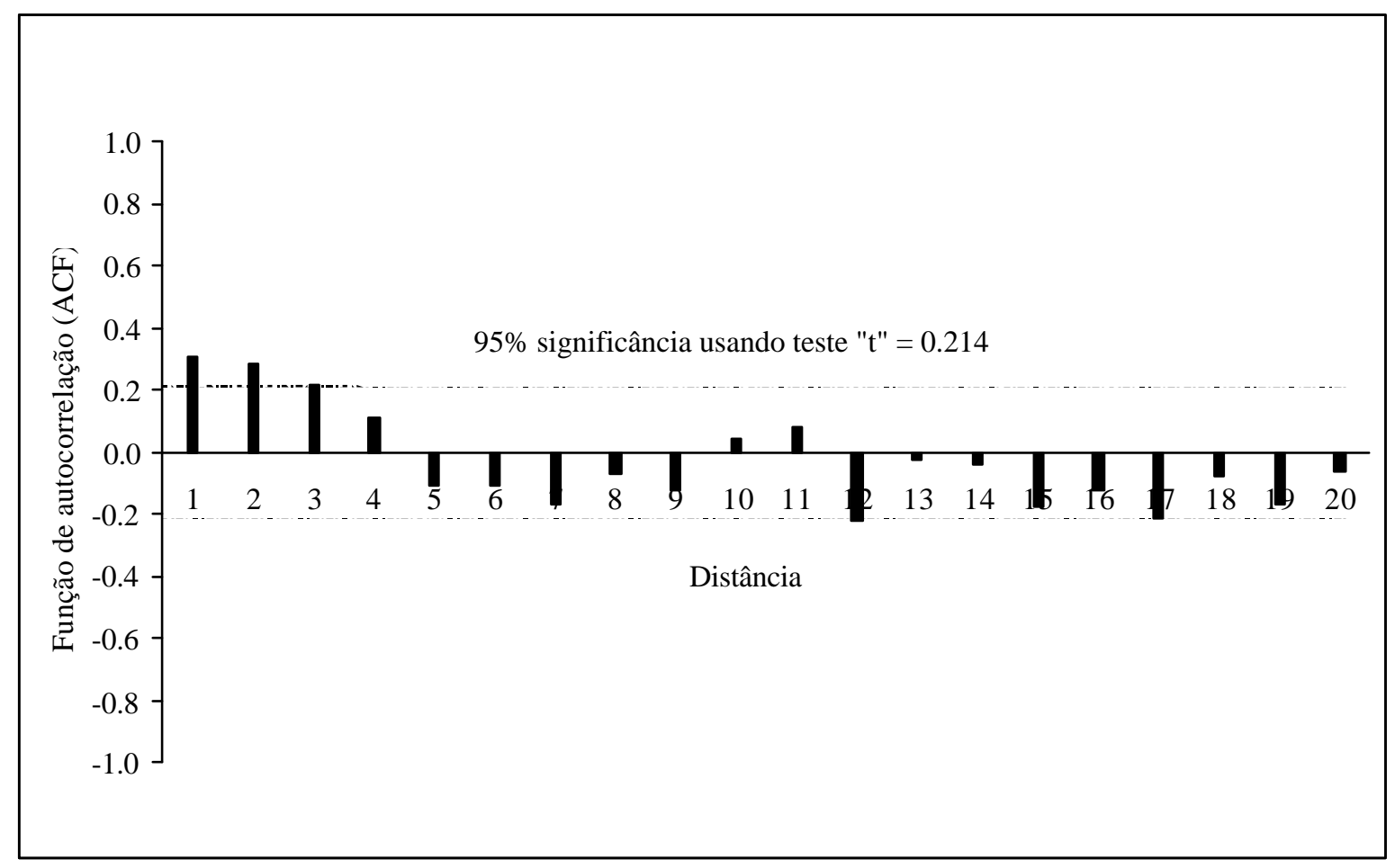

Figura 18 - Função de autocorrelação (ACF) para os resíduos de umidade do solo da Figura 15. 


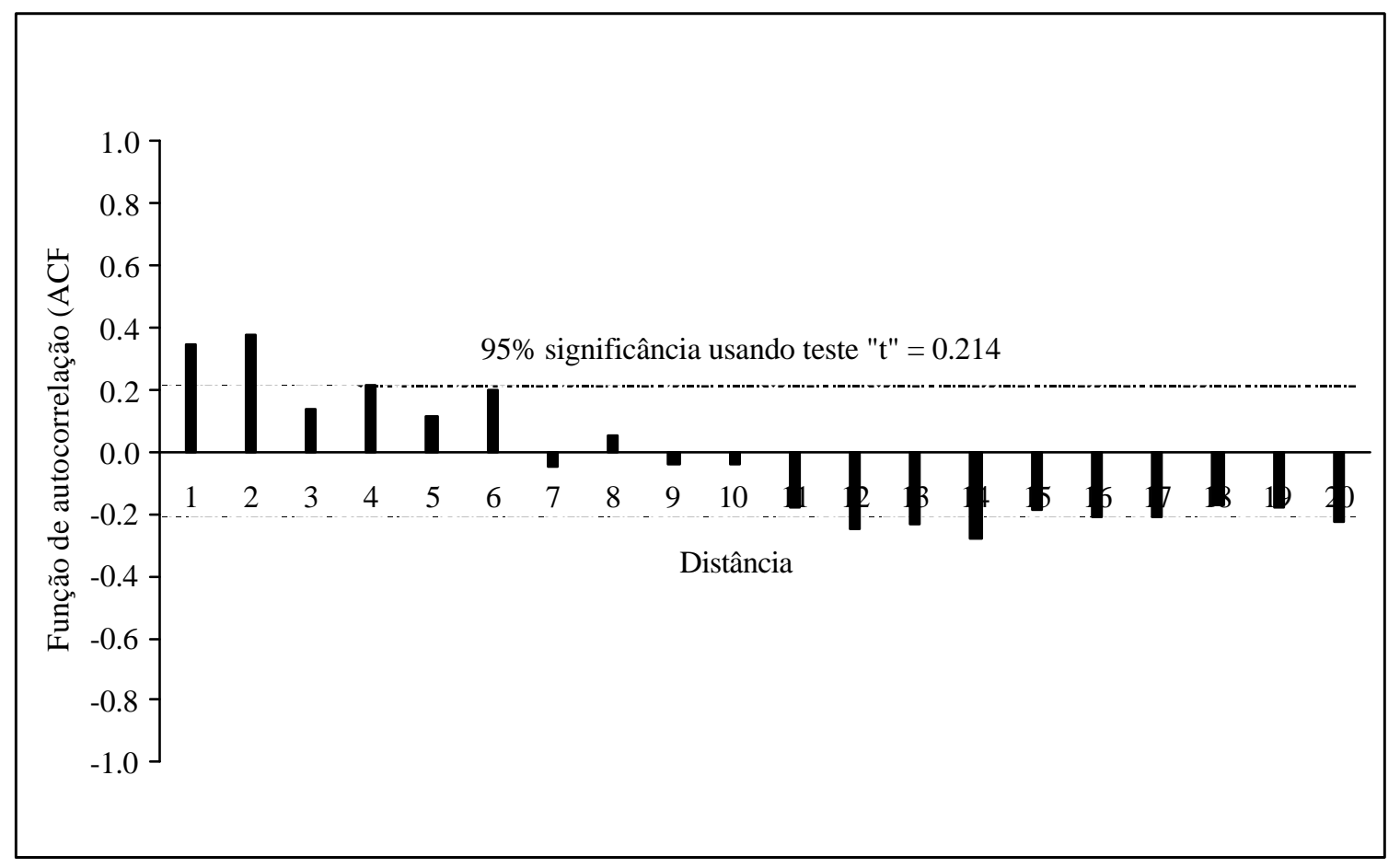

Figura 19 - Função de autocorrelação (ACF) para os resíduos de matéria orgânica do solo da Figura 16. 


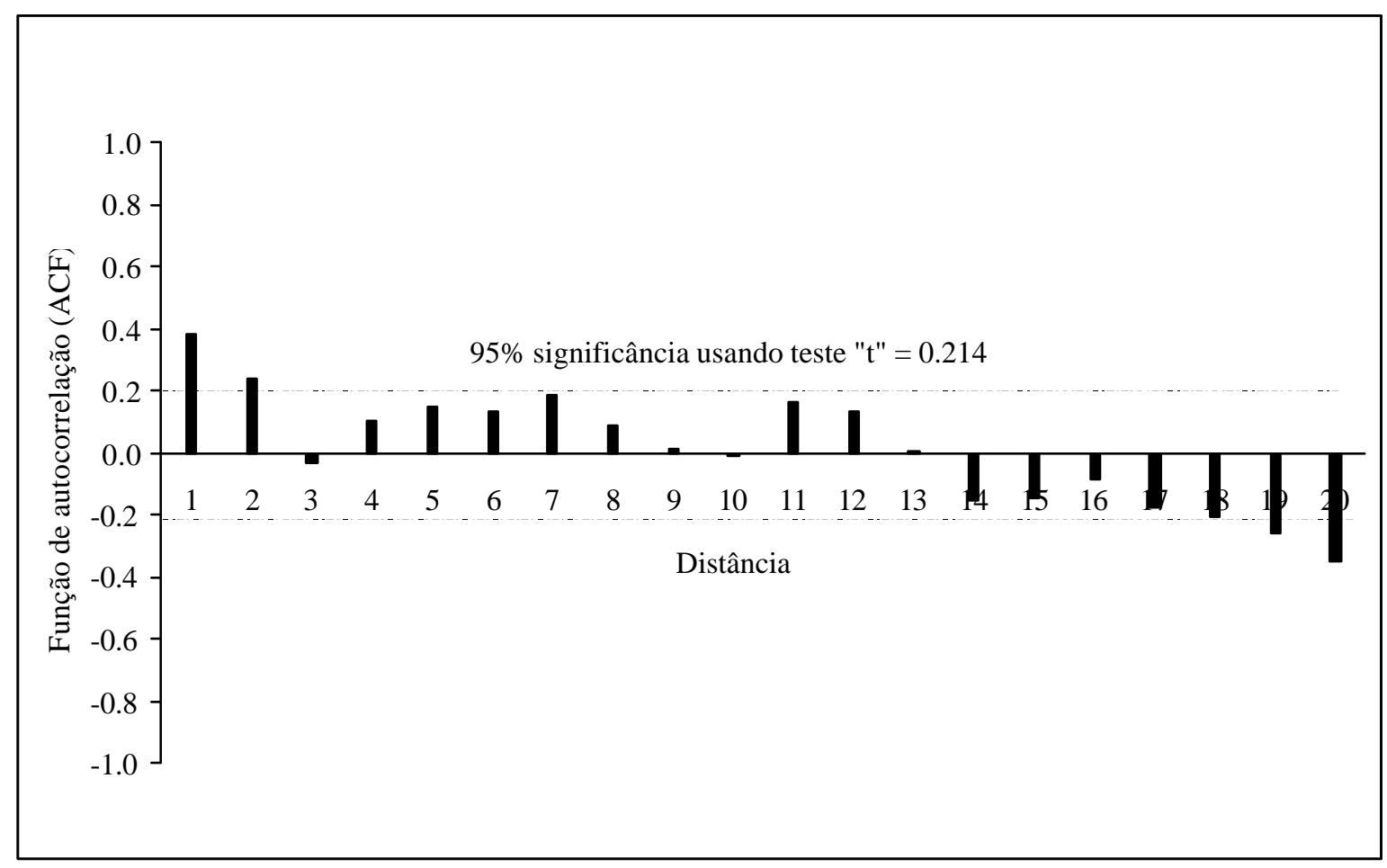

Figura 20 - Função de autocorrelação (ACF) para os resíduos de conteúdo de argila da Figura 17. 
Adicionais análises não revelaram crosscorrelações espaciais entre as séries após a remoção da tendência nas séries de umidade do solo, matéria orgânica e conteúdo de argila.

Os resultados apresentados nas Tabelas 1 e 2 revelaram que as variações espaciais de MO, CC e AS são significativamente relacionadas às variações de $\theta$ ao longo da transeção. Devido ao fato destas equações de espaço de estados serem empíricas, sabe-se que as variações espaciais das séries são relacionadas entre si, mas temos que identificar o porquê delas serem relacionadas, i.e., como as leis físicas e químicas podem ser incorporadas nas equações de espaço de estados permitindo uma seleção mais rigorosa das variáveis de entrada, fornecendo uma explicação mais realística das variações locais e regionais dos processos que ocorrem à nível de campo.

\subsection{Conclusões}

Neste capítulo a análise de espaço de estados foi aplicada à dados de umidade do solo, matéria orgânica do solo, conteúdo de argila e estabilidade de agregados coletados ao longo de uma transeção espacial de 84 pontos com o objetivo de um melhor entendimento da relação entre estas propriedades físicas e químicas do solo. Por meio desta análise, é possível identificar uma variável que relaciona o comportamento local de diversas variáveis e estocasticamente quantificar esta relação levando em consideração os erros associados às observações e ao modelo. Neste sentido, as análises apresentadas aqui fornecem idéias específicas de como os agricultores podem usar esta ferramenta para um melhor manejo do solo e dos recursos naturais no intuito de aumentar a produção da cultura e simultaneamente melhorar a qualidade do meio ambiente. 


\section{CONCLUSÕES GERAIS}

A presença da cobertura vegetal (palhas mais ponteiros) na superfície do solo na cultura da cana-de-açúcar, como uma consequiência da adoção de uma nova prática de manejo sem a queima prévia da cana antes da colheita, reduziu as temperaturas médias na superfície do solo na ordem de $7{ }^{\circ} \mathrm{C}$, evitando picos de temperatura na superfície durante o período inicial da cana soca. Entretanto, a cobertura vegetal afetou negativamente o desenvolvimento da cultura reduzindo o número de colmos e seu peso úmido, no presente estudo.

Com relação aos componentes do balanço hídrico, não afetou os valores do escoamento superficial, fluxo de água no solo no limite inferior do volume de solo e o armazenamento de água no solo. Isto devido às características da cultura da cana-deaçúcar e da precipitação ocorrida na área experimental. Sendo uma cultura semi-perene

que em um período de 60 a 90 dias cobre completamente a superfície do solo, a cobertura vegetal tem efeito somente na evapotranspiração, durante os primeiros 90 dias. Para os altos valores de precipitação, a cobertura vegetal não alterou o processo de infiltração da água no solo e, como conseqüência, os valores do escoamento superficial também não foram alterados.

Os resultados indicaram que o estabelecimento do balanço hídrico da cultura de cana-de-açúcar, prevalecendo estas condições, é problemático principalmente devido ao fato de que o escoamento superficial e os fluxos de água no limite inferior do volume de solo considerado são fortemente afetados pela variabilidade espacial do solo.

A análise de espaço de estados aplicada aos dados de umidade e temperatura do solo coletados ao longo da transeção espacial de 84 pontos, sugeriu que, em muitas situações, devido ao fato dos dados de temperatura do solo serem mais fáceis e mais 
rápidos de serem obtidos no campo de que os de umidade, uma medida poderia substituir a outra.

A análise de espaço de estados quando aplicada aos dados de umidade do solo, matéria orgânica do solo, conteúdo de argila e estabilidade de agregados coletados ao longo da transeção espacial, propiciou um melhor entendimento da relação dinâmica entre estas propriedades físicas e químicas do solo, quando comparada à regressão múltipla que vem sendo aplicada na área agronômica.

A análise de espaço de estado mostrou-se uma ferramenta com um grande potencial de aplicação na área agronômica em estudos onde as variáveis apresentem uma estrutura de correlação espacial, sendo possível identificar uma variável que relaciona o comportamento local de diversas variáveis e estocasticamente quantificar esta relação levando em consideração os erros associados às observações e ao modelo. Neste sentido, ela pode auxiliar os agricultores no melhor manejo do solo e dos recursos naturais no intuito de aumentar a produção da cultura e simultaneamente melhorar a qualidade do meio ambiente. 


\section{REFERÊNCIAS BIBLIOGRÁFICAS}

ABRAMO FILHO, J.; MATSUOKA, S.; SPERANDIO, M.L.; RODRIGUES, R. C.D.; MARCHETTI, L.L. Resíduo da colheita mecanizada de cana crua. Álcool \& Açúcar, n. 67, p. 23-25, 1993.

ALVES, M. H.; MAGALHÃES, P. C.; KELMAN, J. Previsão em tempo real de vazão associada a uma incerteza e utilizando técnica de filtragem de erros. In: SIMPÓSIO BRASILEIRO DE RECURSOS HÍDRICOS, 9, 1991, Rio de Janeiro. Anais. São Paulo: Associação Brasileira Recursos Hídricos, 1991. v.3, p. 111-123.

BRAGAGNOLO, N.; MIELNICZUK, J. Cobertura do solo por palha de trigo e seu relacionamento com a temperatura e umidade do solo. Revista Brasileira de Ciência do Solo, v. 14, n. 3, p. 369-374, 1990.

BRESLER, E.; DASBERG, S.; RUSSO, D.; DAGAN, G. Spatial variability of crop yield as a stochastic soil process. Soil Science Society of America Journal, v. 45, p. 600-605, 1981.

CALDEIRA, D.S.A.; RODELLA, A.A. Influência da temperatura na degradação de compostos orgânicos no solo (compact disc). In: CONGRESSO BRASILEIRO DE CIÊNCIA DO SOLO, 26, Rio de Janeiro, 1997. Resumos. Rio de Janeiro: Sociedade Brasileira de Ciência do Solo, 1997. 
CÁSSARO, F. A. M.; TOMINAGA, T. T.; BACCHI, O. O. S.; REICHARDT, K.; OLIVEIRA, J. C. M.; TIMM, L. C. Improved laboratory calibration of a single probe surface gamma neutron gauge. Australian Journal of Soil Research, v. 38, p. 937946, 2000.

CEDDIA, M.B.; ANJOS, L.H.C.; LIMA, E.; RAVELli NETO, A.; SILVA, L.A. Alterações nas propriedades físicas e mesofauna de solo podzólico amarelo sob diferentes sistemas de corte de cana-de-açúcar (compact disc). In: CONGRESSO LATINO AMERICANO DE CIÊNCIA DO SOLO, 13, Águas de Lindóia, 1996. Anais. Águas de Lindóia: Sociedade Brasileira de Ciência do Solo; Sociedade Latino-Americana de Ciência do Solo, 1996.

CINTRA, F.L.D.; LIBARDI, P.L.; SAAD, A.M. Balanço hídrico no solo para portaenxertos de citros em ecossistema de tabuleiro costeiro. Revista Brasileira de Engenharia Agrícola e Ambiental, v. 4, n. 1, p. 23-28, 2000.

DAVIS, J.C. Statistics and data analysis in geology. 2.ed. New York: John Wiley, 1986. $646 \mathrm{p}$.

DELGADO, A.A. Os efeitos da queima dos canaviais. STAB Açúcar, Álcool e Subprodutos, v. 3, n. 6 , p. 42-45, 1985.

DEMPSTER, A.P.; LAIRD, N.M.; RUBIN, D.B. Maximum likelihood from incomplete data via the EM algorithm. Journal Royal Statistical Society, v. 39, p. 1-38, 1977.

DERPSCH, R.; SIDIRAS, N.; HEINZMANN; F.X. Efeito residual da adubação verde de inverno sobre a umidade e temperatura do solo e rendimentos de culturas de verão. In: CONGRESSO BRASILEIRO DE CIÊNCIA DO SOLO, 19, Curitiba, 1983. Anais. Curitiba: Sociedade Brasileira de Ciência do Solo, 1983. p. 110. 
DERPSCH, R.; SIDIRAS, N.; HEINZMANN, F.X. Manejo do solo com coberturas verdes de inverno. Pesquisa Agropecuária Brasileira, v. 20, n. 7, p. 761-773, 1985.

DINIZ, T.D.A.S.; BASTOS, T.X. Efeito do desmatamento na temperatura do solo em região equatorial úmida. Belém: EMBRAPA, CPATU, 1980. 14p. (Boletim de Pesquisa, 7).

DOURADO-NETO, D.; TIMM, L.C.; OLIVEIRA, J.C.M.; REICHARDT, K.; BACCHI, O.O.S.; TOMINAGA, T.T.; CASSARO, F.A.M. State-space approach for the analysis of soil water content and temperature in a sugarcane crop. Scientia Agricola, v. 56, p. 1215-1221, 1999. Suplemento.

DOWNEY, L.A. Water-yield relation for nonforage crops. Journal of the Irrigation and Drainage Division, v. 98, p. 107-115, 1972.

EMPRESA BRASILEIRA DE PESQUISA AGROPECUÁRIA. Centro Nacional de pesquisa de Solo. Manual de métodos de análise de solos. 2. ed., Rio de Janeiro, 1997. $212 \mathrm{p}$.

FNP CONSULTORIA \& COMÉRCIO. AGRIANUAL 98: anuário da agricultura brasileira. São Paulo, 1999. 481 p.

FRENEY, J.R.; DENMEAD, O.T.; SAFFIGNA, P.G.; WOOD, A.W.; CHAPMAN, L.S.; HURNEY, A.P. Ammonia loss from sugarcane field as affected by fertilizer placement, irrigation and canopy development. In: AUSTRALIAN SOCIETY OF SUCARCANE TECHONOLOGISTS, 13., Bundaberg, 1991. Proceedings. Bundaberg: Watson Ferguson, 1991. p.38-43.

GASCHO, G.J.; RUELKE, O.C.; WEST, S.H. Residual effect of germination temperature in sugarcane. Crop Science, v. 13, n. 2, p. 274-276, 1973. 
GEE, G.W.; BAUDER, J.W. Particle-size analysis. In: KLUTE, A. (Ed.) Methods of soil analysis. 2. ed. Madison: American Society of Agronomy; Soil Science Society of America, 1986. cap. 15, p. 383-411.

GELB, A. Applied optimal estimation Cambridge: Massachusetts Institute of Technology Press, 1974. 374 p.

GOMES, J.; MINE, M.R.M. Estimativa do hidrograma unitário através da técnica do filtro de Kalman. In: SIMPÓSIO BRASILEIRO DE RECURSOS HÍDRICOS, 8., Foz do Iguaçu, 1989. Anais. São Paulo: Associação Brasileira Recursos Hídricos, 1989. v. 2, p. $92-100$.

GOMES, J.; MINE, M.R.M. Estimativa dos parâmetros de um modelo autoregressivo através da técnica do filtro de Kalman. In: SIMPÓSIO BRASILEIRO DE RECURSOS HÍDRICOS, 9., Rio de Janeiro, 1991. Anais. São Paulo: Associação Brasileira Recursos Hídricos, 1991. v.1, p. 428-435.

GOVINDARAJU, R.S.; KAVVAS, M.L.; ROLSTON, D.E.; BIGGAR, J. Error analyses of simplified unsaturated flow models under large uncertainty in hydraulic properties. Water Resources Research, v. 28, p. 2913-2924, 1992.

GREACEN, E.L. Soil water assessment by the neutron method Adelaide: Commonwealth Scientific \& Industrial Research Organization Publishing, 1981. 140p.

GREMINGER, P.J.; SUD, Y.K.; NIELSEN, D.R. Spatial variability of field measured soil-water characteristics. Soil Science Society of America Journal, v. 49, p. 10751081, 1985. 
HANSEN, J.W. Is agricultural sustainability a useful concept? Agricultural Systems, v. 50, p. 117-143, 1996.

HILLEL, D.; KRENTOS, V.D.; STYLIANAU, Y. Procedure and test of an internal drainage method for measuring soil hydraulic characteristics in situ. Soil Science, v. 114, p. 395-400, 1972.

HUI, S.; WENDROTH, O.; PARLANGE, M. B.; NIELSEN, D. R. Soil variability infiltration relationships of agroecosystems. Journal of Balkan Ecology, v. 1, n. 2, p. 21-40, 1998.

IGUE, K.; PAVAN, M.A. Uso eficiente de adubos orgânicos. In: SIMPÓSIO SOBRE FERTILIZANTES NA AGRICULTURA BRASILEIRA, Brasília, 1984. Anais. Brasília: EMBRAPA, 1984. p. 383-418.

KALMAN, R. E. A new approach to linear filtering and prediction theory. Transactions ASME, Journal Basic Engineer, v. 8, p. 35-45, 1960.

KATUl, G.G.; WENDROTH, O.; PARLANGE, M.B.; PUENTE, C.E.; FOLEGATTI, M.V.; NIELSEN, D.R. Estimation of in situ hydraulic conductivity function from nonlinear filtering theory. Water Resources Research, v. 29, p. 1063-1070, 1993.

KEMPER, W.D.; ROSENAU, R.C. Aggregate stability and size distribution. In: KLUTE, A. (Ed.) Methods of soil analysis. 2. ed. Madison: American Society of Agronomy; Soil Science Society of America, 1986. cap. 17, p. 425-442.

KIEHL, E.J. Manual de edafologia: relações solo-planta. São Paulo: Agronômica Ceres, 1979. 264 p. 
LAL, R. Soil temperature, soil moisture and yield from mulched and unmulched tropical soils. Plant and Soil, v. 40, p. 129-143, 1974.

LIBARDI, P.L.; SAAD, A.M. Balanço hídrico em cultura de feijão irrigada por pivô central em Latossolo Roxo. Revista Brasileira de Ciência do Solo, v. 18, n. 3, p. 529-532, 1994.

LIBARDI, P.L.; REICHARDT, K.; NIELSEN, D.R.; BIGGAR, J.W. Simple field methods for estimating the unsaturated hydraulic conductivity. Soil Science Society of America Journal, v. 44, p. 3-7, 1980.

MCGRAW, T. Soil test level variability in Southern Minnesota. Better crops, Potash \& Phosphate Institute, v. 78, n. 4, p. 24-25, 1994.

MENDES, M.E.G.; VILLAGRA, M.M.; SOUZA, M.D.; BACCHI, O.O.S.; REICHARDT, K. Water relations in a rubber-tree plantation of Piracicaba, SP. Scientia Agricola, v. 49, p. 103-109, 1992.

MINE, M.R.M. Modelos estocásticos lineares para previsão de cheias em tempo real. São Paulo, 1984. 127 p. Dissertação (Mestrado) - Escola Politécnica, Universidade de São Paulo.

MINISTERIO DEL AZUCAR. La canã de azucar como base de un desarrollo agroindustrial sostenible. In: CONFERENCIA MUNDIAL SOBRE EL DESARROLLO Y MEDIO AMBIENTE, Rio de Janeiro, 1992. La Habana, 1992. $32 \mathrm{p}$.

MORETTIN, P.A.; TOLOI, C.M.C. Previsão de séries temporais. 2. ed. São Paulo: Atual, 1987. 436 p. 
MORKOC, F.; BIGGAR, J. W.; NIELSEN, D. R.; ROLSTON, D. E. Analysis of soil water content and temperature using state-space approach. Soil Science Society of America Journal, v. 49, p. 798-803, 1985.

MOROTE, C.G.B.; VIDOR, C.; MENDES, N.G. Alterações na temperatura do solo pela cobertura morta e irrigação. Revista Brasileira de Ciência do Solo, v. 14, n. 1, p. 81-84, 1990.

MOTTA, A.C.O.; HOTTA, L.K. Utilização do filtro de Kalman em modelos estatísticos. Campinas: UNICAMP, Instituto de Matemática, Estatística e Computação Científica, 1998. 71 p.

MOURA, M.V.T.; MARQUES JUNIOR, S.; BOTREL, T.A.; FRIZONE, J.A. Estimativa do consumo de água na cultura da cenoura (Daucus carota, L.) v. Nantes superior, para a região de Piracicaba, através do método do balanço hídrico. Scientia Agricola, v. 51, n. 2, p. 284-291, 1994.

NIELSEN, D.R.; TILLOTSON, P.M.; VIEIRA, S.R. Analyzing field-measured soil water properties. Agricultural Water Management, v. 6, p. 93-109, 1983.

NIELSEN, D. R.; ALEMI, M. H. Statistical opportunities for analyzing spatial and temporal heterogeneity of field soils. Plant and Soil, v. 115, p. 285-296, 1989.

NIELSEN, D.R.; WENDROTH, O.; PIERCE, F.J. Emerging concepts for solving the enigma of precision farm research. In: INTERNATIONAL CONFERENCE ON PRECISION AGRICULTURE, 4., St. Paul, 1998. St. Paul: ASA, CSSA, SSSA, 1998. p.303-318. 
OLASANTAN, F.O. Effect of time of mulching on soil temperature and moisture regime and emergence, growth and yield of white yam in western Nigeria. Soil \& Tillage Research, v. 50, p. 215-221, 1999.

OLIVEIRA, J.C.M.; BACCHI, O.O.S.; REICHARDT, K., RESENDE, L.C.L., RUEGGER, W.U.S. Avaliação da compactação do solo em áreas com colheita mecanizada de cana-de-açúcar. In: REUNIÃO BRASILEIRA DE MANEJO E CONSERVAÇÃO DO SOLO E DA ÁGUA, 12, Fortaleza, 1998. Anais. Fortaleza: Sociedade Brasileira de Ciência do Solo, 1998. v. 1, p. 376-377.

OLIVEIRA, M.W.; TRIVELIN, P.C.O; GAVA, G.J.C.; PENATTI, C.P. Degradação da palhada de cana-de-açúcar. Scientia Agrícola, v. 56, n. 4, p. 803-809, 1999.

ORLANDO FILHO, J.; ROSSETO, R.; MURAOKA, T.; ZOTELLI, H.B. Efeitos do sistema de despalha (cana crua x cana queimada) sobre algumas propriedades do solo. STAB Açúcar, Álcool e Subprodutos, v. 16, n. 6, p. 30-33, 1998.

PARR, J.F. Chemical and biological considerations for land applications of agricultural land municipal wastes. In: FAO. Organic materials as fertilisers, Rome, 1975. p. 227-251. (Soils Bulletin, 27).

PEREIRA, A.R.; VILLA NOVA, N.A.; SEDIYAMA, G.C. Evapo(transpi)ração. Piracicaba: FEALQ, 1997. 183 p.

PEREIRA, A.R.; FERRAZ, E.S.B.; REICHARDT, K.; LIBARDI, P.L. Estimativa da evapotranspiração e da drenagem profunda em cafezais cultivados em solos podzolizados Lins e Marília. Piracicaba. Piracicaba: Centro de Energia Nuclear Aplicada na Agricultura, 1974. 13 p. (Boletim Científico, 14). 
PEZZOPANE, J.E.M.; CUNHA, G.M.; ARNSHOLZ, E.; COSTALONGA JÚNIOR, M. Modificação na temperatura do solo causada por cobertura morta (compact disc). In: CONGRESSO LATINO AMERICANO DE CIÊNCIA DO SOLO, 13, Águas de Lindóia, 1996. Anais. Águas de Lindóia: Sociedade Brasileira de Ciência do Solo/Sociedade Latino-Americana de Ciência do Solo, 1996.

PINHEIRO, L.B.A.; SANTOS, G.A.; GARAY, I.E. Efeito da queima da palhada da cana-de-açúcar na população de macroartrópodos edáficos (compact disc). In: CONGRESSO LATINO AMERICANO DE CIÊNCIA DO SOLO, 13, Águas de Lindóia, 1996. Anais. Águas de Lindóia: Sociedade Brasileira de Ciência do Solo/Sociedade Latino-Americana de Ciência do Solo, 1996.

PLACKETT, R.L. Some theorems in least squares. Biometrika, v. 37, p. 149-157, 1950.

REICHARDT, K. Unit gradient in internal drainage experiments for the determination of soil hydraulic conductivity. Scientia Agricola, v. 50, n. 1, p. 151-153, 1993.

REICHARDT, K. Dinâmica da matéria e da energia em ecossistemas. 2. ed. Piracicaba: ESALQ, Departamento de Física e Meteorologia, 1996. 513 p.

REICHARDT, K.; LIBARDI, P.L.; SAUNDERS, L.C.V.; CADIMA, Z.A. Dinâmica da água em solo cultivado com milho. Revista Brasileira de Ciência do Solo, v. 3, n. 1, p. $1-5,1979$.

REICHARDT, K.; LIBARDI, P.L.; MORAES, S.O.; BACCHI, O.O.S.; TURATTI, A.L.; VILLAGRA, M.M. Soil spatial variability and its implications on the establishment of water balances. In: CONGRESSO INTERNACIONAL DE CIÊNCIA DO SOLO, 14, Kyoto, 1990. Anais. Kyoto: Sociedade Internacional de Ciência do Solo, 1990. v. 1, p. 41-46. 
REICHARDT, K.; ANGELOCCI, L.R.; BACCHI, O.O.S.; PILOTTO, J.E. Daily rainfall variability at a local scale (1,000 ha), in Piracicaba, SP, Brazil, and its implications on soil water recharge. Scientia Agricola, v. 52, n. 1, p. 43-49, 1995.

REICHARDT, K.; PORTEZAN, O.; BACCHI, O.O.S.; OLIVEIRA, J.C.M.; DOURADO-NETO, D.; PILOTTO, J.E.; CALVACHE, M. Neutron probe calibration correction by temporal stability parameters of soil water content probability distribution. Scientia Agricola, v. 54, p. 17-21, 1997. Número Especial.

REICHARDT, K.; PORTEZAN, O.; LIBARDI, P.L.; BACCHI, O.O.S.; MORAES, S.O.; OLIVEIRA, J.C.M.; FALLEIROS, M.C. Critical analysis of the field determination of soil hydraulic conductivity functions using the flux-gradient approach. Soil \& Tillage Research, v. 48, p. 81-89, 1998.

RIPOLI, T.C.; MOLINA JUNIOR, W.F.; STUPIELLO, J.P.; NOGUEIRA, M.C.; SACCOMANO, J.B. Potencial energetico de residuos de cosecha de la caña verde. STAB Açúcar, Álcool e Subprodutos, v. 10, n. 1, p. 22-28, 1991.

RIPOLI, T.C.; VILlLANOVA, N.A. Colheita mecanizada da cana-de-açúcar: novos desafios. STAB Açúcar, Álcool e Subprodutos, v. 11, n. 1, p. 28-31, 1992.

RIPOLI, T.C.C.; MOLINA JUNIOR, W.F.; RIPOLI, M.L.C. Energy potential of sugarcane biomass in Brazil. Scientia Agricola, v. 57, n. 4, p. 677-681, 2000.

ROSE, C.W. Agricultural physics. Oxford: Pergamon Press, 1966. 230 p.

ROSE, C.W.; STERN, W.R. Determination of withdrawal of water from soil by crop roots as a function of depth and time. Australian Journal of Soil Research, v. 5, p. 11-19, 1967. 
SALAS, J.D.; DELLEUR, J.W.; YEVJEVICH, V.; LANE, W.L. Applied modeling of hydrologic time series. Littleton: Water Resources Publications, 1980. 484 p.

SALTON, J.C.; MIELNICZUK, J. Relações entre sistemas de preparo, temperatura e umidade de um Podzólico Vermelho-Escuro de Eldorado do Sul (RS). Revista Brasileira de Ciência do Solo, v. 19, n. 2, p. 313-319, 1995.

SARRIÉS, G.A. Apostila tutorial do sistema SANEST. Piracicaba: Centro Informática na Agricultura, 1991. 64 p.

SHUMWAY, R.H. Applied statistical time series analyses. Prentice Halll: Englewood Cliffs, 1988. 379 p.

SHUMWAY, R. H.; STOFFER, D. S. An approach to time series smoothing and forecasting using the EM algorithm. Journal Time Series Analysis, v. 3, p. 253$264,1982$.

SHUMWAY, R. H.; STOFFER, D. S. Time series analysis and its applications. New York: Springer, 2000. 549 p.

SIDIRAS, N.; VIEIRA, M.J. Comportamento de um Latossolo Roxo Distrófico, compactado pelas rodas do trator na semeadura: rendimentos de três culturas. Pesquisa Agropecuária Brasileira, v. 19, n. 4, p. 1285-1293, 1984.

SIDIRAS, N.; PAVAN, M.A. Influência do sistema de manejo na temperatura do solo. Revista Brasileira de Ciência do Solo, v. 10, n. 3, p. 181-184, 1986.

SOUZA, R.C. Modelos estruturais para previsão de séries temporais: abordagens clássica e bayesiana. Rio de Janeiro: $17^{\circ}$ Colóquio Brasileiro de Matemática, Instituto de Matemática Pura e Aplicada do CNPq, 1989. 171 p. 
SPAROVECK, G.; ALlEONI, L.R.F.; PEREIRA, J.C.; ROSSETO, R. Aptidão das terras de Piracicaba para o corte mecanizado de cana-de-açúcar. STAB Açúcar, Álcool e Subprodutos, v. 15, n. 5, p. 14-17, 1997.

TIMM, L.C.; OLIVEIRA, J.C.M.; TOMINAGA, T.T.; CASSARO, F.A.M.; REICHARDT, K.; BACCHI, O.O.S. Soil hydraulic conductivity measurement on a sloping field. Revista Brasileira de Engenharia Agrícola e Ambiental, v. 4, n. 3, p. $480-482,2000$.

TIMM, L.C.; FANTE JUNIOR, L.; BARBOSA, E.P.; REICHARDT, K.; BACCHI, O.O.S. Interação solo-planta avaliada por modelagem estatística de espaço de estados. Scientia Agricola, v. 57, n. 4, p. 751-760, 2000.

TRIVELIN, P.C.O.; VICTORIA, R.L.; RODRIQUES, J.C. Aproveitamento por soqueira de cana-de-açúcar de final de safra do nitrogênio da aquamônia- ${ }^{15} \mathrm{~N}$ e aplicado ao solo em complemento à vinhaça. Pesquisa Agropecuária Brasileira, v. 30, n. 12, p.1375-1385, 1995.

TRIVELIN, P.C.O.; VICTORIA, R.L.; RODRIQUES, J.C. Utilização por soqueira de cana-de-açúcar de início de safra do nitrogênio da aquamônia- ${ }^{15} \mathrm{~N}$ e uréia- ${ }^{15} \mathrm{~N}$ aplicado ao solo em complemento à vinhaça. Pesquisa Agropecuária Brasileira, v. 31, n. 2, p. 89-99, 1996.

TRIVELIN, P.C.O.; BENDASSOLLI, J.A.; OLIVEIRA, M.W. Potencialidade da mistura de aquamônia com vinhaça na fertilização de canaviais colhidos sem despalha a fogo: I. Estabilidade química da mistura. STAB Açúcar, Álcool e Subprodutos, v. 16, n. 2, p. 26-29, 1997. 
TURATTI, A.L.; REICHARDT, K. Variabilidade do armazenamento de água em Terra Roxa Estruturada. Revista Brasileira de Ciência do Solo, v. 15, n. 3, p. 253-257, 1991.

URQUIAGA, S.; BODDEY, R.M.; OLIVEIRA, O.C.; LIMA, E.; GUIMARÃES, D.H.V. A importância de não queimar a palha na cultura de cana-de-açúcar. Seropédica: EMBRAPA, 1991. 12p. (Comunicado Técnico, 5).

VAN LIER, Q.J.; LIBARDI, P.L. Variabilidade dos parâmetros da equação que relaciona a condutividade hidráulica com a umidade do solo no método do perfil instantâneo. Revista Brasileira de Ciência do Solo, v. 23, n. 4, p. 1005-1014, 1999.

VAUCLIN, M.; VIEIRA, S. R.; BERNARD, R.; HATFIELD, J. L. Spatial variability of surface temperature along two transects of a soil. Water Resources Research, v. 18, p. 1677-1686, 1982.

VIEIRA, S.R.; NIELSEN, D.R.; BIGGAR, J.W. Spatial variability of field-measured infiltration rate. Soil Science Society of America Journal, v. 45, p. 1040-1048, 1981.

VIEIRA, S.R.; NASCIMENTO, P. C.; SARVASI, F.O.C.; MOURA, E.G. Umidade e temperatura da camada superficial do solo em função da cobertura morta por resteva de soja em plantio direto. Revista Brasileira de Ciência do Solo, v. 15, n. 2, p. 219$224,1991$.

VILLAGRA, M.M.; MATSUMOTO, O.M.; BACCHI, O.O.S.; MORAES, S.O.; LIBARDI, P.L.; REICHARDT, K. Tensiometria e variabilidade espacial em terra roxa estruturada. Revista Brasileira de Ciência do Solo, v. 12, n. 3, p. 205-210, 1988. 
VILLAGRA, M.M.; BACCHI, O.O.S.; TUON, R.L.; REICHARDT, K. Difficulties of estimating evaporation from the water balance equation. Agricultural and Forest Meteorology, v. 72, p. 317-325, 1995.

WARRICK, A.W.; NIELSEN, D.R. Spatial variability of soil physical properties in the field. In: HILLEL, D. (Ed.). Applications of soil physics. New York: Academic Press, 1980. p. 319-344.

WENDROTH, O.; AL OMRAN, A. M.; KIRDA, K.; REICHARDT, K.; NIELSEN, D. R. State-space approach to spatial varialility of crop yiel. Soil Science Society of America Journal, v. 56, p. 801-807, 1992.

WENDROTH, O.; REYNOLDS, W. D.; VIEIRA, S. R.; REICHARDT, K.; WIRTH, S. Statistical approaches to the analysis of soil quality data. In: GREGORICH, E.G.; CARTER, M.R. (Ed.). Soil quality for crop production and ecosystem health. Amsterdam: Elsevier Science, 1997. p. 247-276.

WENDROTH, O.; JÜRSCHIK, P.; GIEBEL, A.; NIELSEN, D.R. Spatial statistical analysis of on-site-crop yield and soil observations for site-specific management. In: INTERNATIONAL CONFERENCE ON PRECISION AGRICULTURE, 4., St. Paul, 1998, St. Paul: ASA, CSSA, SSSA, 1998. p.159-170.

WENDROTH, O.; JÜRSCHIK, P.; KERSEBAUM, K.C.; REUTER, H.; VAN KESSEL, C.; NIELSEN, D.R. Identifying, understanding, and describing spatial processes in agricultural landscapes - four case studies. Soil \& Tillage Research, v. 58, p. 113-127, 2001.

WEST, M.; HARRISON, J. Bayesian forecasting and dynamic models. 2. ed. London: Springer-Verlag, 1997. 680 p. 
WHITMAN, P.C.; BUL, T.A.; GLASZIOU, K.T. The physiology of sugarcane; VI: Effects of temperature, light, and water on set germination and early growth (Saccharum spp). Australian Journal Biological Science, v. 15, n. 2, p. 415-428, 1963.

WOOD, A.W. Management of crop residues following green havesting of sugarcane in north Queensland. Soil \& Tillage Research, v. 20, p. 69-85, 1991. 